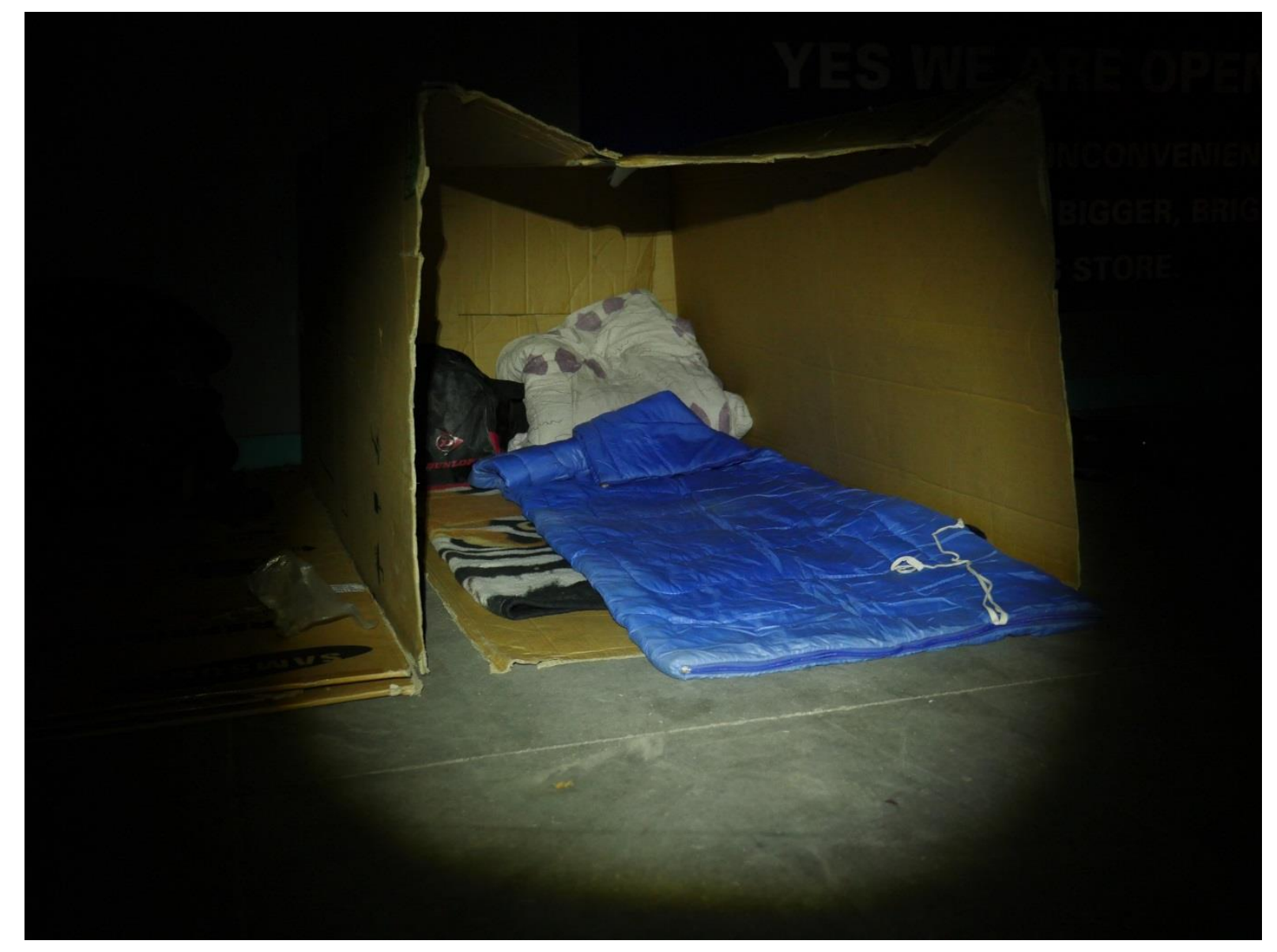

\title{
A Place to Call My Own: Navigating Life in the Margins
}

\author{
Jonathan Paul Foster
}

A Thesis

Submitted to Victoria University of Wellington In fulfilment of the requirements for the degree of

Master of Arts

In Cultural Anthropology

Victoria University of Wellington

2017 


\section{Abstract}

This thesis explores the lives of people who are, or have recently been, living on the streets in Wellington City. It examines what it means to 'be and belong' while living on the streets, the ways in which Streeties become existentially and discursively 'homeless', what it means to feel 'at home' in the world, and the ways Streeties attempt to make a life worth living on the margins. It does this by exploring the way Streeties carve out new spaces for living in the city, how they construct their sense of self, and the ways in which they hope for a better life. Many of these Streeties had been rejected from the traditional channels which distribute socially legitimate forms of personhood and meaning, while others had actively rejected these channels for impinging on their ability to live a dignified life. Consequently, they have had to carve out new ways of relating to themselves and asserting their autonomy. None of them, however, wanted their autonomy to come at the expense of others. In fact, their struggles for autonomy were also simultaneously struggles for belonging - their autonomy was never isolated or bounded, but was always related to a respect for their position as individuals within wider systems of relations that contained relatives, other Streeties, members of the public, special places, worldviews or spiritual beliefs. The thesis is part ethnographic film, and part written thesis. The film is included on a USB accompanying this thesis. 


\section{Acknowledgements}

I am indebted to my primary supervisors, Dr Caroline Bennett and Dr Paul Wolffram, for their creative direction, intellectual insight and the generosity of their time, energy and aroha. My appreciation for the input both of you made goes beyond words. Likewise, I extend my gratitude to Hal Levine, who provided supervision and assistance in the early stages of my thesis, before his retirement, for which I congratulate him.

I would like to say thanks to the entire School of Social and Cultural Studies - the lecturers, post graduate students, and the office administration team, who have all made studying at Victoria University of Wellington such a worthwhile and enjoyable experience. I owe Annabel Bennett and Hannah Gibson special thanks for taking the time to proofread my thesis, despite being called on at such a last minute!

I am sincerely indebted to Professor Brigitte Bönisch-Brednich for the support she has provided me over the years. Her encouragement and understanding has been integral to my intellectual development, as well my overall confidence and self-esteem. I doubt I would ever have made it to this position without it.

I would like to thank my family and my father Mark Connell for their support and encouragement. I owe my mother, Barbara Isabel Foster, the biggest thanks of all. You have always taught me, and demonstrated, the importance of compassion, empathy and understanding.

I furthermore extend my gratitude to Stephanie McIntyre, director of the DCM, and the rest of the DCM team, for facilitating my research and so graciously and generously welcoming me into your world. The guidance many of you provided has played a large part in shaping the scope of this thesis. Finally, and most importantly, I want to say a huge thanks to all the Streeties who took part in this research, whether through a passing conversation or an indepth interview. You have all shown me so much consideration and generosity, I hope I have been able to show you the same level of respect in my thesis. 


\section{Contents}

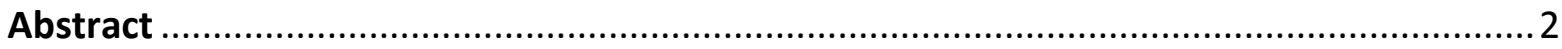

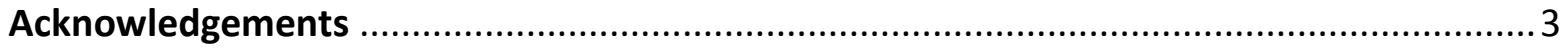

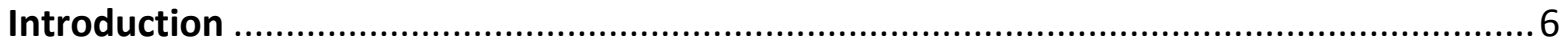

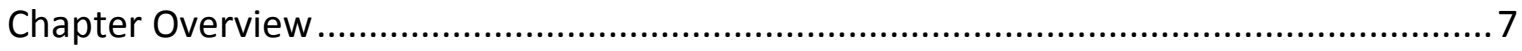

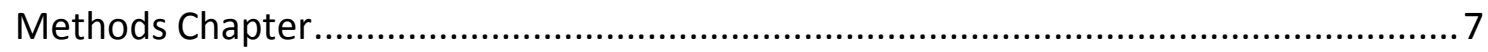

Chapter One - Being and Becoming 'Homeless': If you don't do things like normal

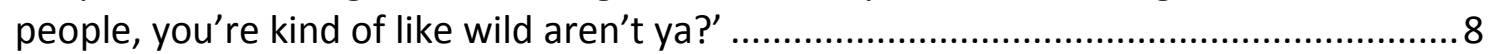

Chapter Two - I'm Houseless Not Homeless! ................................................................. 8

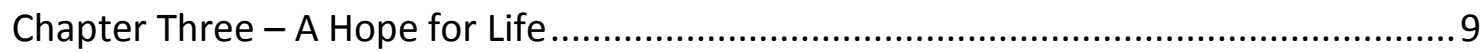

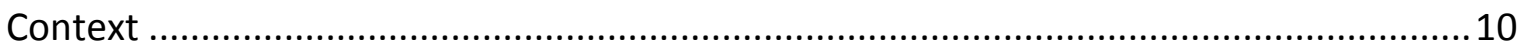

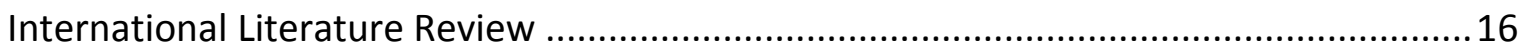

Homelessness in Wellington and New Zealand: Literature Review...............................19

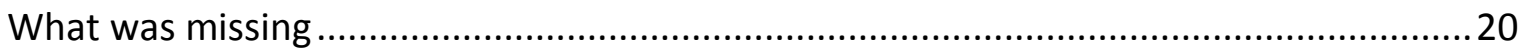

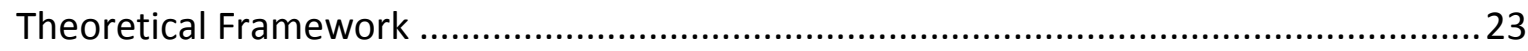

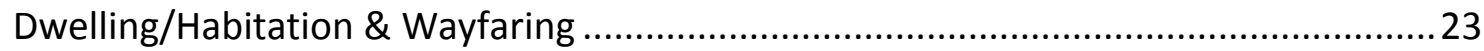

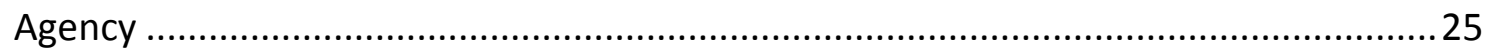

Jackson's Existential Anthropology and Intersubjectivity ........................................27

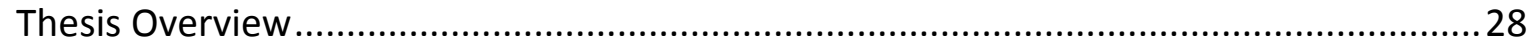

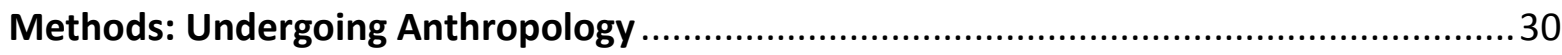

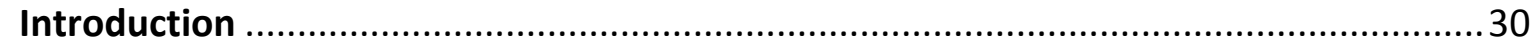

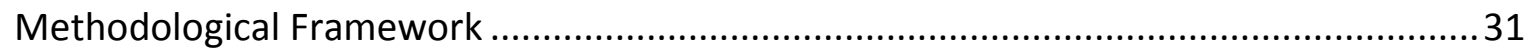

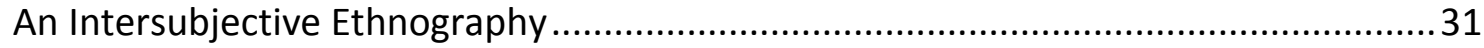

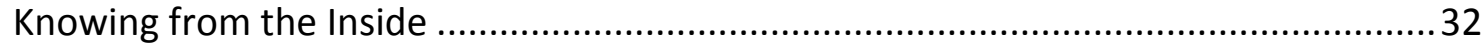

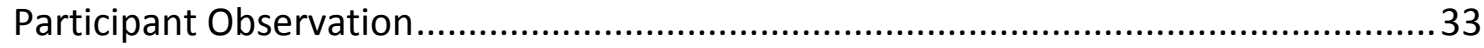

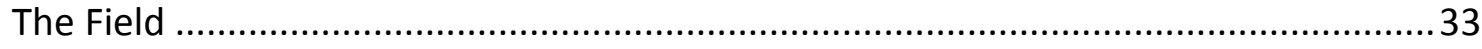

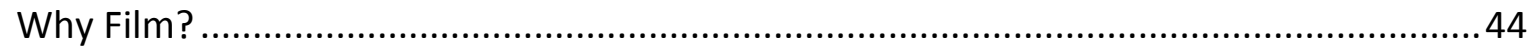

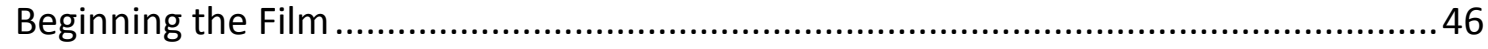

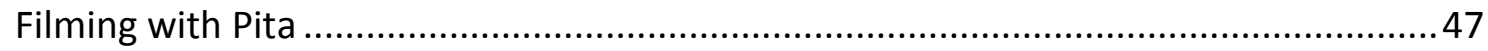

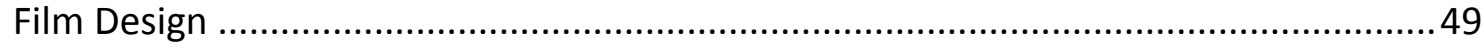

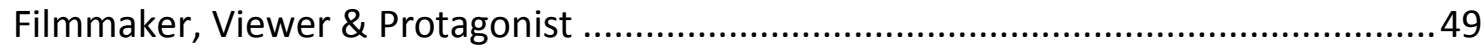

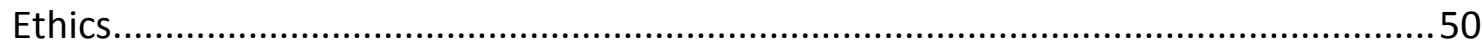

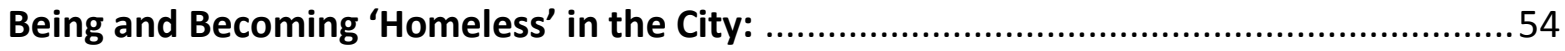

'If you don't do things normally, you're kind of like wild aren't ya?' ................................54

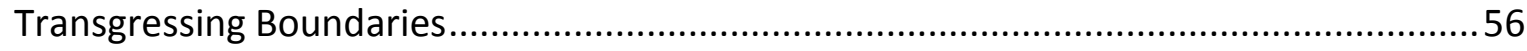

Governmentality: An Intersubjective Relation of Control ............................................57 


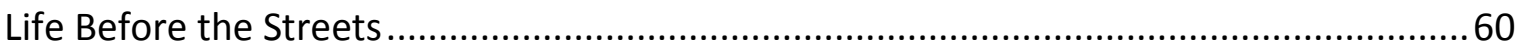

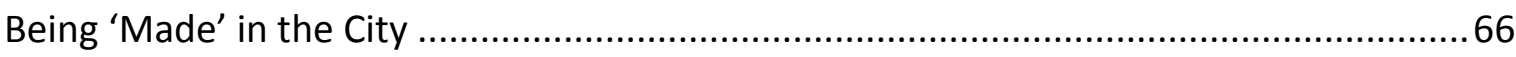

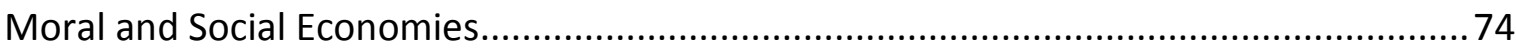

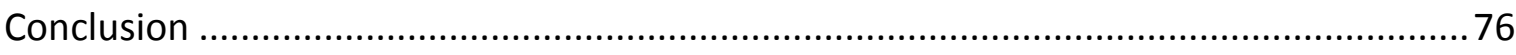

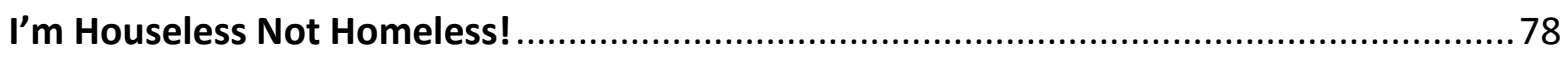

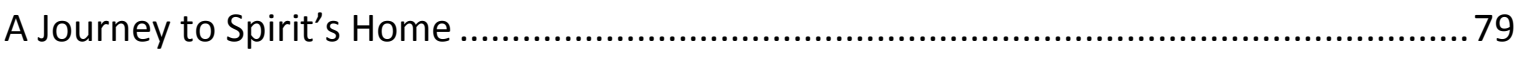

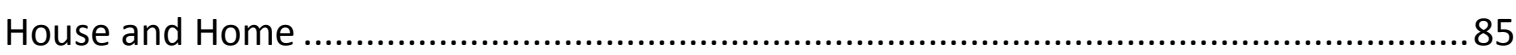

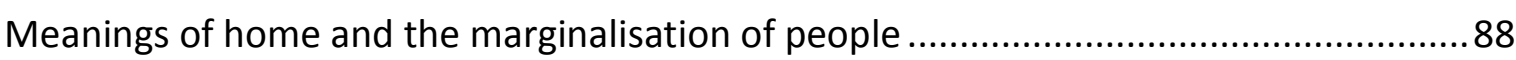

'Choosing' the Streets/Making the Streets Home............................................................89

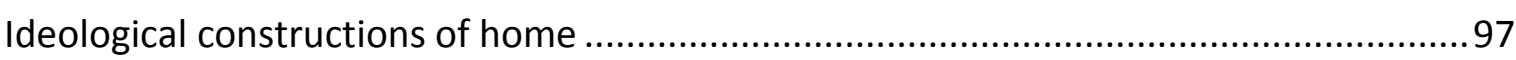

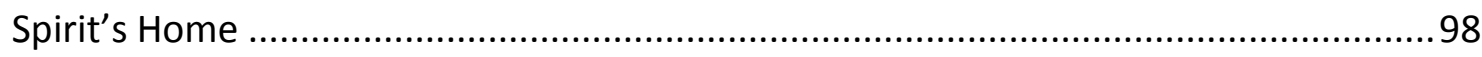

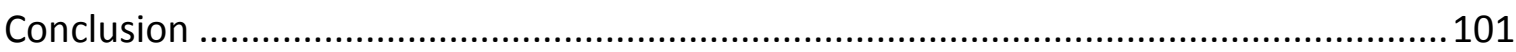

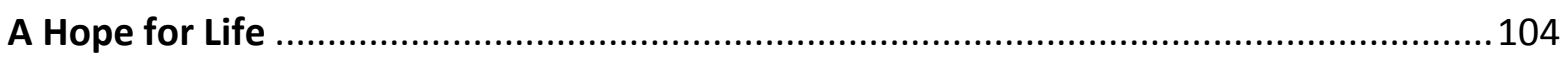

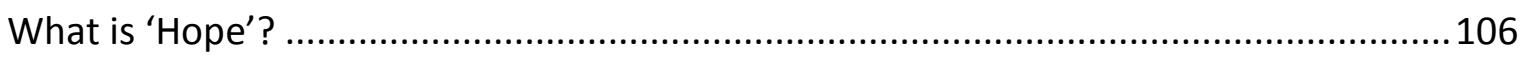

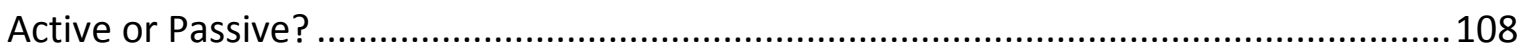

Hope, Movement and Time: Journey Through the Present.........................................110

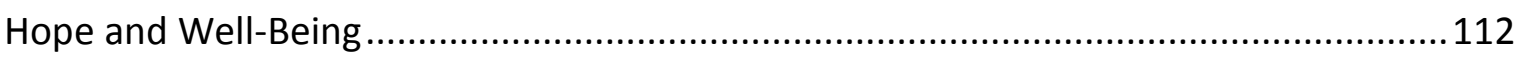

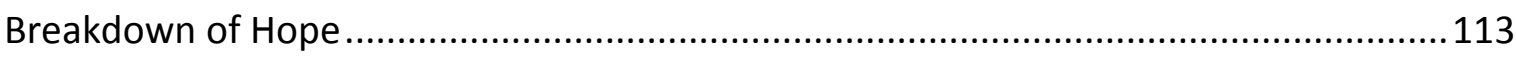

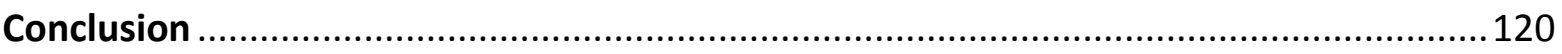

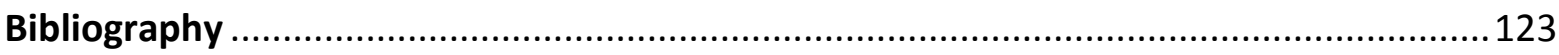

\section{List of Figures}

Figure 1: Stuff.co.nz Figure 2: Radio New Zealand ..................................................... 11

Figure 3: 'Problems of poverty and homelessness must be addressed' ............................... 15

Figure 4: Newshub: 'John Key: Homeless don't want help' .............................................. 15

Figure 5: Pita points to an old sheltered sleeping spot, behind Plimmer Steps, Lambton

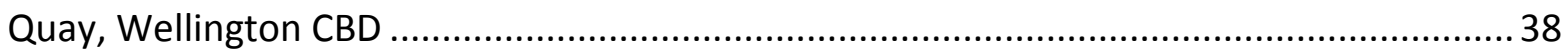

Figure 6: Pita takes a rest in a covered seating area in the Wellington Civic Centre............. 38

Figure 7: Walking down Tory Street towards Harvey Norman ........................................ 40

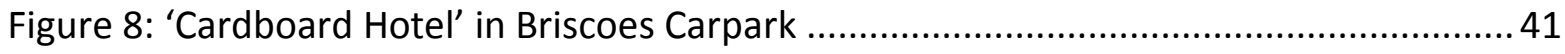

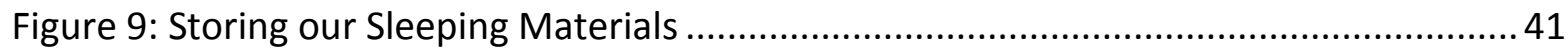

Figure 10: Walking towards Sisters of Compassion Soup Kitchen ........................................42

Figure 11: Comment Section on The Wireless Facebook Page .............................................. 58

Figure 12: Nicola Young Public Facebook Post..............................................................6 68 


\section{Introduction}

This thesis explores the lifeworlds of Streeties ${ }^{1}$ living in Wellington, New Zealand and the everyday negotiations they must make to get by and live well. It has both a written and a film component. It engages with ideas of being, belonging, and personhood, of house and home, and of how 'hope' as a contested state of being shapes Streeties relationship to time, space and wellness. It is concerned with the interplay between discursive understandings of homelessness and the lived experiences of Streeties. By exploring this relationship and unpacking the conventional logic that underpins media representations, policy recommendations and the perspectives of everyday people, both housed and non-housed, I aim to elucidate the complex choices Streeties face, and the decisions they must make, which sometimes appear counter-intuitive, and undermine their access to help or resources which could alleviate their situation. I suggest that to understand the choices Streeties make, and their way of being in, and relating to, the world around them, we need to comprehend how they make sense of their livelihoods, when they have been largely denied from the traditional channels which distribute socially legitimate forms of being. Being, in this context, refers to the sense of identity and purpose we glean from our participation in society, necessary to live a meaningful life (Gibson 2011, 14).

I argue that as a coping strategy, it is necessary to understand the ebb and flow between agency and patiency ${ }^{2}$ in the lives of Streeties who face significant hardships to their physical, social and emotional well-being. Agency, here, refers to the intentional actions we take as subjects, with an intended goal or outcome for change (Ortner 2001), and patiency, as a submission or deferral to our ontological or epistemological predicament. That is, when we are posed with a situation or problem, which seems out of our control, or is unable to be explained, we recourse to acceptance of our situation or forfeit control to a higher power. My argument is not that one is better than the other, nor that one is distinctly active, while

\footnotetext{
${ }^{1}$ Streeties is the name people I spoke to often used to refer to one another in a general sense; This was also noted by McGovern (2013) in her PhD thesis on Wellington homeless man 'Ben Hana', 'A Life Lived on the Corner'.

${ }^{2}$ The relationship between agency and patiency was discussed in a Masterclass with Distinguished Professor Michael Jackson, May 2017
} 
the other is passive, but that both are necessary coping strategies for getting by and living well in the face of adversity and hardship. Similarly, neither is agency located solely within the individual, but, rather, is contingent on relationships with other people, places and things. Moreover, bound up in this tension between agency and patiency, I observed a struggle for both autonomy and belonging. My participants were often caught up in a complex web of interactions, actions and non-actions, which were contingent on their perception of a situation, and how much it infringed on their individual self, or on their ability to belong to a set of relations wider than themselves, but of which they were a vital part. Thus, I argue throughout that homelessness cannot solely be defined as either an economic or material condition, but rather should be understood as having both existential and physical qualities and implications. It is animated by a continuous struggle to dwell, to be, to belong and to live well in a world, which has largely excluded Streeties from the distribution of socially legitimate forms of being and personhood, and whose systems remain, for the most part, outside of their direct control.

\section{Chapter Overview}

\section{Methods Chapter}

In the methods chapter I outline my methodological approach, which draws on a phenomenological anthropology, inspired by Michael Jackson (2013) and Tim Ingold (2000; 2011). I explore the ways I did ethnography, and 'underwent' anthropology in the process (Ingold 2014). The field, for me, was messy and demanding; sometimes it was seemingly open ended, while at other times it felt severely limiting. In this chapter I discuss how I negotiated these spaces, the ways I went about doing research and the ethical implications of doing anthropology with Streeties. I also discuss my use of visual methods and how film fits into my thesis's wider aims of carrying out an exploratory, phenomenological inquiry of life on the streets.

\section{Film - A Place to Call Home (12 min)}

My film, 'A Place to Call Home' (12 min), is a short experimental ethnographic film, which explores the lifeworld of Rangi. Rangi was living on the streets when I began my research, but moved into a council flat not long after, having lived on the streets for five years. The 
film explores the way Rangi relates to, and moves through, time and space, in the process weaving a sense of home and place. It is concerned with his sensuous engagement with his surroundings, and seeks to immerse the viewer in his embodied lifeworld, elucidating the complex interweaving of factors shaping Rangi's trajectory, foregrounding the way his motivations and values influence his movement through life. It aims to highlight the tensions he faces trying to get his life back on track, and the institutions, which still shape his access to socially legitimate forms of being and his experience of the city. Though, it also shows Rangi maintaining a sense of self, enjoying life, and taking hardships as they come, doing what he can to improve his lot, while accepting certain realities.

Chapter One - Being and Becoming 'Homeless': 'If you don't do things like normal people, you're kind of like wild aren't ya?'

In chapter one, I argue that Streeties come to inhabit spaces that are perceived by most housed people, discursively and existentially, as 'wild', and, consequently Streeties themselves are perceived as disruptive to our normative order of being and belonging, physically, socially and morally. A result of this is that approaches to dealing with homelessness tend to try and 'reign' homeless people in, domesticating them, without necessarily understanding or acknowledging the processes which come to produce homeless subjectivities or how homeless people actively engage with these identities. In this chapter, then, I focus on the way Streeties negotiate their personhood and construct a sense of self in an environment where their access to legitimate forms of personhood have been severely limited. By exploring the back and forth interplay between discursive understandings of homelessness and the lived experience of people inhabiting homeless spaces, I argue that Streeties must construct alternative ways of relating to both themselves and their surroundings to survive and live dignified lives. In the process, Streeties sometimes actively challenged normative assumptions about what constituted legitimate forms of being, meaning and personhood, embracing life in the margins and creating new spaces for recognising themselves and their positions within a wider nexus of relations.

\section{Chapter Two - I'm Houseless Not Homeless!}

In the second chapter of my thesis I explore the way Streeties come to engage with the concept of home, elucidating some of the tensions and contradictions, which emerge from 
the process of housing people materially. I argue that the apprehension Streeties express towards 'going inside' ${ }^{3}$ emerges not just from a fear of change, but from the potential for the erosion of the sense of self and personhood they have developed while living on the streets, in relation to both their physical surroundings and other people. As Westerners inhabiting built environments, we tend to presuppose that people share what Jackson calls our 'material habitus', which "sees boundaries as a precondition of meaning" $(1995,85)$. We are unnerved and feel uncomfortable by the presentation of unbounded sites, indeterminate horizons and fragmented realities. Yet for people who have been forced to carve out a life on the streets, inhabiting spaces that are both physically and socially marginalised, understandings of what constitutes a home may differ radically. As may their experience of what it means to feel comfortable, secure and 'at home' in the world. By exploring the ways Streeties create non-traditional living spaces, though, we can begin to broaden our understandings of what constitutes a home, and what it means to feel 'at home' in the world.

\section{Chapter Three - A Hope for Life}

In the final chapter, building on the argument concerning the construction of personhood on the streets, I explore my participants' relationship to time and space, and their desires for change by turning my attention to hope. It explores the way Streeties articulate their hopes, how they relate to their future, and how hope shapes their actions in the present. I argue that in contrast to the literature, which often categorises hope as being either active or passive, in the lifeworlds of my participants, hope was neither clearly one nor the other. Large, open-ended and unrealistic hopes often served as motivation to survive and live well in the present, even if they were not likely to be achieved in their immediate lives. In contrast, frustrations and a sense of hopelessness arose when they were unable to control their situation or manage their expectations of what was realistically achievable, despite facing significant barriers. In these circumstances, resigning oneself to one's situation was often a powerful and necessary coping strategy for getting by and living well. I argue that it also served to counter balance the neoliberal form of agency, focused on empowerment and autonomy often promoted by state institutions and social services. Their hopes generally envisioned a world in which their needs, desires and current values could be met and

\footnotetext{
3 'Going inside' was a phrase Streeties often used to refer to the process of being housed
} 
honoured; where their existences had meaning and purpose, both in relation to themselves and others, and where they were respected as autonomous individuals, yet also remained enmeshed in a wider system of relations, with which they bore a responsibility towards, whether it be through children, family members, other Streeties, their spiritual beliefs or special locations. Although the form and expression of their hopes differed, the underlying motivations could generally be regarded as a desire to live well, both in and with themselves, and in concert with other people and places. I argue that understanding the way Streeties construct and negotiate hope and wellbeing challenges normative assumptions that presuppose both as being contained within the individual, and of having clearly defined and quantifiable markers such as material wealth, social standing or physical health, and problematizes the equally self-assumed logic of what people need, why they act the way they do and how they think about the world they inhabit.

\section{Context}

When I initially set out to complete this thesis, the topic of homelessness had been on my mind for some years; although I could not put my finger on it, I felt as if something was distinctly missing from the conversation surrounding homelessness. Homeless people were frequently rendered one dimensional regardless of whether the article was hostile or sympathetic to their plight.

I began to take an interest in the conversation surrounding homelessness, reflected through media articles, government reports, social media comment threads, and the opinions of people around me. Publicly, reporting on homelessness and even accounts of the homeless themselves, came across as very literal and simplistic. Homeless people seemed largely absent from this conversation, rarely talked to, or even better, 'talked with', and were predominately, 'talked about'. When they were spoken to, it was usually an interviewer or passer-by pocketing a soundbite more reflective of their own agenda than the realities of people living on the street. In 2013, the 'Alternative Giving Campaign', a Wellington council project, kicked off (Wellington City Council Press Release 2013). It had been brought about, in part, by an increase in complaints regarding begging in the city. Based on the logic that giving to charities was a more effective use of money than giving to beggars who may spend their money on drugs and alcohol, the project failed to garner support, raising little money 
during its existence and in fact steered away, or at least discouraged, a vital source of income for many of Wellington's homeless community (Heather 2014).

This led me to consider the way we construct ideas about, and respond to, homelessness as a society, and the ways in which our thoughts and actions alter the landscape within which homeless people must navigate their lives. I wanted to unpack the logic that underpinned ideas about how and why people end up homeless, what it means to be homeless, how homelessness is experienced, and what the solutions to homelessness are.

In the media, the category of homeless was used broadly and without a lot of clarity. Stories of homelessness were usually dominated by images of rough sleepers, those that make their home and life on the street and are the most visible (Figures 1 and 2).

\section{Homelessness rising in New Zealand}

12:00 PM Friday Jun 3, 2016 SHARE: $\mathbf{f} \boldsymbol{g}$ G in $\hat{k}$

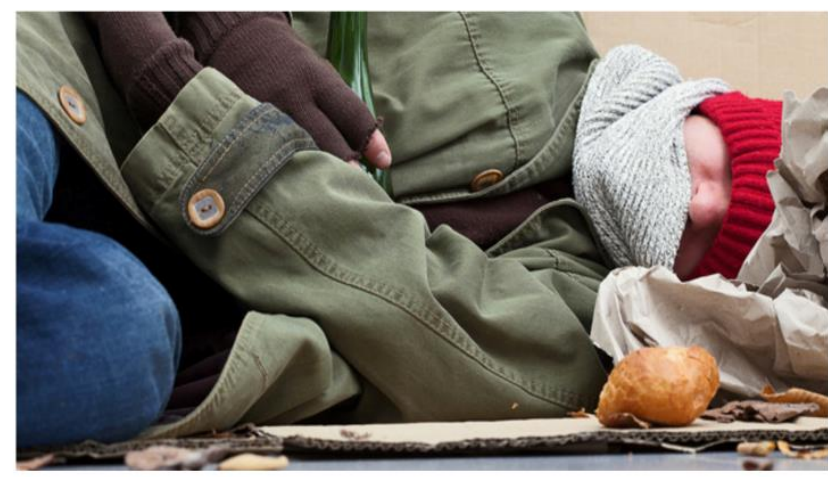

Figure 1: Stuff.co.nz

\section{Homelessness 'a national problem'}

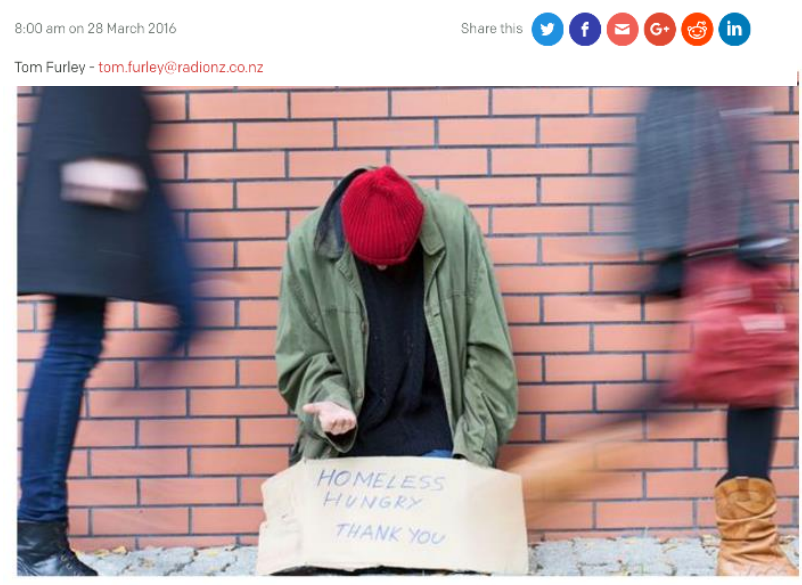

Figure 2: Radio New Zealand

This is even though, according to a 2013 study, of the 41,000 New Zealanders experiencing severe housing deprivation, only 4,000 were entirely without shelter, living either on the streets, in an improvised dwelling or a car (University of Otago 2016). Most people were caught up in cycles of transitional and unstable housing arrangements, living in garages, staying in caravan parks and motels, or bunking up in significantly overcrowded dwellings with relatives, friends or other less benevolent people, who saw an opportunity to exploit others' precarious living situations for personal gain. There was a diversity of the types of people experiencing homelessness, in the scale of homelessness they were experiencing, as 
well as the reasons that landed them there, the issues they faced when experiencing severe housing depravation and their desires for change.

As my masters progressed, media became increasingly cognisant of the complexity surrounding homelessness, and this was reflected in their changing content. A Newshub article from July 2016, for example, reported on a Housing First project, which was based on the logic that it was critical to house people first before they could deal with their issues, and was being offered funding for the first time by the New Zealand government (Lynch 2016). In the article, they discussed the story of a man, Awatea Hawke, who had previously lived on the streets, and noted that "the struggle didn't end simply putting a roof over his head" (Lynch 2016). Similarly, an article in 'The Press' from May 2016, titled "City's homeless population not always visible" (Spink 2016) noted that people were increasingly living in cars, garages and other substandard living conditions and would often suffer in silence, nervous of repercussions. There were families, for example, who feared "Child Youth and Family would remove their children if they disclosed their situation" (Spink 2016). Moreover, they noted that people liable to experience severe housing depravation faced barriers to the private rental market, such as low income, pet ownership (which provide companionship), and stigmas.

Despite these not to be understated positive developments, and a general move away from explanations of individual choice, there still appeared to be some stereotypes taken for granted, as well as a conflation of the perceived solutions to different types of homelessness. For example, after announcing they were going to invest in the housing first approach, housing minister Amy Adams commented that there was not a quick fix to homelessness and that we need to address the underlying causes, but her explanation for these still included "mental health issues, alcoholism or family violence" (Jones 2017). Where distinctions were made between people experiencing severe housing depravation, it was usually in terms of their status as deserving or underserving, depending on how likely they were to have contributed to their situation. The recent attention given to working families living in cars and garages, for example, was said to cut at the heart of New Zealand's egalitarian ethos, reflected during a recent cross party inquiry into homelessness, led by the NZ Labour Party, the Greens, and the Māori Party (Cross Party Inquiry 2016): 
While homelessness had been an issue in New Zealand for some time, the "deepening" housing crisis meant many unlikely people, such as those in work and families, were now being affected There is this almost universal public disquiet to see families living in cars and government agencies referring people to slum landlords...people I think are profoundly disturbed by that (emphasis added; Sachdeva 2016)

These people, it was said, had been failed by government negligence and inability to tackle the Auckland housing crisis, which was being felt nationally. Yet Streeties, those people inhabiting the extreme end of severe housing depravation were usually portrayed as either culpable for their situation by making poor life choices or as unable to manage the basic functions of life.

Individual pathologies, such as drug addiction or mental health, still pervaded much of the public discourse concerned with how people ended up homeless or how best to support them once they were on the street. Generally, wrap around services, in which Streeties are provided with constant care and supervision to deal with their issues, were considered necessary, especially once they were housed, and giving to beggars was discouraged. This is consistent with findings from the literature, which have documented the medicalisation of homelessness (Mathieu 1993; Lyon-Callo 2000). Mathieu $(1993,170)$ argued that the transition from punitive measures of dealing with homelessness, to its increasing medicalisation within government reports, media representations, and public discourse, appeared as a more benevolent response, but in fact, was:

an attempt to delegitimate the plight of homeless people as victims of national political and economic shifts and to divert attention from the structural causes of growing poverty. The characterisation of homeless people as mentally ill undercut their credibility in the drama played out in the media, where government officials assumed the roles of defining homelessness and dealing with it.

Such an approach, while frequently invoked for reasons of protecting the mentally ill, the homeless, or the drug-addicted, was more often aimed at controlling and managing the homeless population, and removing them from public spaces (McGovern 2013; Dooling 2009; 
Hodgetts, Chamberlain, Groot \& Tankel 2014). Moreover, it locates a pathology of deficit as occurring within the individual, while ignoring structural factors, such as welfare cuts, deindustrialisation, lack of jobs, privatised rental market, endemic poverty, the on-flow effects of colonisation, and racism in the criminal justice system.

Lyon-Callo (2000, 332), similarly, found in his three years of ethnographic research at an emergency homeless shelter, that medicalised discourses of deviancy had achieved hegemony in the standardised practices of well-intentioned shelter workers, who worked to "reproduce and reinforce the image of homelessness as a social problem with an origin in individual deviancy". He noted that while some cities were criminalising homeless, many local communities, advocates and policy makers were developing a 'continuum of care' model (Lyon-Callo 2000, 330). Through this approach, community workers create what are perceived to be the necessary services to treat the various symptoms considered to result in homelessness, and to support people into sustaining housing. The logic that underpinned this approach was influenced by a broader effort on the part of "advocates and policy makers to reframe homelessness as a condition afflicting those victimised by disease and dysfunction rather than the result of bad individual choice" (Lyon-Callo 2000, 330). While these wellintentioned approaches can alleviate certain individual cases of suffering by facilitating the delivery of services focused on internal pathologies, the approach fails to address the ways in which homeless subjectivities are produced through the unequal distribution of resources in society. Moreover, they actually obscure structural issues, side-lining them from discussion by prioritising individual and medical explanations, which can then influence public perceptions. This model placed people on a continuum between normal and deviant, with the intention of 'correcting' people, teaching them to govern themselves and work towards normalcy, in this context, managing to live in a house. Consequently, efforts of shelter workers to 'help' homeless shelter users focused on 'reforming' the individualised self to reach the desired state (Desjarlais 1997).

Here in New Zealand, much of the conversation surrounding homelessness still reflects a dichotomy between individual choice and deficit (Figure 3), though the political left and some 
social services have been increasingly vocal about the need to address structural factors, such as a lack of housing ${ }^{4}$.

\section{Tom O'Connor: Problems of poverty and homelessness must be addressed}

TOM O'CONNOR

Last updated 20:05, May 12017

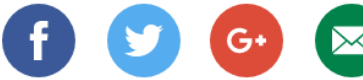

Other homeless people live on the streets, in old sheds and under bridges, and every city has them. For a small number of these people it is a lifestyle of choice or the result of mismanagement and not knowing how or where to seek help. For most, however, the reason they are homeless is well beyond their control or even their knowledge.

Figure 3: 'Problems of poverty and homelessness must be addressed'- Tom O'Connor, Waikato Times

Simplistic and reductive understandings of homelessness, however, still permeate mainstream conversations and actions. Prime Minister John Key, for example, suggested that the homeless did not want help, based on a 'Flying Squads' project enacted by the government to rapidly target those experiencing severe housing depravation by physically locating them and linking them with sources (Lynch 2016):

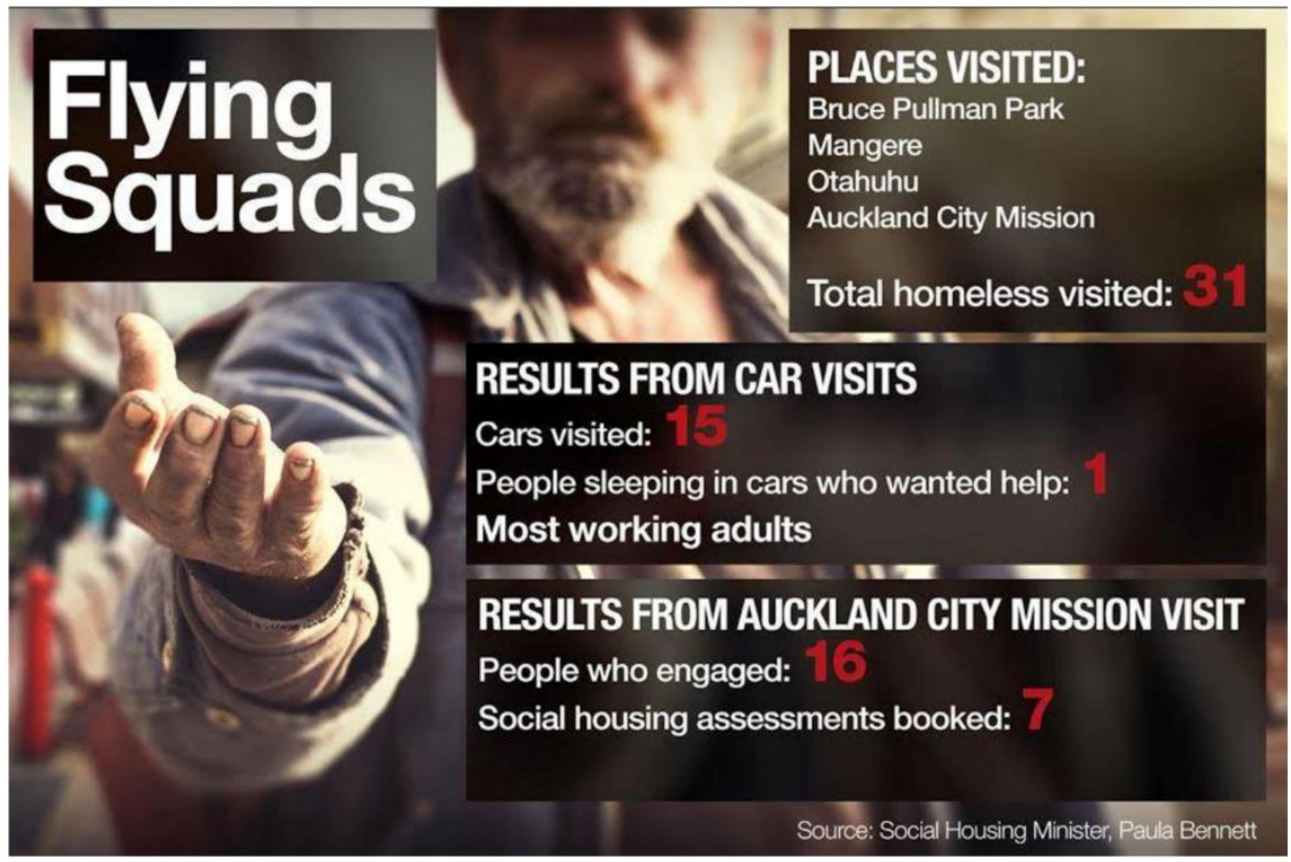

Figure 4: Newshub: 'John Key: Homeless don't want help'

\footnotetext{
${ }^{4}$ Ending Homelessness in New Zealand: Final Report of the Cross-Party Inquiry on Homelessness.
} 
Yet, it was revealed he had been given incorrect information and it turned out his 'Flying Squads' had not been out on the night in question. Even so, this model assumes that people sleeping on the streets and in cars want to be approached by authority figures, and that they are unaware of the existence of services. Moreover, in 2016, Wellington mayoral candidate Jo Coughlan stated she would happily house someone living on the street as a way of tackling the crisis of homelessness, revealing the assumption that people are only on the streets because they don't have access to a physical home.

\section{International Literature Review}

The phenomenon of urban homelessness and poverty has been documented in anthropology since the emergence of skid rows in the United States where populations of largely alcoholic single men lived in geographical clusters of liquor stores and cheap accommodation such as single room occupancy hotels (Spradley 1970; Levinson 1974).

Since then a range of anthropologists and social theorists have tackled the subject, utilising a multitude of frameworks and research angles with various outcomes. Watson and Austerberry (1986) analysed the experiences of 60 homeless women through a feminist lens and found that the meaning of home and homelessness were fluid and not necessarily determined solely by shelter. In response to their findings they developed the home-tohomelessness continuum, from 'rough sleepers' at one end to the marginally housed at the other, a framework that has been influential on public policy to this day (Watson \& Austerberry 1986, 21-22).

Others have focused on space and place to determine the way in which homeless people living in urban centres negotiate their private existences in the public sphere (Baxter \& Hopper 1981; Duneier 1999). In relation to space and place, anthropologists have also focused on mobility (For example, Ruddick 1996; Jackson 2015). Rowe and Wolch (1992) studied the mobility patterns of homeless men and women living in makeshift encampments and on beaches in Los Angeles to determine what resources were available, how they were accessed and the various coping strategies enacted by their participants. Jackson (2015), in comparison, focused on the way in which young people living in an increasingly multicultural 
London navigate the structures that impinge on their everyday lives to make meaning and survive the city in a context of increasingly punitive neoliberalism.

Many researchers interested in homelessness have taken identity as their angle, analysing the impacts of, and role played by, gender, ethnicity and sexual orientation (See, Duneier 1999; Liebow 1993; Bourgois \& Schonberg 2009). Passaro $(1997,158)$, for example, found "that beliefs about the differential social value of people of various genders, races, and family statuses were central to the persistence - as opposed to the occurrence - of homelessness among men in general, and black men in particular." During her fieldwork alongside New York's homeless community, Passaro found that it was largely single, African American males living on the street. It turned out this was partly the result of the 'Housing Tier' system, which privileged females and children at risk of homelessness. She argued that this policy rationale was influenced by patriarchal norms of the nuclear family structure, and the paternalistic need to protect women. Men, who could not provide for themselves, were seen as failing their socially sanctioned gendered role of being the breadwinner.

Research has also highlighted the increasing medicalization of homelessness in public and political discourse (Glasser \& Bridgman 1999; Mathieu 1993). These scholars have argued that medical explanations, rather than criminal, still perpetuate systemic inequalities because they attribute the blame to individual pathologies such as mental illness, while ignoring the impact of structural factors such as rising house prices, welfare cuts, increasing gentrification and job losses resulting from the closing of factories.

Many of these studies have used a political economy framework to explore the effects of the changing economic system. In particular, the effects neoliberal reforms to public policy have had on societal norms and how these reforms impact homeless people (Borchard 2005; McGovern 2013; Duneier 1999; Bourgois \& Schonberg 2009; Dolson 2015). A common theme amongst all these works was the narrative of personal responsibility, which is echoed throughout government conversations surrounding homelessness. The most well-known of these studies is Bourgois and Schonberg's ethnography Righteous Dopefiend (2009). In this, they analysed the way in which the punitive version of neoliberalism achieving hegemony in the United States at the time, criminalised homeless people, the urban poor and drug addicts, 
forcing them into an 'abusive carceral cycle', where their criminal record condemned them to chronic unemployment once released from prison. With no available rehabilitative programs, even those of his participants who wanted to make change, despite their best efforts, ended up back on the streets unable to find stable shelter (Bourgois 2011, 3).

Others have been critical of the lack of agency portrayed in academic research on homelessness, which is concerned with causes and solutions, instead of trying to understand homeless peoples' capabilities and wills (Ruddick 1996; Gowan 2010; Robinson 2011). In light of this, scholarship in geography has recently attempted to move towards an analysis of the performative dimensions of life on the street (Cloke et al. 2010; DeVerteuil et al. 2009). Lancione (2016), an urban geographer, however, is critical of the way social scientists have studied homelessness and their inability to weave the relationship between experience, space and socio-historical forces. He claims that most studies concerned with homelessness have been concerned with population in the Foucauldian sense. Consequently, he argues there "is a lack of thoughtful inquiries revolving around the ontology and epistemology of being (and becoming) a homeless woman or man" (Lancione 2016, 145). Lancione suggests the last thoughtful inquiry into homelessness came from anthropologist Robert Desjarlais in Shelter Blues (1997).

Desjarlais (1997) was interested in how the individual subjectivities of homeless people were produced through the practices and spaces of a homeless shelter. He used a critical phenomenological framework to explore the relationship people share with their everyday environments and how this encompassed the multiplicity of dimensions framing homelessness from the sensory level. He argued that experience is not innate, but shaped by social, political, historical and pragmatic processes throughout people's lives, concluding that to understand homelessness, one needs to understand how experiences of homelessness are constituted in the course of peoples' sensuous engagement with their lifeworlds. His approach has been particularly influential on this study. 
Homelessness in Wellington and New Zealand: Literature Review

Due to a range of circumstances, homelessness has become an increasingly pressing concern in New Zealand (Hodgetts, Chamberlain, Radley, Nikora, Stolte \& Nabalarua 2009). This is in line with increasing inequality in many other OECD countries (Hodgetts \& Stolte 2015). Research on homelessness policy has found that activists and advocates who work alongside and provide for the homeless community are constrained by governmental language and ideas, which demand efficacy and simplicity (Leggatt-Cook \& Chamberlain 2015). This means service providers must often abandon their conceptual understandings of homelessness, to pragmatically frame their concerns as housing issues to affect any kind of policy change. Without the privilege to produce critical reflections at a distance, organizations advocating for the rights of homeless people must often use "limited and uncertain knowledge to achieve maximum immediate impact" (Leggatt-Cook \& Chamberlain 2015, 10) to maximize the resources at their disposal to help homeless people.

Collins (2010), in his comparison of homelessness policy between Canada and New Zealand, found that our heritage of social welfare provision and the building of state houses had created persistent attitudes that homelessness was not a problem; choosing to view those on the streets as living there by choice. Because of these perceptions at the time of Collins study, there had been little research done on the scale of homelessness in New Zealand, something that was reflected in governmental policy, leading to a cultural invisibility of the issue. Since this time, however, homelessness has proliferated immensely, and has consumed far more attention than in previous years, reflected in the range of articles in 2016 concerned with rising homelessness and inequality. Although many of the attitudes he has highlighted still exist, there is an increasing acknowledgement that something must be done to address the situation.

In New Zealand, there is little anthropological literature relating to homelessness and even less in Wellington. McGovern's (2013) PhD. thesis 'A Life Lived on the Corner' is the most notable exception. Her thesis, which utilized a sociological and ethno-methodological approach, was based on 3 years of in-depth ethnographic research with 'Brother', also known as 'Blanket Man'. Central to McGovern's research was an analysis of the "way in which wider social structures and institutions bear upon the local micro-setting" $(2013,3)$. She examined 
the ability of classification processes by these structures to 'make, remake, and unmake people'. Furthermore, by focusing on space, body and social interaction as her core research concepts, McGovern explored the way in which Brother rejected his status, as well as traditional normative understandings of home, and maintained a sense of home in the 'cityas-whare'. Highlighting the dearth of research on what McGovern $(2013,42)$ calls 'street life' in Wellington, she states "my study will therefore not so much 'fill a gap' in the literature as it will plant seeds in what has remained until now, unexplored sociological terrain in Aotearoa New Zealand's capital city". It is my hope that I will be able to draw from the seeds she has planted to nourish my own exploration of 'street life' in Wellington.

Based in Christchurch, Marsh's Master's Thesis (2006) compared the way in which society viewed and understood female homelessness with the actual lived experience of homeless women. In her study, she found that the dominant discourse surrounding female homelessness and the way they were represented labelled female Streeties as deviant, positioning them as social failures, which was then internalised by her interlocutors themselves. The resulting social exclusion made it difficult for them to break out of the cycle of poverty.

The most prolific research done on homelessness in New Zealand comes from a team of Waikato University social psychologists. They have explored the leisure practices of homeless people in urban space (Hodgetts \& Stolte 2015), the role of informal economies such as begging and window washing (Groot \& Hodgetts 2014), the way in which homeless people construct private spaces in public places (Hodgetts, Stolte, Chamberlain, Radley, Groot \& Nikora 2010) and the role played by engaging in cultural practices for the wellbeing of a Māori homeless woman (Groot et al. 2011). Much of their research is ethnographic based and takes an intimate look at the way life is lived on the streets, though it is all Auckland or Waikato based.

\section{What was missing}

As I spent time doing fieldwork, meeting Streeties and socialising at drop-in centres and soup kitchens, what I felt was lacking from the literature was a portrait of the complex, yet subtle 
everyday negotiations and decisions people living on the street had to make to get by and create a life that worked for them on their own terms. There were a plethora of personalities inhabiting the spaces homeless people traversed in their everyday life - social workers and volunteers at drop-in centres and social service organisations, other Streeties who may be friends, partners or foes, family members, authority figures, members of church organisations, the general housed public, academic researchers and reporters.

On an immediate level, people in these spaces held different beliefs, attitudes and ideas about what people living on the street needed, who was deserving of attention, who had responsibility in a situation, and what the appropriate action to take in the face of a change in circumstance was. At a more general level, people also held contrasting and sometimes conflicting opinions of what it was humans needed out of life, what values we should hold and how we are meant to conduct ourselves - the responsibilities entailed in our belonging to a certain kind of society. These moral, political, and personal sentiments expressed themselves in a variety of ways, both expected and unexpected, depending on factors such as a person's mood, daily disposition, previous experiences and their personal outlook.

Moreover, it was not just other people whom Streeties had to navigate relationships with, but also the physical environments they inhabited. They had connections with the streets, parks, nooks and crannies, libraries and other places where they slept, socialised, generated income, found solace from the weather, avoided confrontation with others, or just sought respite from the general stresses of daily life. Their access to these spaces was, for the most part, mediated by what was deemed acceptable and appropriate behaviour in a given area, and of whose presence was considered legitimate, decisions which changed over time, and were generally determined by an intersection of local and national legislation, private property interests, media attention, and the will of the public, influenced by cultural underpinnings of who and what urban and green spaces were designed for.

Streeties I worked with had relationships, however fraught, with the places they grew up in, had previously lived, and sometimes visited. They progressed through state institutions, whether it be 'Child, Youth and Family', boys' homes, and borstals as children and adolescents, or prisons, court houses, police stations, police cars, Housing New Zealand and 
Work and Income offices as adults. Similarly, they moved through transitional housing, rehab facilities, and night shelters. They sought food and help from social services such as the DCM food-bank and their drop-in centre Te Hapai, the Sisters of Compassion Soup Kitchen, the Wellington Free Store, and the Salvation Army Hope Centre. Some of them attended church and participated in church run spaces, while others had relationships with organisations attempting to house people in a range of accommodation from boarding houses to churches and Marae. Some spaces, such as prison, often proceeded boys' homes and Child Youth and Family, but movement between transitional housing, the streets, services, and institutions didn't always occur in a linear fashion. Streeties came to the drop-in centre, sometimes signed up to the DCM never to return, while others consistently showed up at the same time every day. Along my journey, I met people who had moved inside, only to find out they were back on the street the next time we crossed paths. Moreover, as the visibility of homelessness in New Zealand increased, these physical spaces increasingly began to seep into the discursive zones of media outlets, social media comment threads, government reports, and academic research.

What I came across in the Streeties I spoke to, was an ambivalence to 'go inside' as they frequently framed it. There was often a reluctance to be housed in the material sense, sometimes even bordering on righteous defiance, despite expressing an interest in a change of circumstance. When they did move inside, there were often difficulties and tensions that accompanied the transition, which sometimes saw them back out on the streets or in deteriorating frames of mind. They occasionally had disputes with social workers over the correct course of action, or with other Streeties over proper conduct on the streets, as well as with authority figures over drinking and sleeping in inappropriate and illegal locations. In these situations, people living on the streets had little power to direct or control the narrative, shape or influence outcomes, or to offer alternative explanations of their situation that drew on their experience and perspectives. They were confined by linguistic, epistemological, social and material parameters, which were set by the prevailing neoliberal politicaleconomic orthodoxy, disseminated through the media, government policy, service provision requirements, authorities and public attitudes (Desjarlais 1997). 
As my MA progressed, I became increasingly interested in the ambiguity surrounding the lifeworlds of Streeties, and the layers of conflicts and tensions that arose in the process of trying to address homelessness as a problem. I wanted to explore this complex web of relations, which involved landscapes, people (both housed and unhoused), institutions and meta-discourses, from the perspective of people who, for whatever reason, called the street their home. I wanted to know what their motivations were, what the things were that were driving them - their desires, needs, and values. How did they make sense of their reality, what were the things that mattered to them, where did they see themselves in the scheme of things, and how, in turn, did they relate and engage with the wider web of relations with which they were enmeshed in? Moreover, as previously alluded to, I was interested in how the experiences of Streeties, and their understandings, were not necessarily illustrative of given truths, but were constituted by, and contingent on, their historical trajectories, which were shaped by intersecting factors but which were always unfolding in the present.

Currently, no anthropological research has addressed these issues surrounding homelessness in Wellington. Moreover, there is no literature linking historical understandings of experience and home, to Streeties contemporary situations in Wellington or New Zealand. Likewise, while research has focused on the ways homeless people have agency, or don't have agency, there are no studies that problematize this distinction and instead suggest acts of submission in the lives of Streeties are a necessary coping strategy to get by and live well. Thus, there is room for research investigating, from an anthropological perspective, how members of the Wellington homeless community experience movement and being in their everyday lives.

\section{Theoretical Framework}

\section{Dwelling/Habitation \& Wayfaring}

To understand the way homelessness is felt or experienced during everyday life I turned to Ingold's (2000) 'dwelling' perspective, which privileges the knowledge and experiences gained and learnt through our phenomenological interaction with the surrounding landscape. It does this by considering the "understandings that people derive from their lived, everyday involvement in the world" (Ingold 2000, 189). In understanding how we inhabit the world, 
he contrasts the building perspective, the dominant mode of thinking in the Anglo-European West, with 'Dwelling'. Sissons ${ }^{5}$ has since revised Ingold's terminology, referring to the builder's perspective as the architect's or state planners' perspective. In this view, buildings, cities, and other human creations are imagined in the mind before being built and constructed. Both understandings situate ontologies of detachment over ontologies predicated on a perceptive engagement with the surrounding world, instead privileging the gaze of technocratic professionals in the management and development of life and the environment, in the process marginalising "local people in the management of their environments" (Ingold 2000, 216). These worldviews, which permeate contemporary bureaucratic thinking and practice have a specific relevance to the way in which the state, and social service agencies attempt to manage homelessness and the tensions which emerge when these goals digress from the desires of Streeties. It's useful to grasp the way technocratic management privileges professionals, while undermining the values and experiences gained by Streeties on their journeys through everyday life, imposing solutions that reify the normative assumptions of the dominant group.

Ingold has suggested we re-orient our ontological understanding of the environment, by considering the way knowledge and understanding emerges from situated, embodied engagement. He argues we should adopt the sphere as a modality of understanding experience, and human-environment relations stemming from "an active, perceptual engagement with components of the dwelt-in world, in the practical business of life" (Ingold $2000,42)$. In this sense, knowledge of the world emerges through a person's constant interaction with that which surrounds them (Ingold 2000).

More recently, Ingold has resituated his focus on dwelling to movement and wayfaring to emphasise the way life does not just exist, but comes into being through an ongoing process. He advocates an anthropology that 'comes to life', and recognises life's capacity to continually:

\footnotetext{
${ }^{5}$ This revision was made by Associate Professor Jeff Sissons during the course of ANTH 215: Culture and the Material World
} 
overtake the destinations that are thrown up in its course. It is of the essence of life that it does not begin here or end there, or connect a point of origin with a final destination, but rather that it keeps on going, finding a way through the myriad of things that form, persist and break up in its currents. Life, in short, is a movement of openings not closure (Ingold 2011, 4)

Life, unable to be contained, "overflows any boundaries that might be thrown around it, threading its way like the roots and runners of a rhizome through whatever clefts and fissures leave room for growth and movement" (Ingold 2011, 83). No longer bounded by perimeters, life is lived along lines; these lines have no beginning or end but are constantly issuing forth. The environment, in this case Wellington city, is not seen as a series of discreet entities according to such an ontology, but is rather viewed as being composed of an endless number of lines, which weave their way together, forming knots, or 'haecceities', before dispersing again (Ingold 2011, 88).

Critical of the terms 'space' and 'place', which he argues create a perimeter between 'here' and 'there', between inside and outside, and evoke a sense of being disembodied, suspended from life, Ingold argues we should understand our lives as lived along these lines. He describes this embodied experience of movement as wayfaring, suggesting that "it is as wayfarers, then, that human beings inhabit the earth" (Ingold 2000, 148). As opposed to the notion of being place bound, human existence is 'place-binding'. As we move around, journeying through life we leave a trail. When we meet with other inhabitants, both human and non-human, our trails become intertwined, momentarily becoming bound up with one another and forming knots. For Ingold, these knots are like places. Knots function as intense centres of activity, around which lines entwine but they are never fully encompassed and are able to disperse along lines of flight into new knots. Place, then, becomes animated by activity. In this view, knowledge is not transmitted but emerges from a life in motion.

\section{Agency}

Ingold is critical of theorists, such as Ortner $(2001 ; 2006)$ who see agency as human centric, located within one's subjectivity and defined by 'acts' of intentionality. He is also critical of theorists such as Gell (1998) and Latour (1999) who, while sharing a distaste with Ingold for 
the human exceptionalism present in Ortner's definition, remedy this by extending the ability to act intentionally to the world of non-human 'agents' or 'actants'. Instead of agency, Ingold posits the concept of 'Correspondence'. For Ingold we are immersed in action, and our behaviour is shaped by a process of corresponding to our environment based on our sensory engagement with it.

In the case of Streeties, Ingold's theoretical positions offer a fruitful framework for capturing the dynamic and vital aspects of their lives. Streeties, as wayfarers, are in a constant state of movement, weaving and winding their way through life like nodes in a complex nexus of relations. Their relationships to places and people are emergent from their journey through the city. Ingold's analytical outlook emphasises the need to move away from seeing Streeties as discreet bounded entities, and towards seeing them as caught up in the material flows of the city. The ways they respond to this material world are often spontaneous or dependent on too numerable factors to be understood by looking at agency as something that exists within the self. For this reason, his de-centering of agency either being located solely within an individual, or of being intentional in nature, and his focus on correspondences, allows us to comprehend the diverse ways in which Streeties think, make judgements, and act in relation to their surrounding environment as it unfolds in the present. This is particularly pertinent in the realm of Streeties lives, where neoliberal narratives of self-enhancement and empowerment, which sync well with certain anthropological notions of individual agency, saturate the policy and service provision landscape (Desjarlais 1997, 204). By seeing life as an open-ended, transformational space, where meaning, knowledge and understanding emerges through embodied practice and movement, we can begin to privilege the understandings and meanings that Streeties derive from their perceptive engagement with their surroundings. Moreover, it means being able to see the potentiality of their existence as always eclipsing the closed boundaries of bureaucratic management. Where it falls short, however, is in its often romanticised and a-political portrayal of wayfaring, correspondence and habitation, a critique that was addressed, somewhat vaguely and incomplete, in his article 'The Politics of Dwelling' (Ingold 2005). In the lifeworlds of Streeties and those without power, however, I argue that dwelling and wayfaring are contested and ongoing struggles to make life work for them in a meshwork whose weave would otherwise be unhospitable. 


\section{Jackson's Existential Anthropology and Intersubjectivity}

To account for this struggle, I turned to Jackson's existential anthropology, which focuses on intersubjectivity, shifting "our emphasis away from notions of the person, the self, or the subject as having a stable character and abiding essence, and invites us to explore the subtle negotiations and alterations of subjective experience as we interact with one another" (2013, 5). Such a perspective is critical of the idea that we possess, as humans, a stable, immutable essence or identity; suggesting, rather, that we are in constant state of transformation, forming and reforming throughout the course of our relationships with others, both people and things, and motivated by our struggle to obtain what we require at that particular moment to sustain ourselves and find meaning or fulfilment. It is a particularly promising theoretical position to understand the way in which the personal and political, as well as the particular and the abstract, intermingle with one another, mutually arising, each being the "condition of possibility of the other" (Jackson 2013, 6).

His notion of the lifeworld in this instance, provides a valuable conceptual tool, for understanding how people who live on the street negotiate their everyday existences, not as passive recipients of an internalized subjectivity, but as lively beings caught up in a vital, yet ambiguous and unpredictable social field, "a constellation of both ideas and passions, moral norms and ethical dilemmas" $(2013,7)$, that is in a constant state of emergence, eluding definition and clearly defined parameters. It is a way of understanding the world that requires a descent into everyday life, and which sees every encounter as altering the conditions of our possibilities, without uncritically disregarding those factors that may limit or predetermine aspects of our human potentiality, such as class, ethnicity or gender.

Agency, for Jackson, is more human centric than Ingold's interpretation, but is neither solely confined to the individual, nor located in the social. Heavily influenced by his time among the Kuranko in Sierra Leone, he sought to define:

the way in which human beings, faced with nonnegotiable, overwhelming, or degrading situations, attempt to salvage some semblance of comprehension and control such that in some measure they govern their own lives, are complicit in their own fate, and not simply insignificant and impotent creatures of circumstance $(2013,15)$. 
In the lifeworlds of Streeties I encountered, institutional or socially legitimate forms of power were largely outside their control. Their ability to mount any kind of meaningful collective resistance against these structures was equally limited. Thus, they often faced circumstances in which they had to find alternative means to assert control over the direction of their lives. Control or management, in this context, was not always associated with conventional notions of 'self-improvement' or rationally trying to increase one's social status, but rather ways to live well, to live on their own terms, to retain a sense of self or to help others. Jackson's approach is productive in this setting because it emphasises the "role of contingency, playfulness, unpredictability, mystery and emotion in human life" (Jackson 2013, 14). Drawing on the writing of thinkers such as Nietzche, Jackson asserts that humans are not just motivated by rational drives to improve or adapt, but also "by a transgressive drive to throw caution to the wind, expend surplus energy, interrupt routine, and experiment with consciousness" $(2013,16)$. Of particular interest to me, in this process of making the world one's own, is the relationship between agency and submission. The ability to withstand the suffering of life, for Jackson (2013), is as much the result of submission as it is acting.

During a masterclass with Professor Jackson (2017), he expanded on this point, by suggesting that to understand the ways people inhabiting precarious positions make life livable, we need to comprehend the interplay between agency and patiency. By focusing on the way my participants made sense of their lives, exerted control over the circumstances, and existed as beings caught in entanglements with a myriad of other people, places and things, I set out to understand ideas of autonomy, home, and belonging, as well as the ambiguity and uncertainty of constructing personhood and retaining a sense of self in the face of immense hardship.

\section{Thesis Overview}

Underpinning the entire thesis, and tying all these chapters and film together is a struggle for both autonomy and belonging, and the tension between life as an unbounded, ever flowing entity, and the concepts which seek to cut up the indeterminacy of life and experience into clearly bounded concepts and frameworks. As individuals with unique histories, dispositions and personalities, the Streeties I met were constantly committed to 
living life on their own terms, even when this sometimes came at the expense of being housed, obtaining necessary resources, or receiving other kinds of help, which to most outsiders, would have seemed like rational solutions. This was not because they were necessarily belligerent, immature, or irrational, but because it was critical their wellbeing and survival to live in line with their values, and the moral economies within which they were embedded. These values were influenced by their experiences inhabiting marginalised spaces and how they saw themselves and others positioned within the world, physically, socially and spiritually.

Many of these Streeties had been rejected from the traditional channels which distribute socially legitimate forms of personhood and meaning, while others had actively rejected these channels for impinging on their ability to live a dignified life. Consequently, they have had to carve out new ways of relating to themselves and asserting their autonomy. None of them, however, wanted their autonomy to come at the expense of others. In fact, their struggles for autonomy were also simultaneously struggles for belonging. Their autonomy was never isolated or bounded, but was always related to a respect for their position as individuals within wider systems of relations that contained relatives, other Streeties, members of the public, special places, worldviews or their spiritual beliefs. Thus, this thesis looks at what it means to be and belong, to be an autonomous individual, and a member of wider network of relations, what it means to feel 'at home' in the world, what it means existentially and discursively to 'be homeless', and what it means to live 'well' on the margins. It does this by exploring the way Streeties carve out new spaces for living, how they construct their sense of self, and the ways in which they hope for a better life and relate to their environment through both film and text. 


\section{Methods: Undergoing Anthropology}

\section{Introduction}

In his review of Michael Jackson's 'Lifeworlds', Ingold $(2014,771)$ states that anthropology is something that happens to us as ethnographers and researchers during the phases of study, be it planning or conducting field research. It is something we undergo rather than do, the things that occur when we least expect it, and the moments that escape our definitions and concepts. It comes about through the process of momentarily sharing in the lifeworlds of others, which like our own, cannot be easily defined and bound up into coherent wholes to be explained away. He takes this position further, stating "participant observation should be understood not as a method of data collection at all but as a practice of exposure, entailing considerable existential risk, which allows us to grow in knowledge and wisdom from within the lifeworlds into which we are cast" (Ingold 2014, 772).

Much of this sentiment underlined my experience of doing fieldwork with the Wellington Streeties community. At times, I felt overwhelmed by the sheer contingency of trying to delineate a manageable and reasonable ethnographic framework and field site, when my own life, the lives of Streeties and the surrounding circumstances seemed hell-bent on challenging any possibility of a stable, consistent and easily definable site of participation. However, at other times, it did not feel as if it was unfolding in such a 'flux' so to speak. There were frequent impasses where my entry into the lifeworlds of Streeties was characterized by slow moving, regimented processes, often influenced by the institutional structures which frame Streeties lives. Thus, anthropology, I realized, was a process of exposure not just to the people with whom we plan to study with but an exposure to the kinds of institutions and structures that inhibit or enable their movements.

In this section I will outline the ways I went about 'doing' research, and how I 'underwent' anthropology in the process. I will start by introducing my methodological framework, which draws on the phenomenology of Michael Jackson and Tim Ingold. I will then discuss my fieldwork experiences, how my field site developed, the ways I met the Streeties who eventually became my participants, and the impasses and disjunctures that shaped the kind of research I produced. I will elucidate the ways I tried to make sense of the messiness of 
fieldwork and understand the lives of others, by using participant observation, field notes, semi-structured interviews and visual methods, highlighting how these techniques enabled and limited my research. Finally, in a stand-alone section I will explore my use of visual methods and the production of a film to accompany my written thesis, detailing why I chose film and how it worked out.

\section{Methodological Framework}

\section{An Intersubjective Ethnography}

Interested in questions of how people live and negotiate life on the streets, what it means to feel 'at home in the world', and how one thinks about their situation, I turned to the existential anthropology of Michael Jackson (2013), which, as outlined in the previous chapter, emphasises the indeterminacy and contingency of social life and existence, asking anthropologists to embrace the ambiguity and plurality that permeates intersubjective life and imploring us to explore the 'subjective in-between', those "subtle negotiations and alterations of subjective experience as we interact with one another" (Jackson 2013, 5).

The ethnographic commitment that separates us, according to Jackson, from Kant's project, "is a commitment to explore empirically the lived experience of actual people in everyday situations" (Jackson 2013, 9). Ethnography is predicated on entering a world where the comforts and norms that underpin one's own sense of self are replaced by the unfamiliar, displacing our emotional, intellectual, social and sensory faculties. It is in this deterritorialisation of one's notion of the self, where one becomes liminal that the possibility for understanding emerges. Understanding, in this sense, is not an ethnographic conceit, whereby the researcher, through techniques and training, is able to absolve himself from his own ways of thinking and preconceptions to empirically understand the other, or how the world is experienced from their vantage point. Instead it offers the researcher the possibility to perceive themselves as they could be or could have been under different circumstances. Realising that both "knowledge and identity are emergent properties of the unstable relationship between self and other" (2013, $10-11)$.

His radical empiricism, moreover, encourages anthropologists to include equally, in fieldwork, the subjectivity of the observer, to give primacy to the relations between observer and 
observed, "making knowledge effectively conditional upon the nature of this relationship" (Jackson 2013, 23). It also means that the researcher should also be seeking out knowledge from within the lifeworlds of our participants, rather than searching for transcendental truths.

Knowing from the Inside

\begin{abstract}
"What we might call 'research' or even 'fieldwork' is in truth a protracted masterclass in which the novice gradually learns to see things, and to hear and feel them too, in the ways his or her mentors do. It is, in short ... 'an education of attention'”' (Ingold 2013, 2)
\end{abstract}

I also turned to the writings of Tim Ingold (2013), whose perceptions of anthropological inquiry and the resulting understanding are akin to 'Knowing from the Inside', complementing Jackson's existential and phenomenological focus on intersubjectivity and his descent into everyday life. For Ingold, it is equally contemptuous to suggest that there is a world out there composed of discreet pockets of knowledge embedded in the cultural and symbolic forms shared by a group of people, ready to be pilfered by anthropologists lying in wait. What anthropologists undergo in the field is a process of learning to learn, of being taught by the world rather than presenting facts about it (Ingold 2013, 2). It is to shake off our preconceptions and destabilise our sense of understanding, converting "every certainty into a question, whose answer is to be found by attending to what lies before us in the world, not by looking it up at the back of the book" (Ingold 2013, 2). He argues that it is naïve if not fallacious to separate theory from method, because our knowledge of the world is always emergent from, and dependent on, our engagement with it. For this reason, it is participant observation, which defines and distinguishes anthropology as a discipline:

if its method is that of the practitioner, working with materials, its discipline lies in the observational engagement and perceptual acuity that allow the practitioner to follow what is going on, and in turn to respond to it. This is the method, and the discipline, known in the trade as participant observation (Ingold 2013,4) 


\section{Participant Observation}

Participant observation is fundamentally grounded in an appreciation of how life is lived and experienced in specific times and places, but, because people are always developing, changing and growing in relation to the future which lies before them, it is also oriented toward the unknown and unstable, toward the possibilities that proceed our existences. Furthermore, learning and knowing, for Ingold, emerge through "the course of direct, practical and sensuous engagements with our surroundings" $(2013,6)$. This means attuning our 'perception' and 'action', the skills with which all beings are endowed to navigate the material flows of the world, with the movements of our participants. It is to join with them in the practical activities of life, responding to one another through the act of correspondence, as our capacities allow. It is in undergoing this 'education by attention' that anthropologists make an ontological commitment to both their participants and the material world they inhabit through the practice of participant observation (Ingold 2014, 388).

The Field

In this section I will elucidate how I negotiated and navigated the complexities of my field site, and the personalities and places that texturized the lived-in world of Streeties, from finding participants, building relationships and doing participant observation, to the barriers and impasses I faced that shaped my research but which highlighted aspects of being at home in the world of Streeties in Wellington.

I initially reached out to the director of the $\mathrm{DCM}^{6}$, a Wellington central based social service, in December 2015, to outline my research and ask about volunteering at the centre. We exchanged a series of emails before she invited me to come for a meeting. I had decided to approach social services as opposed to finding people on the street for several reasons. I thought approaching people on the street and asking if they would like to be involved in research could be invasive. I was naive to the kind of etiquette or habitus that shaped street relationships and needed some guidance. Moreover, I thought it would be difficult to get an overview of the situation if I was only going through people I met on the streets. Social

\footnotetext{
${ }^{6}$ Downtown Community Ministries
} 
services, I believed, would allow me to cross paths with a wider cross section of the homeless community than approaching people on the street alone. DCM seemed like a good social service to contact due to the number of services they provide, such as a money management system, a food bank and advocacy on behalf of their 'clients' when dealing with government agencies, as well as their sheer level of infrastructure for dealing with homelessness. Moreover, I was cognizant of the fact research and fieldwork can often be an extractive process, whereby the researcher gains a great deal, while participants receive little in return (Pink 2007, 56). As such, I thought volunteering would be a tangible way I could at least be of some use during my research.

In my first meeting with the director, we discussed the outline and aims of my research and she expressed her interest in helping to facilitate it. In setting out the parameters of their rules and regulations, however, she stated that volunteers were not allowed to associate or spend time with their taumai ${ }^{7}$ outside business hours or off the premises. A minimum of two staff members attended house visits, at least one of them trained in dispute resolution. Although I understood those precautions, the nature of doing a phenomenological study required me to do research outside the organization. We agreed to meet later down the track when I had a clearer sense of direction, to see if we could come to an alternative arrangement where it was clear to their taumai that I was there as an independent researcher. Thus, the first boundary of sorts was drawn up around my field site.

To begin with, we agreed that I would volunteer behind the front desk with some of their other staff members, answering phones, meeting taumai and helping people fill out food parcel forms. I also assisted in the day to day running of the upstairs drop-in centre, Te Hapai, which is where I ended up spending most of time. Because of the unfortunate and untimely death of a staff member they were short on numbers, and needed at least three people to be upstairs at any given time to remain open. This meant my presence helped them stay open on several occasions, and earned me some respect with other staff members and taumai.

\footnotetext{
${ }^{7}$ Taumai is a neologism created by DCM to describe their service users.
} 
My introduction to the world was unsettling. On one of the first days, the director introduced me and my research to some of their taumai and one young Māori man was quick to challenge my methods, telling me 'you can't understand what it's like to be homeless until you've been homeless yourself.' Everyone vocalised their agreement. Standing in the centre of the room, I nervously laughed. A woman across from him shared her story of ending up on street after losing her support network. I stood there, appropriately uncomfortable, not knowing what to say, offering only meek agreement that it must be tough, but that I would like to do my best to understand. It hardly seemed enough. This initial experience and the associated sense of unease and discomfort was critical to developing a more nuanced perception of what it means to understand, as well as its limits.

After this introduction, I tried to grasp my basic duties behind the desk - answering the phone, signing people in for the foodbank, restocking the bread freezer, and putting out baking and food donated by local bakeries and cafes on the coffee table in the middle of the waiting room. Sometimes I chatted to taumai, but often they were more preoccupied with their upcoming meetings with social workers over housing, benefit or other advocacy issues.

Upstairs in Te Hapai, I got to know the social workers, volunteers and taumai better. It spanned two interconnected rooms, and three smaller offshoot rooms. At the entrance was a sign-in sheet that all guests were required to fill out every day. Next to this was a table with a stereo where the social workers normally sat. Slightly further in from the dining table was the most popular feature of the room - a small table with a boiling water zip, cups, instant coffee, sugar and tea bags. The connected room had chairs surrounding the edges, a bookshelf, a central table, some plants and art on the walls, and a few guitars lying around. There was kitchenette, a room with about six computers and a small room which served as an office when social workers needed a meeting space or to work in quiet.

I met a plethora of personalities in Te Hapai and observed friendships, confrontations, laughter, solidarity, and creativity, as well as struggle and sadness. There were ex-Streeties who were celebrated as success stories, social workers with particular perspectives on religion and empowerment, eccentric characters with code names, distinctive styles and habits, and other quiet, more reserved taumai, who kept to themselves. 
When I was no longer needed as a volunteer I came along to socialize, navigating relationships with taumai, social workers and volunteers. I struck up a longstanding friendship with one man, $\mathrm{Bob}^{8}$. He introduced me to people he thought I would be interested in chatting to, as well as giving me advice and sharing his perspective on situations as they arose. He had been homeless around ten years earlier but had since moved into a council flat, and worked as a volunteer at the drop-in centre and the soup kitchen, Monday to Friday. A Māori man, he was an avid reader with sharp intellect, strong political opinions, and a talented guitarist. He was eagerly learning Te Reo, and had an astute knowledge of Kaupapa Māori and Tikanga practices, and was, for the most part, non-religious. He seemed to have a more fluid relationship with the other taumai, perhaps because he was a volunteer at both the drop-in centre and Soup Kitchen, and less involved in the machinations of either organization.

I ended up heading along for several months, on his advice, to the Sisters of Compassion Soup Kitchen, on Tory Street, which opened for breakfast around 7.30am. On arrival, there were normally a few people hanging out in the car park, young men listening to music, others standing in circles smoking cigarettes, and a few who sat in fogged up cars filled with possessions. Bob often sat on a nearby stairwell, smoking a cigarette, reading or working on a crossword. Past the entrance way a small ramp led into a waiting area which connected to the cafeteria. Here, people lined up and waited to be served. Once I received my tin bowl of soup and a piece of bread l'd find somewhere to sit and chat with others.

Between these two places, the drop-in centre and the soup kitchen I became gradually familiar with people's faces, striking up friendships, having informal conversations and nervously pottering around the edges. I found that any previous notion of finding an 'accurate' cross section of the homeless population was a myth. Some people used the services, but many did not. Some wanted to talk to me, but plenty did not. Those that did want to chat, could sometimes talk for hours, and other days, when we agreed to interview, were nowhere to be found. I did my best to adjust to the rhythms of living on the street and accepting the transience of peoples' lives. I avoided placing obligations on them, and took

\footnotetext{
8 Pseudonyms are used for all participants and individuals who I spoke with
} 
interviews and conversations as they came, in this way, taking note of Pink's $(2004,10)$ emphasis on the importance of the ethnographic process remaining flexible and adaptive to fit into the lives and schedules of participants. In these spaces, it seemed suspicious to take field notes (Henley 2000, 221), so I tried to keep track of things in my head as they transpired, making small entries in my phone if there was something I felt particularly important. Once I had left these spaces, I wrote down everything that happened, capturing the details of the day, points to be considered for future reference, interactions between different people, and made a note of those who had expressed interest in chatting with me.

I tried to engage in the everyday activities of the people I was hanging around with, sharing tobacco and smoking cigarettes, playing guitar, helping re-stock the coffee supplies and passing food around to those at the drop-in centre. I had been chatting to one man, Pita ${ }^{9}, \mathrm{a}$ Māori male in his mid-30's who was living on the streets. We sometimes sat together at the Soup Kitchen and socialised or played guitar at the drop-in centre. During my research, he moved into a council flat after five years living on the street. One morning at the soup kitchen, when he expressed his interest in making a film about homelessness, I told him I was planning on shooting a film for my thesis. We joked about the kinds of things I should look at and he was keen to be involved. The following week we met at Te Hapai, drank a coffee and ventured off into the streets with my camera. He took me to various locations where he slept, socialized, or drank, while living on the streets. Stories came out as we moved around the city, we laughed and joked about things we were witnessing, or talked about people and incidents at the Te Hapai and Soup Kitchen.

\footnotetext{
${ }^{9}$ He chose this pseudonym for the written component of the thesis but is identified by his real name in the film.
} 


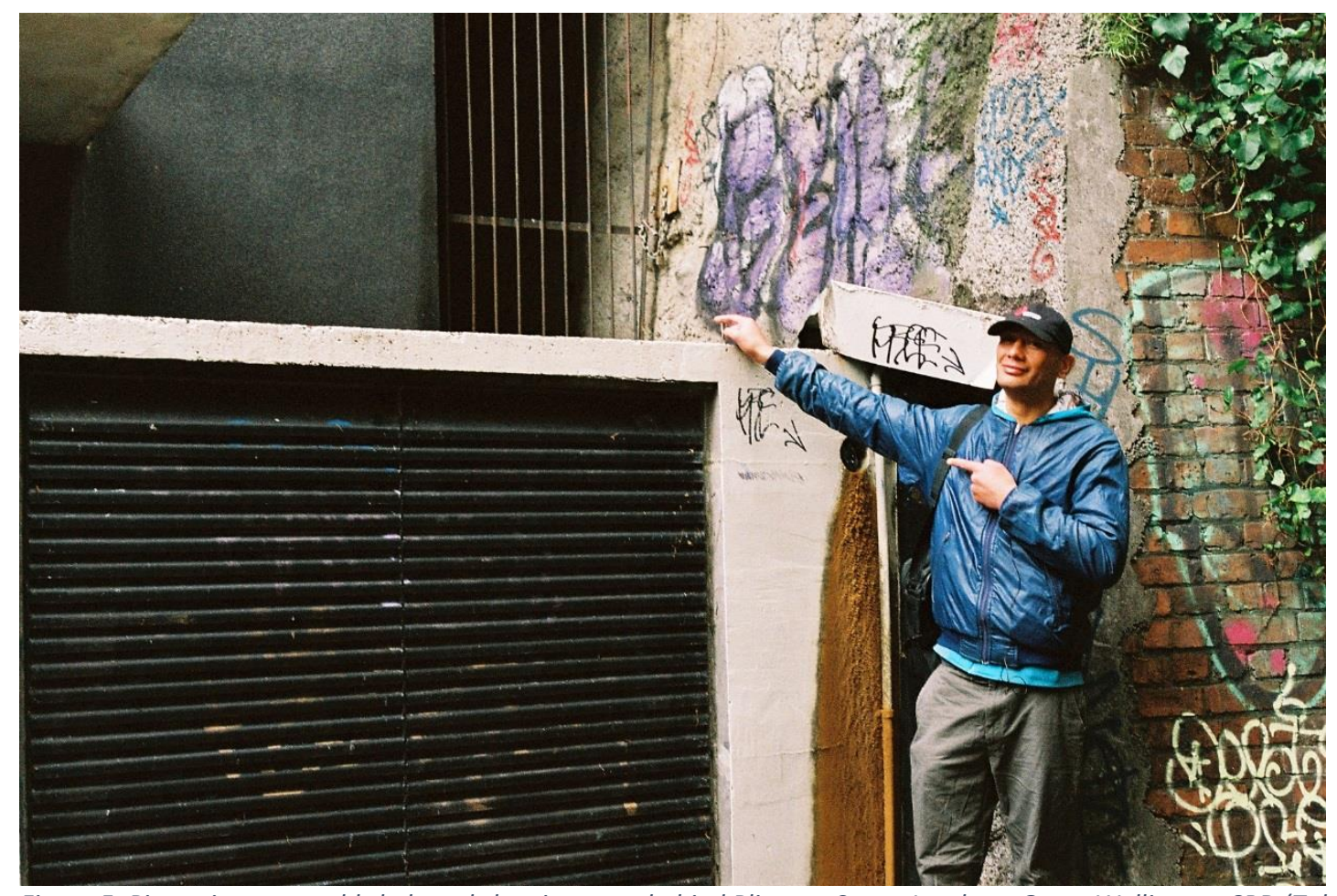

Figure 5: Pita points to an old sheltered sleeping spot, behind Plimmer Steps, Lambton Quay, Wellington CBD (Taken by Jonathan Foster)

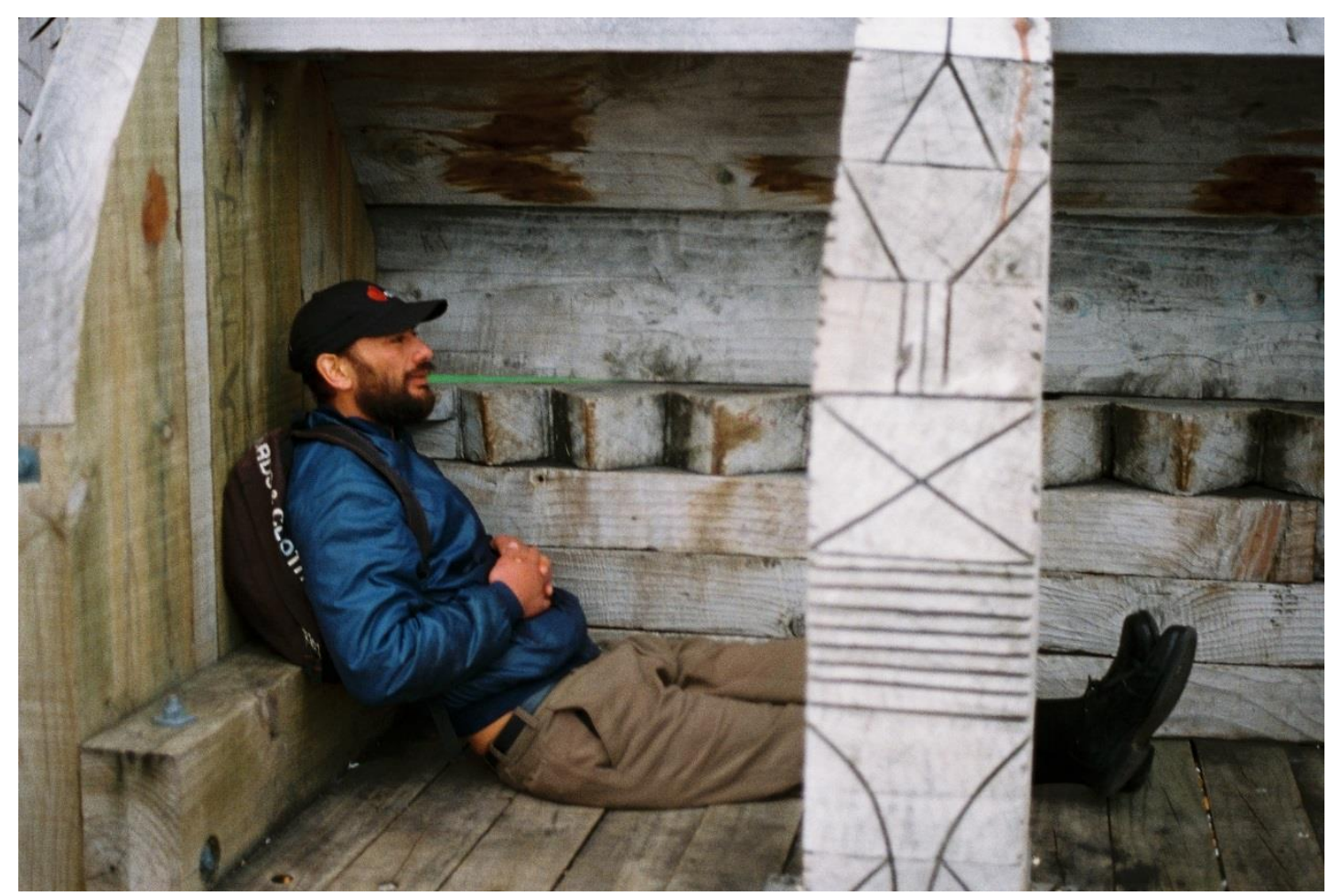

Figure 6: Pita takes a rest in a covered seating area in the Wellington Civic Centre (Taken by Jonathan Foster) 
While my connection with Pita developed organically over a sustained period, others I met eagerly gave me their number, expressed an interest in being interviewed, but disappeared when I tried to follow up. I had issues interviewing a man, John, who had been having trouble with the courts, and was also being bothered by another homeless man. He frequently had to reschedule our interview, until eventually it fell through, which speaks to the chaotic and changeable nature of people's lives on the Streets.

When he was finally housed, we agreed to meet but this led to a tension with the rules and regulations of volunteers at the DCM. The director felt that because I had chosen to go through their organisation, I should stick to their rules and stay within the boundaries of Te Hapai, due to safety concerns for myself, the taumai, and the organisation. I contested that the nature of my research required me to be venturing outside their organization, and asked if I could send her an outline of my research to give her an idea of what I was covering and then meet again in a week to discuss.

The issue with both the drop-in centre, and the presence of social workers, was not so much that they were doing bad things, because for the most part they were doing critically important work and were valued by many of their taumai, but they also sometimes made Streeties uncomfortable because Streeties had to work with them to get the resources they needed to survive. Similarly, the drop-in centre was a small space where you could hear other people's conversations with ease. People had different relationships with each other and were not always on friendly terms. Some of the people I interviewed, for example, did not get on with my other participants, and I would have to engage in conversations and interactions with all of them, trying to balance how I was being perceived, who I was spending time with, and what I was talking about. Streeties would often congregate in these spaces, but just as frequently they would dissipate, moving out on to the streets, hiding along the green belt, or temporarily staying at a friend's place. As fast as a friendship could be struck up, an argument or uncomfortable dynamic could send a person packing. As I got used to seeing familiar faces, people would disappear and new ones would turn up in their place.

I articulated these concerns, drew up a plan of what I intended to do, emphasizing that I was planning on staying in mostly safe, public locations, and we managed to come to an 
agreement. Soon after, Bob introduced me to another Streetie, who invited me to a barbeque on Saturday night for the homeless. Here I met the church group who organized the barbeque and found out that they had been housing people living on the street out at their church in Wainuiomata. I was invited to sleep rough with some of the Streeties and two of the church goers the following week. I met them in Courtenay Place Burger King where we socialized for a couple of hours before setting off down the road to Harvey Norman on Tory Street to collect our sleeping materials for the evening (Figure 7). Having attained what I was assured were the top tier cardboard boxes for fridges from the bins of Harvey Norman, we set off to our sleeping spot in the Briscoes carpark (Figure 8). During this experience, I chatted to the church goers, the Streeties, and passers-by who stopped to chat with us. Drug arm, an outreach program saw us and stopped by in their van, which was set up with a zip in the back, as well as tea, coffee and milo. During the middle of the night, one of the Streeties who had decided to sleep somewhere else arrived with a man he had found walking around the streets who was sleeping rough for the first time. He brought him to our campsite and gave him a blanket, some food and drink and introduced him to everyone and said we would make sure he was safe. In the morning, we got up, neatly stacked away our sleeping materials (Figure 9) and went for breakfast at the soup kitchen (Figure 10), before I said my goodbyes and headed home.

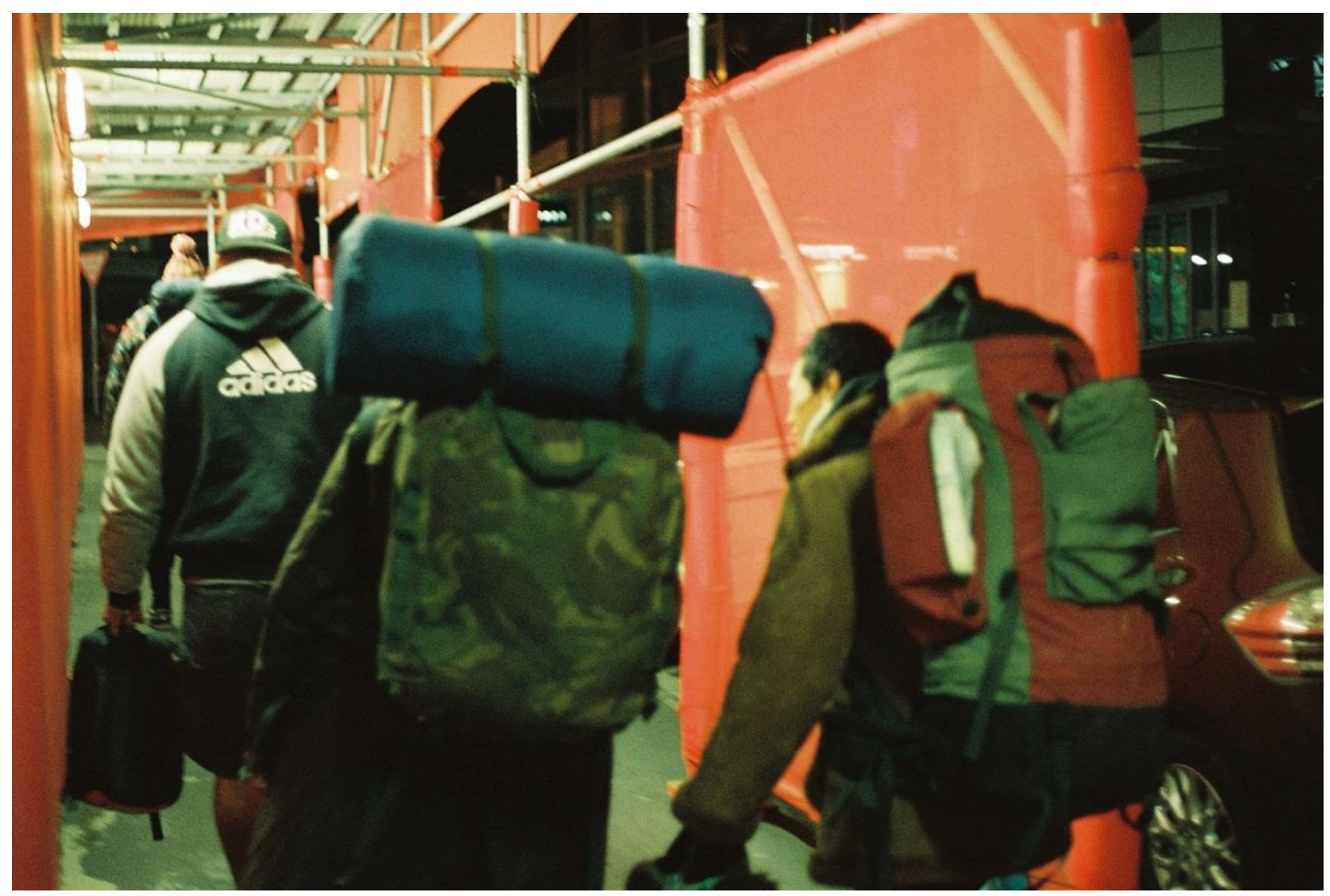

Figure 7: Walking down Tory Street towards Harvey Norman (Taken by Jonathan Foster) 


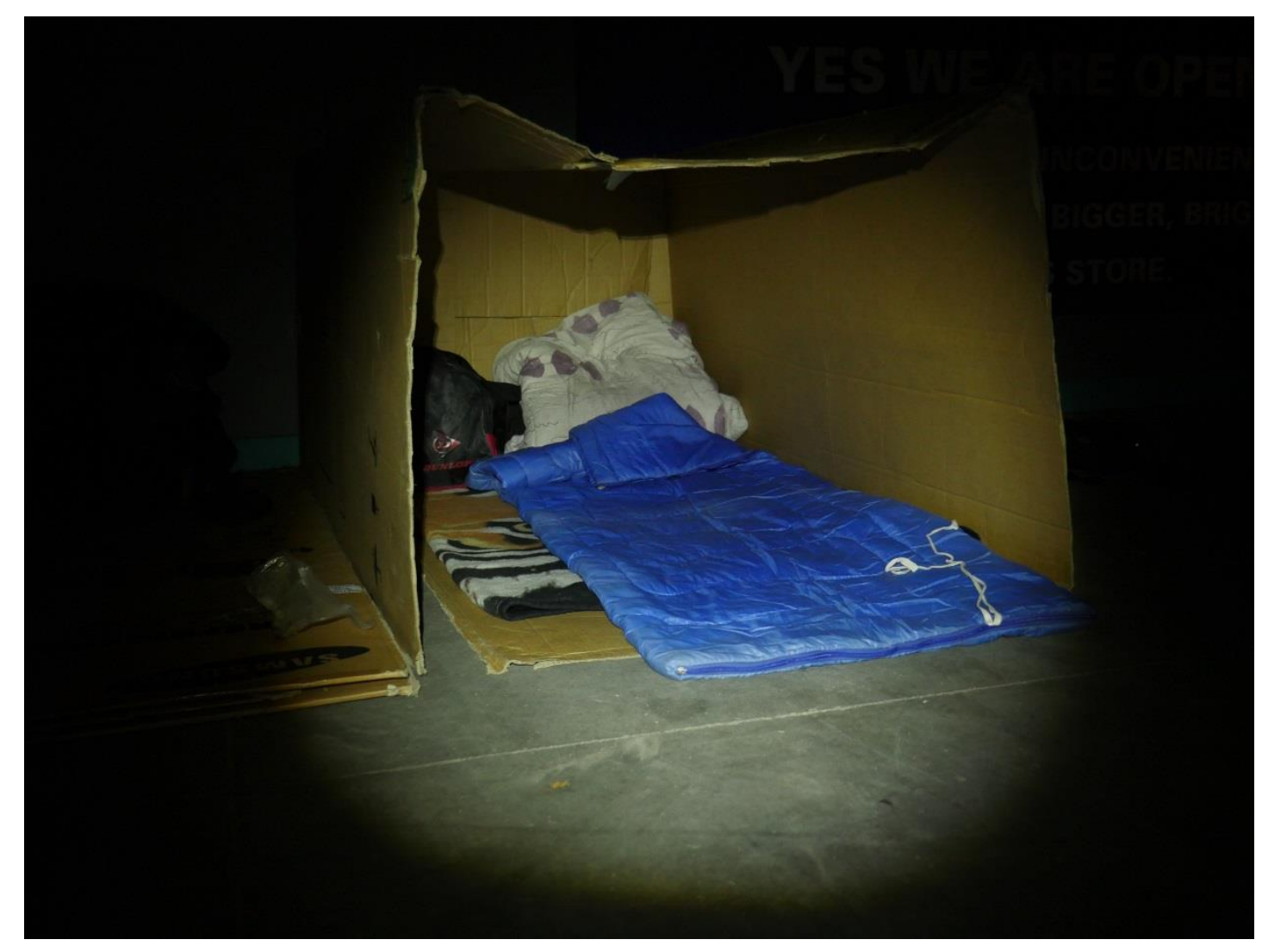

Figure 8: 'Cardboard Hotel' in Briscoes Carpark (Taken by Jonathan Foster)

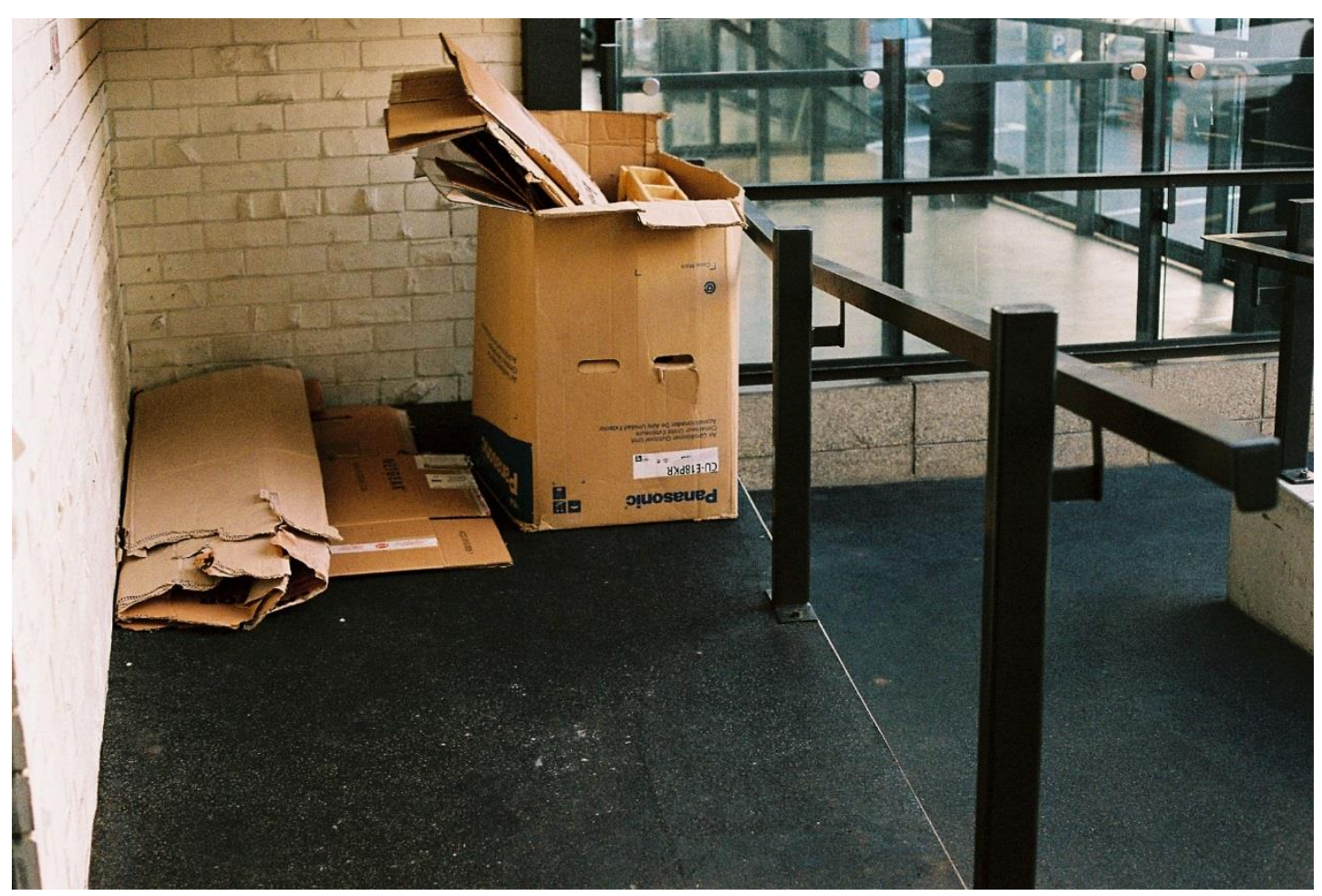

Figure 9: Storing our Sleeping Materials (Taken by Jonathan Foster) 


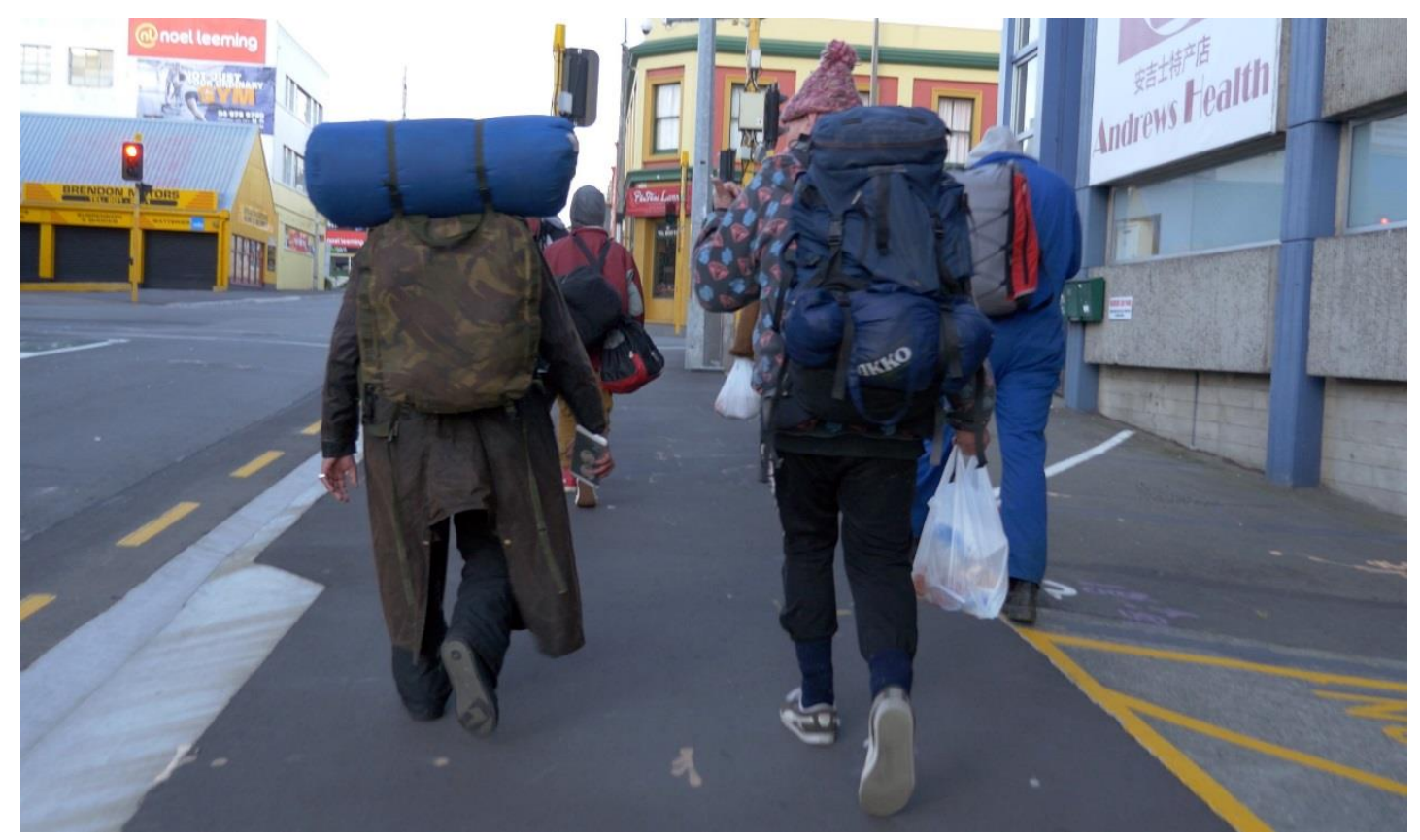

Figure 10: Walking towards Sisters of Compassion Soup Kitchen (Taken by Jonathan Foster)

While I had lost contact with John, who was no longer responding, my fieldwork began to flow through the streets, entwining with the various individuals whose lives texturize the material flows of the city. By chance, a week after the above night sleeping rough, for example, I was on my way to a friend's house on a Friday night, when I recognized a Streetie hustling on Courtenay Place. He was the Streetie who had brought along the man to our camp in the middle of the night the previous week. I re-introduced myself and he told me his name was Spirit. We got chatting and he said he'd be happy to do an interview and gave me his number. The following week we met up on Courtenay Place at night, outside a subway. He had brought a milk crate along for me to sit on. We spoke for an hour and a half, while he hustled. We arranged to meet up again, if I came across something I wanted to discuss.

In this way, both Pita and Spirit became my closest participants, the people who I spent the most time with, and conducted the most interviews with, and, as such, much of the thesis takes shape from the relationship that developed between us. Although there were minor setbacks, the longevity of our research relationship led to very specific kinds of insights, and the ideas produced in this thesis are the result of that dynamic. Pita and I, for example, did two recorded interviews, an hour to an hour and a half in length, with around two weeks between them. But we had been talking for months prior to this, and as we worked on the 
film, we continued to see each other, and chat for months afterwards. During this time, we sometimes lost contact, but I also got to witness the way his situation changed, how he was dealing with living inside, how his relationships to others developed, what the things he valued were, and how he worked towards these, even if this occurred in a fragmented, partial and incomplete manner.

Spirit and I also did two recorded interviews, roughly two weeks apart, and stayed in contact much longer. When we initially organized to meet following our first interview, I came into town looking for him, only to find him on the phone in a heated discussion with an ex. Stressed out he asked if we could do the interview another time to which I agreed. In the meantime, however, he had brought along his friend, another Streetie in his 50's, who had expressed an interest in talking to me, which I will return to. Doing fieldwork this way, I could check things over with Spirit I had missed in our first interview, and I was able to observe his changing relations with others, and with his motives and desires, also sharing some of my own background with him in the process. As Heyl $(2001,369)$ states, ethnographic interviews should be based on ongoing, established relationships where there is an open-ended and genuine exchange of understandings.

While my relationships with Spirit and Pita form the basis for both the film and the written thesis, I had interviews with four other individuals. Tony, a self-described gay pacifist, was an eccentric man with a deep interest in Jungian psychoanalysis, who claimed to have once been wealthy, but renounced his life of materialism to pursue his Buddhist beliefs. He was sceptical of institutions, and appeared to be the most cognizant of the way in which social services and the state attempt to contain and control people. He lived in a self-styled Bedouin tent along the green belt. Wayne, the man who accompanied Spirit to the second interview, initially expressed a desire to not be interviewed, saying he was nervous and not feeling up to it. When I assured him that it was fine if he didn't want to speak, we ended up chatting for an hour and a half. While I had not recorded it, I raced home to type up our exchange. A few weeks later, I ran into him again and he expressed a renewed interest in being interviewed, only to stop replying to my texts not long after. A fortuitous encounter with him a week later, outside Te Hapai, led to us working out an arrangement. He said he was having issues and did not have the time to be interviewed currently, so I asked if I could draw on material from 
the first time we spoke, to which he replied 'Yeah bro, go hard! Anything I said to you then is all good for you to use!'

I realised I had not spoken with any women; as a young, university-educated Pakeha male, I felt somewhat on edge about asking them for their stories. I spoke to the director of DCM and she suggested I make a flyer and leave it on tables in the drop-in centre. From this, I ended up interviewing Katelyn and Red. Both interviews were around one hour in length, and I attempted to arrange a follow up interview with Katelyn, which fell through. These interviews alone did not necessarily give me a window into the complexities of being a female Streetie, but they did provide an insight into some of the differences. Outside these more formal interviews, I had conversations with many different Streeties who were integral to my understanding of life on the streets of Wellington.

\section{Why Film?}

My desire to use film relates to an intersection between the anthropological ideals, as articulated by Ingold (2008), of producing a critical inquiry in to the ways in which human beings experience the world around them, and the basis of observational cinema, which MacDougall explains as being "founded on the assumption that things happen in the world which are worth watching, and that their own distinctive spatial and temporal configurations are part of what is worth watching about them" $(1991,6)$. In this section I will illustrate how film fits into my wider theoretical and methodological framework of exploring lived realities through a phenomenological lens, and the kind of engagement and knowledge that emerged as a result. To do this, I will begin by outlining some of the filmic approaches that informed, inspired and underpinned my thinking and highlight how they relate to the overall aims of my thesis. Then, I will flesh out the ways I did visual research, highlighting the tensions which arose, generating both questions and insights into the ethical and political underpinnings of visual representations in contemporary society. By focusing on the use of film as a method of exploration, I will tease out the tension of negotiating my identity as both an anthropologist and filmmaker, balancing the goals and imperatives of producing an experimental film on the one hand, while being trained in a heavily textual based discipline 
on the other. Finally, I will evaluate my use of ethnographic film, and the kind of insights it produced, in relation to the wider goals of my thesis.

For much of the $20^{\text {th }}$ century, ethnographic film was relegated to the margins of academic anthropology, a discipline still very much tied to its textual traditions (Grimshaw 2001). It has, however, enjoyed a resurgence in the last few decades, due in part, to the rise of scholarship concerned with attention to sensuous engagement, lived experience and embodiment (see, for example, Jackson 1989; Desjarlais 1997; Stoller 1997; Cox, Irving \& Wright 2016), with which it shares many of the same commitments (Leimbacher 2014).

Whereas the written word lends itself to the drawing up and mapping out of boundaries, cutting up experience and ideas into concepts and categories, whereby moments, actions and feelings can be rendered discursively intelligible, and given a sense of consistency and coherency, film immerses the viewer and filmmaker in the affective texture of the lived-in world (Leimbacher 2014). Where text retroactively links emotions, feelings, and the landscape, film shows the myriad and subtle ways, objects, beings, and affects overflow the Cartesian boundaries we have drawn up for them, seeping into one another.

Film as a medium is particularly effective at locating experience within time and space, depicting a world in movement, where "successive film frames evokes the sensation of movement over time quite literally through movement over time, and captures the experience of animate presence in a way that neither photographs nor text can" (CastaingTaylor 1996, 79). MacDougall (1999) implored ethnographic filmmakers to explore this 'multidimensionality' of film as a medium, for its ability to convey the phenomenological reality of social aesthetics in the life of a protagonist. This is because it is through our senses that we come to understand the qualities of our surroundings, in its movement, temporal structure, gestures, behaviour, appearance, colours, and texture - and it is these through these affects that world appears either familiar or strange.

Pink (2008, 2), focusing on place making, has argued that visual anthropology should attend "to the routes and mobilities of ethnographers and research participants." She has argued that the practice of producing films, which 'walk with' participants create place in two different ways (Pink 2007). Firstly, phenomenologically through the research encounter and, 
secondly, through the experience of the viewer watching the representation of place (Pink 2007). Pink (2008, 3) states that as visual anthropologists, we explore how place comes into being through the dialogic relationship between ourselves and our participants, and how it is reconstituted in our representations, as well as the ways audiences weave their own sense of place through their journey of watching.

Thus, the goals of an experimental and sensory-based filmic anthropology merge well with my theoretical and methodological framework, of anthropology as an open ended, yet critical inquiry in to the potentials of human life on the street. Moreover, my phenomenological approach of understanding the situated and embodied practice of wayfaring and habitation as key ways in which humans relate to the world around them, very much sync with the tenets of an experimental visual approach (Ingold 2011; Pink 2010).

\section{Beginning the Film}

Contrary to Pink's (2007) premise that a researcher should not know whether visual methods are applicable in advance of entering the field, the logistical requirements of completing an $\mathrm{MA}$, and doing a creative component, meant that I very much had to make that decision prior to engagement. While I would have liked to have taken things slow, meet people in the field and establish whether filming was a good idea, the pressures and constraints of MA research meant that the reality of the situation was not so accommodating to flexibility.

This did not mean, however, that I burst into the field with a camera ready to shoot. I started taking a camera with me to the drop-in centre, but felt apprehensive about bringing it out to begin with. Pink $(2007,13)$ argues that a researcher should consider the appropriateness of the technology they use, because it will influence the way people construct their identities in the researcher's presence, affecting social relationships and interactions, a view which is shared by other visual researchers (Collier \& Collier 1986). In the context of the drop-in centre, my uneasiness was in relation to the stark power dynamics at play between myself, as a researcher with access to expensive technology, and taumai who were experiencing severe financial hardship. I wanted to respect their space by not brandishing a camera around. Most people, however, were unperturbed by its presence, and it sometimes even sparked conversation. One man, for example, asked me to take a photo for his Facebook 
profile. Others even saw the potential power of the camera, and invited me along to events so that I could take pictures and film for them. As Braun (1998) points out in his video essay, the people whose lifeworlds we find ourselves in, will often find their own uses for us, and their own understandings of the role we are playing, and by perceiving an inherent power balance, based on factors such as ethnicity, class, and gender, we risk creating one that the participants may not actually feel themselves.

\section{Filming with Pita}

Having already spoken with Pita, I decided to focus on producing an open-ended exploration of his lifeworld. Through the film, I wanted to explore a more sensuous engagement with the world Pita inhabited; to engage not just with Pita, but the city with which he moved around, inhabited and which shaped his daily practices, or his emplacement (Pink 2007). Originally, I had been thinking of making a film that sought to capture the motion of living on the streets, and the temporal cycle of life on the streets, but Pita moved inside during my fieldwork and so I had to rethink this.

Nervous that I was not going to be able to make the film I wanted to, I became fixated on trying to get him to tell me about his experiences of living on the street and getting him to take me to spots that meant something to him while he was homeless. Ironically, where I had set out to make an experimental film, concerned less with narrative and more with feeling, I fell prey to the hegemonic logic of textual thinking (Castaing-Taylor 2016). Henley (2000) and Collier and Collier (1986) have both argued that this is a struggle anthropologists trying to make films face, because their formal training is literary rather than visual.

This tension became intellectually generative in its own way, as I tried to navigate the identity of anthropologist - amateur filmmaker, caught between two different practices. On the one hand, I wanted to produce something innovative and challenging that produced novel insights into what it means to live on the streets, capturing the more intangible and spontaneous moments, which would typically elude even the most poetic textual account (Henley 2000). On the other, I was apprehensive of imposing my aesthetic and intellectual interests on Pita, and of romanticizing or obscuring the reality of his livelihood and the existential uncertainty that underpinned much of his reality. 
Slowly, however, I found my interaction with the camera become more fluid and natural. As I walked around with Pita, my thinking became progressively attuned to the visual and aural elements of our surroundings, and to the affective texture of his lifeworld. To his expressions and movements, to the way he engaged with his surrounding environment, what he looked at, or was aware of. Similarly, he became more comfortable with the camera, and cognizant of it, helping me set up, suggesting places we should go and things we should film, and his way of engaging with the camera became more self-aware and playful as we progressed. Moreover, I began to realise his life was still very much shaped by the institutions that shaped his experiences on the street. Although he had moved inside, he was still dependent on foodbanks, he was still going to court, to the police stations for breaching his bail by drinking in public, and to use the library for internet and warmth. He tried to do 'active' things, like look for work, sorting out ID cards, and working on his alcohol habit, but by and large his time was still mainly structured by waiting for others.

In an interview with Lucien Castaing-Taylor regarding Sweetgrass (2009), a film he made with his wife llisa Barbash, he points out that:

It's out of fashion to see nature as anything other than some secondary cultural construction, but we're all part of it, as much as city folks suppose otherwise, and throughout history humans and animals have commingled in ways that have deeply affected the kinds of beings we've become (Castaing-Taylor 2016, 121)

In their film, he wanted to evoke more than just the lifeworlds of the sheepherders themselves; he wanted to immerse the viewer in a world that was composed of diverse elements - sheepherders, sheep, mountains and machinery. Lancione (2016) has suggested scholars interested in homelessness have fallen into the same trap regarding the city. He argues that often, the city, at best, is interwoven into the lives of the homeless "on the basis of utility and proximity; at worst, the one portrayed as just the backdrop for the other's actions" (Lancione 2016, 146). In my film, therefore, I wanted to immerse the viewer in the world Pita inhabits, which includes other Streeties, security cameras, security guards, shops, alcohol, the weather and the city's nooks and crannies. These diverse elements do not exist as a backdrop to Pita's life, but are constitutive of his whole being, influencing his options, 
available choices, and his time and living structure; his life is shaped by his immanence in the city, highlighting the diverse cultural, political, material, and pragmatic forces shaping his everyday movements and existence (Desjarlais 1997). Film, I felt, was a powerful way to explore a kind of phenomenology of life and place on the street. Particularly so, because the setting is not some far off location but is the same city I inhabit as a researcher, student, and person.

\section{Film Design}

To represent the soundscapes that permeate the environment of the film (Henley 2007) I overlaid certain scenes with the sounds of the city, to evoke the intense cacophony of noise, which surrounds life on the street. I did this, for example, in the opening scene where Pita talks about his reasons for drinking, stating the need to drown out the noise of the city. I mixed bus ambient city noises, people talking, buses, cars, skateboards, and music to create a sense of aural landscape, which framed his time on the street.

For both pragmatic and aesthetic reasons, I decided to overlay most of the film with voice recordings of Pita. Pragmatically, I was finding it difficult to manage filming, sound recording, interviewing and walking all at the same time. It would have also become a film focused on Pita's linguistic expression of the places we visited, rather than a visual exploration itself. Thus, I felt by overlaying the visual with aural recordings of Pita and I chatting, I could free the visual up to focus on its strengths. Once we arrived at a location, we ended up doing what Pita would normally do, which was stop, roll a cigarette and have a smoke. I felt like this became an interesting way to frame the shots of the different place we ended up, as well as pacing the movement, allowing the viewer to dwell in the scene. The close-ups of Pita's face, in the scene outside the library in Civic Square, for example, allow for an intimate connection to develop between Pita, the camera and the observer.

\section{Filmmaker, Viewer \& Protagonist}

Not only is film able to privilege the mutual entanglement of protagonist with their lifeworld, restoring anthropological inquiry to the material world, evoking the existential texture where meaning, being and personhood emerge, but it also brings the viewer into the fold, 
establishing a relationship between themselves, the filmmaker and the protagonist. I wanted the film to be reflective of the subtle ongoing negotiations between myself and Pita during the process of making the film, reflecting the dialogic relationship of the filmmaker and the protagonist. Rather than offer a thesis, or a closed off entity, which seeks to present a coherent and clarified understanding of experience and reality, ethnographic film's strength lies in its ability to remain open ended, and subject to multiple interpretations; the presence of what happens on camera, often eclipsing the intentions of the filmmaker (Castaing-Taylor 1996). Moreover, the limitations of my ability as a filmmaker adds a certain vulnerability to the film, which foregrounds the messy, imperfect, and constructed nature of fieldwork, in a way that is not often visible in a polished text, where all the messiness of research gets ironed out.

Ethics

The process of making the film revealed ethical tensions between myself, Streeties, and staff at the drop-in centre. The DCM director had reservations about how their organization and taumai would come across in the film. I managed to assure her the primary purpose was focused on exploring homelessness, movement and embodiment. Her apprehension was understandable, however, and highlighted the issues surrounding the power and politics of visual media and representation in contemporary society, where viral videos have the chance to reach large audiences through social media, and can damage reputations or misrepresent situations (Pink 2007).

This is further complicated by the funding structures of services in the community sector (Grey \& Sedgewick 2013). They must meet certain requirements to receive government funding, and are required to do a lot of community outreach for donations to survive. The DCM, for example, runs an annual large scale book-fair, takes part in appeal days, and relies on donations from private individuals and businesses. To entice the latter two, they must be constantly doing tangible things, and disseminating outcomes through accessible content, both written and video based. This means that any potential negative coverage has huge implications for an organization's ability to function. This is part of a wider trend in the nongovernmental sector, attributed by scholars (Grey \& Sedgewick 2013) to the rise of the contract state under neoliberalism. In their study of social service provision in New Zealand, 
Grey and Sedgewick (2013) indicated that organisations are caught between serving the needs of their respective community, while simultaneously having to spend a large portion of their resources on self-preservation.

Similarly, many Streeties I encountered during fieldwork expressed ambivalence or outright rejected the idea of being filmed. Some had previously had bad experiences with footage of them being used out of context, and were worried about the potential impact the film would have on their livelihood and others. They were often deeply aware of the power inscribed to knowledge production and sharing, the possibility of visual media to be misinterpreted, as well as the power of the visual to alter their everyday lives in unforeseen, potentially negative ways. Spirit, for example, challenged me during a conversation where I had asked him about whether he wanted to be involved in the film:

Spirit: See cause like drop-in centres and that, there's like some of us that don't really use those. And like back in the day before I used to do this [panhandling] I used to jump tables and all sorts brother. Eat food out of the bin, not these bins, but skip bins. But that's giving shit away you know what I mean? Some shit people shouldn't know ay, cause it can fuck up food sources for others bro. That's who we gotta watch out for aye. Just so you know too, cause you know, you might be doing a good thing and you might fuckin' kill food off for some, you know? Some survive in different ways than others bro. It's not just all about drop-in centres and living to the norm... It's up to you to use your knowledge and wisdom that you learn and to have your discretion, if you know what I mean, if you really understand what I was just saying. Cause fuck, it's happened to me up there, but it's happened from other Streeties that have fucked up food sources and then it gets harder bro. And that was like going in supermarket bins, where it's actually illegal so you can get charged, so you're better not to say that or do it. You know what I mean though aye?

Jonathan: House people do that too though...

Spirit: Yeah but still if it gets known hardout some people will complain bro, some people will watch it and think fuck. And then someone will come along and fuck it up bro. You know? That's normally how it goes. 
Others voiced concern about the impact of media soundbites of other Streeties or about the appropriation of their stories. When I first met Dave, for example, he saw my camera bag and made a joke along the lines of 'you wouldn't catch me dead on there!' An Auckland Streetie had recently appeared on television saying homeless people were living on the streets by choice and making lots of money begging. Dave said that although he agreed with him to some extent, and that he respected him for being able to say it, he knew the man would be experiencing a lot of criticism from others in the homeless community as a result. As such, he was somewhat fearful and reserved to begin with, that I would be recording or filming him, and of where it might end up.

People who live on the street may voice opinions, which imply that they, or others, are living on the streets by choice, or that it's easy to get by out there. However, such static and disembodied soundbites usually fail to address the rationale for voicing such opinions, or the context within which they occur. And, unfortunately, as Pink (2007) says, non-academic audiences may conflate visual media with objectivity and interpret such comments as truth, reinforcing dominant discourses that imply homelessness is caused by an individualized failure of personal responsibility and poor decision making. These narratives then make their way into the collective pool of social and linguistic resources of which society derives its understandings of homelessness and poverty, and from which homeless people also draw on for understanding and communicating their experiences. Thus, I had to think about how I could visually explore homelessness, privileging the voices of my participants to tell their own story, while also being careful to avoid reifying dominant discourses of homelessness being the cause of individualized character deficiencies, even if this was sometimes how my participants initially described their, or others', predicaments.

Throughout my fieldwork process I reflected on the tensions faced by anthropologists who are attempting to engage with creative media and practices, in a discipline that is still very much textual bound, both in terms of ethnographic means of production and ethical guidelines. How do we use and produce visual media in a way that allows us to explore issues and ideas in a way that text cannot, while remaining sensitive to ethical considerations, such as the promise of anonymity, which may be difficult to provide, and may even underwrite some of the power of the final product? And, what kind of knowledge's and feelings are 
produced using visual practices, and how might these be created while highlighting the power relationships that underpin the film that emerges from the ethnographic encounter?

I hope that I have made a small step towards understanding how film and text can be combined to produce an intimate exploration of the complexities of people's lives, and their immersion in lifeworlds animated by struggle. 


\section{Being and Becoming 'Homeless' in the City: \\ 'If you don't do things normally, you're kind of like wild aren't ya?'}

In this chapter, I argue that being homeless is not just a material or economic location, but is a state of existential exclusion, produced and re-produced throughout Streeties' lives, and in the everyday practices of living on the streets in Wellington City. Through processes of exclusion, control, and containment, inequalities materialise in both the bodies and subjectivities of people living on the streets. As a result, I suggest that Streeties come to inhabit spaces that are perceived by most housed people, discursively, existentially and physically, as 'wild'. The sight of Streeties, consequently, becomes disruptive to our perception of the normative order of being and belonging in society, physically, socially, and morally. A consequence of this is that approaches to dealing with homelessness tend to try and 'reign' homeless people in, domesticating them, without necessarily understanding or acknowledging the processes which come to exclude Streeties and produce homeless subjectivities in the first place. Nor does it recognise how homeless people actively engage with these identities, and the moral and social economies they are embedded in.

I focus on the way Streeties negotiate and construct a sense of self in an environment seen as 'wild', where their access to legitimate forms of personhood ${ }^{10}$ have been severely limited. By exploring the back and forth interplay between discursive understandings of homelessness and the lived experience of people inhabiting homeless spaces, I argue that Streeties construct alternative ways of relating to both themselves and their surroundings to survive and live dignified lives. Experience, in this context, is not seen as a universal, essentialised, enduring or innate concept of feeling, but rather emerges from a "process built sharply out of cultural, historical, political, and pragmatic forces" (Desjarlais 1997, 10). Sometimes this took the form of strategically or subconsciously embodying narratives of personal responsibility to gain the necessary resources and relationships that could alter their circumstances, while at other times, Streeties challenged normative assumptions about

10 'Personhood': Denotes being - one's individuality and particularity - and belonging - the society within which their being takes on meaning; never fixed, nor solely particular or general, but is in a state of fluctuation and becoming 
what constituted legitimate forms of being, meaning, and personhood by embracing life in the margins and creating new spaces for recognising themselves and their positions within a wider nexus of relations.

I begin with an ethnographic vignette which centres on an encounter I had with a man on Lambton Quay while I was interviewing Pita. I then contrast this experience to a newspaper article that Desjarlais $(1997,2)$ used as an analytical tool to illustrate the ways in which stereotypes of homeless people as 'animal-like broods' are produced discursively. I suggest that while I agree discursive representations of homeless people generally seek to exploit easily identifiable differences, there was something particularly confronting and visceral about the encounter in my vignette, which piqued my curiosity regarding how people living on the streets 'become' homeless in a physical and existential sense. I then turn to the stories of my participants, demonstrating how their upbringings illustrate the ways they were denied access to regular channels of societal personhood, predisposing them to homelessness, through poverty, abuse, time spent in boys' homes and borstals. In the process I contextualise the situation, which gave rise to their intimate experiences of abuse, suffering and exclusion, in the form of colonialism and neoliberalism.

I then argue that these processes are not just located in the past, but are caught up in the flows of the material city. Their access and experience of urban and green spaces was, for the most part, mediated by what was deemed acceptable and appropriate behaviour in a specific area, and of whose presence was considered legitimate. Decisions which changed over time and were generally determined by an intersection of local and national legislation, private property interests, media attention, and the will of the public, who in turn were influenced by cultural underpinnings of who and what urban and green spaces were designed for.

Despite these conditions, Streeties are not just passive recipients of an externalised order that defines their access to meaning, being and belonging. They are caught up in an ebb and flow, within which they are actively engaged in an ongoing process of negotiating a sense of self, their enmeshment in a wider nexus of relations, and the meaning they derive from the world, in a way that works for them. I finish by arguing that although the existential, 
discursive and physical world that Streeties inhabit is largely defined, and historically constituted, by structures, which have limited their access to socially legitimate forms of being, they are unable to fully explain or define the conditions of their life possibilities. The freedom of their existence residing in that space that is not yet known, ill-defined and subject to change.

\section{Transgressing Boundaries}

"FUUUUUUUCCCCCCCCKKKKKK!!!!!!!!!!!!!!" bellowed an elderly looking man with his back hunched, hobbling down Lambton Quay, Wellington CBD periodically stopping to scream indiscriminately. Pita and I, walking along the opposite side of the road, glanced over.

"FUUUUUUUCCCCCCCCKKKKKK!!!!!!!!!!!!!" he roared once again. I recognized the man; I've seen him around Wellington. His clothes are mismatched and his appearance dishevelled, mucus and other bodily fluids visible on his exterior. He walks with a crooked back and smokes cigarettes from the gutter.

Passers-by and others in his general vicinity turn their heads and look on uncomfortably, as his seething self-expression temporarily pierces through the socially constructed barriers of class cushioning our everyday existences. They avert eye contact wherever possible and briskly shuffle past, continuing with their days.

The above scene occurred one day while I walked the streets interviewing Pita. The unease of passers-by and the man's physical appearance reminded me of a newspaper outtake titled 'Compassion Fatigue' that Desjarlais discusses in the introduction of 'Shelter Blues: Sanity and Selfhood Amongst the Homeless' $(1997,1)$, where a homeless man was portrayed as interrupting the lives of people in a café, by turning up covered in blood, shrieking and wailing with pain, breaking the boundaries keeping despair at bay.

Desjarlais (1997) proceeded to scrutinize the article and its portrayal of homelessness, highlighting the way the writer juxtaposed a "collision of motifs", peaceable civility and the pain and suffering of the underclass. The social contours of the former disrupted and unsettled by the appearance of the latter. A typical literary trope deployed to intensify the differences observed between social strata; in these narratives, the homeless shed elements 
of their humanness to become "animal-like brood who threaten the peaceful, artful air of cafes, libraries, and public squares... The homeless themselves serve to counter images of health, wealth, purity, and high culture" (Desjarlais 1997, 2). No longer defined solely by the temporary absence of a material dwelling, homelessness becomes a state of being characterized more by transgressions against civility, order and moral worthiness, in both social and bodily forms; transgressions, in other words, against the very facets of society with which we measure our 'humanness'.

These bourgeois ideals about what constitutes civilized society and what are considered human qualities have long roots, some of which can be traced back to Greek times, others finding their full expression during the Victoria era, and the works of Darwinian evolutionism (Ingold 2011). The neoliberal narrative of personal responsibility, which currently permeates our cultural worldview, however, brings a distinctive hue to the perspectives we form when we see people who appear to have 'failed' to manage themselves. These people are deemed unworthy of assistance for they have been unable to live up to the social contract which we all knowingly, or unknowingly, abide by. This sits in contrast to those who have been made homeless through no fault of their own, in the case of a natural disaster for example, and are seen as worthy of our empathy and assistance.

\section{Governmentality: An Intersubjective Relation of Control}

Part of the neoliberal narrative owes its existence to what Foucault $(1979-80 ; 1997)$ called 'governmentality' in his exploration of liberalism and state-societal relations of the $20^{\text {th }}$ century. He sought to highlight the way in which government was not just concerned with political structures or state management, but was "an activity that undertakes to conduct individuals throughout their lives by placing them under the authority of a guide responsible for what they do and for what happens to them" (Foucault 1997, 68). It was underpinned by the political rationality of liberalism, which sought to solve the problem of too much government intervention, by managing populations through diffuse and ubiquitous means. The state, Foucault argued, achieved this through its technologies of power and procedures of directing human behaviour. By teaching people how to manage themselves, biopower shifted responsibility away from the state, dispersing it among a population of newly constructed political subjects. 
Promoting ideas of autonomy, individual agency, and free will, Rose, drawing on Foucault, argued that neoliberal governmentality embodied a specific ethical argument that situated freedom as a principal strategy of control (Rose 1990; Rose, O’Malley \& Valverde 2006, 92). The freedom implied in the neoliberal narrative was necessary to produce easily governable populations by encouraging an internalized subjectivity that sought self-preservation of physical, mental, social, and economic wellbeing through careful management of the self, hereby creating the docile bodies necessary for the function of capitalism.

Consequently, when we see people, and specifically their bodies, who exhibit visible markers of having transgressed the boundaries of this ethical and political economic code, they stand out, and we hold them responsible for their fate. They embody the failure of selfmaintenance, inspiring either scorn or sympathy, but always serving as an example, for the former, as a potential life trajectory should they choose to ignore the 'guidance' and 'wisdom' of society, or, for the latter, should they be forced or excluded from the state institutions which would've provided them with access to the resources needed to live a fulfilling and autonomous life.

Such views are evident in the following series of comments that were posted by members of the public on an article I published in 'The Wireless' regarding my research (Figure 11).

The Wireless NZ $\odot$ More about the series from one of the co-writers: http://thewireless.co.nz/.../homelessness-is-more...

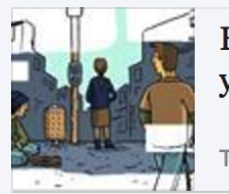

Homelessness is more complicated than you think

THEWIRELESS.CO.NZ

Like · Reply · 4

People actually feel sorry for these animals? It's poor life choices that got them into the messes they are. They don't have the intelligence or aspirations to actually be decent people and make a good future for themselves.

Like · Reply · 2

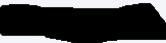

People need to be responsible for themselves

as they hold their own autonomy

Like · Reply · 1

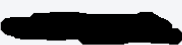

Figure 11: Comment Section on The Wireless Facebook Page 
The irony is that this freedom and autonomy is more illusionary than real, dependent on our compliance with neoliberal regimes of control. Eloquently summed up by Pita in an exchange following the opening encounter:

Jonathan: Do you reckon he's homeless?

Pita: Yeah I think he is... I think he's just nuts [laughs].

Jonathan: Do you find a lot of people on the streets have mental illness?

Pita: Ahh yup! I find a lot of people that aren't on the streets who have mental illness too! [Laughs]. It doesn't matter if you're homeless or not, there's always mental issues, isn't there?

Jonathan: Yeah, it just seems like one of those things where I think people see someone homeless or a few homeless people who are mentally ill [Pita: yeah] and they're like 'oh you know, they're homeless because they're mentally ill'.

Pita: Yeah yeah yeah! Well I was walking around with my radio the other day and I was trying to wind my radio up! [emphasis] and everyone's looking at me, kind of all weirdly! [laughs]

Jonathan: Wind your radio up?

Pita: Wind my radio! You know, you wind them up and you can listen to music or it's got a torch and that on there. Yeah, yeah so I spose if you don't do things like 'normal' people I guess, well normal people in society, if you don't do things normally then you're like wild aren't ya?

And if you're not, yeah doing all the same things that everybody else is doing they look at you weirdly. [Laughs] 'Not allowed to do that!'

Jonathan: 'You're free to be like everyone else!' [both laugh]

Pita: Which is pay ya bills, pay ya power, go to work, sit around and do nothing, I s'pose aye, just pretty much living day to day.

Jonathan: Do you feel like that's a life you don't really want to live?

Pita: $M m m$ yeah not really.

Moreover, the neoliberal narrative obscures the way autonomy, being and personhood are distributed unequally and felt differently by different people in society. Many of my participants' pathways to prosperity, societal belonging, and socially acceptable forms of being were severely limited. Leaving them in a position where they must navigate the tricky terrain of strategizing to accumulate the resources they need to get by, be it emotional, social, 
or material, while retaining a sense of themselves as dignified individuals; in the process negotiating interpersonal relationships, often characterised by pain, loss and suffering. Sometimes this involved stealing food and alcohol, drink and drug use to cope with trauma, damaged relationships and the demands of life on the street, or supporting friends even if this came at the expense of, or jeopardised, their chance of moving inside to a home.

\section{Life Before the Streets}

For many reasons my participants had been in short supply of legitimate socially sanctioned personhood in their lives prior to living on the streets, whether it be because of their ethnicity, gender, sexuality, class, upbringing in low income deindustrialized towns, mental health issues, drug and alcohol addiction, or other health complications. Wayne, for example, grew up in a semi-rural, predominately Māori community, where he was surrounded with gangs, crime, poverty, and drugs. He suffers from ADHD and dyslexia, neither of which were recognised by the medical world when he was growing up, and his behaviour was deemed problematic. Consequently, he was placed in a boys' home, and then in Kenepuru hospital to undergo experimental treatments, including shock therapy, the use of strong tranquilisers such as barbiturates, and eventually opiates. ${ }^{11}$ By the time he was old enough to leave, he had a drug habit, and Wellington was awash with heroin imported by the 'Mr Asia Syndicate ${ }^{12}$. He has since been in and out of prison for most of his adult life.

Red also grew up in a house during the era of Mr Asia, and her family was involved in the drug business. She had already begun using by her early teenage years, and has struggled with addiction for the rest of her life, though she is now living in a house and on methadone treatment. Her childhood was characterised by interpersonal family violence committed by her father from a young age. She had children relatively young with a man who she ended up falling out with, and who leveraged her situation against her, by calling 'Child, Youth and

\footnotetext{
11 Many others I spoke with discussed their own experiences of abuse in state care, a topic covered in-depth in Elizabeth Stanley's (2016) recent book 'Road to Hell: State Violence Against Children in Postwar New Zealand'.

12 The 'Mr Asia Syndicate' was a well-known large scale, international heroin importing operation controlled by New Zealander's Terry Clark and Marty 'Mr Asia' Johnston, who flooded New Zealand with significant volumes of cheap, pure heroin in the late 70's and early 80's.
} 
Family' (CYFs). After a court case and battle with CYF's, she lost custody of her children, and was sent to jail. Left with few options once she was released, she ended up sleeping in a tent on Mount Victoria.

Katelyn, on the other hand, was adopted at birth, only finding her parents when she was growing up. As such, she has experienced conflicted notions of family life since she was young. Her sanguine parents, who lived in the same community, drank and partied, while her foster family were relatively stable. As she grew up, she moved between both homes, associating with both sets of parents and trying to figure out who she was. Added to this was the fact her foster parents were Pakeha while she was Māori, something she didn't even realise until someone pointed it out at school. Growing up between two homes, trying to relate to two sets of parents, while coming to terms with one's own identity and indigenous heritage, could produce an immense sense of dislocation early on, even before becoming homeless in the material sense.

Experiences with themes like these - dislocation, interpersonal violence, poverty, disputes with state authorities and disciplinary procedures - were common among people I spoke to. They represented only the tip of the iceberg of the ways peoples' life trajectories had limited their access to the mainstream channels of socially legitimate forms of personhood, and they were never isolated nor coincidental but were shaped by socio-political and cultural histories.

All but one of my participants were Māori, who are overrepresented in homelessness statistics (see Gravitas Research and Strategy 2005; DCM Annual Report 2015; King, Hodgetts, Rua \& Te Whetu 2015). Scholars have argued this is due to being subject to historical processes of colonialism, social exclusion, land dispossession, and continuing social and economic marginalisation in the present (King et al. 2015; Groot, Hodgetts, Chamberlain, Radley, Nikora, Stolte \& Nabalarua 2008; Groot 2010; Groot 2011). Māori ways of being, of knowing, and of relating to the world around them were systemically undermined, and their communal identity eroded by colonial and capitalist doctrine that saw their quick assimilation into Pakeha society as a necessary pretext to a healthy nation (King et al. 2015). Part of this process involved a psycho-social violence on the behalf of settlers: 
Destroying the world-view and culture of indigenous peoples has always been as important as taking their lives, because the actual process of disempowerment, the key purpose of any colonisation has to function at the spiritual and psychic level as well as the physical and political (Jackson 2007, $177-178$ ).

Scholars have documented the remarkable likeness between experiences of indigenous people worldwide, and the impacts the on-flow effects of colonisation have had on their health, such as high mortality and suicide rates, shorter life spans, and the presence and impact of easily avoided illnesses, as well as their experiences of domestic violence, poverty, addictions and mental illness (Fong, Braun \& Tsark 2003; Anderson, Crengle, Kamaka, Chen, Palafox \& Jackson-Pulver 2006; Durie 2006; Bryers Brown 2015).

This is not to mention indigenous peoples' experiences of racism in the criminal justice system, where Māori account for just over $50 \%$ of the adult prison population, while making up only $14.9 \%$ of the total population (Corrections 2016; NZ Census 2013). An issue that has often been cast as a 'problem', the over-representation of Māori representing a threat to social order, which requires state social intervention (Tauri 2014). Some have suggested Māori prison rates arise from the intersection of confounding factors, such as a lack of access to education, high unemployment, and living in areas of concentrated poverty. Scholars, however, are critical of explanations that focus on socioeconomic indicators while failing to acknowledge colonisation, 200 years of land dispossession and the subjugation of Māori autonomy and racism within a predominately Pakeha criminal justice system (Jackson 1989; Tauri 2014).

While the entire history of colonialism, its intended goals and outcomes on the behalf of settlers, and the practices of settler nations are often justified in the name of civilising, Bauman contends that "the civilising process is not about the uprooting of, but about the redistribution of violence" $(1995,141)$. This violence manifests itself structurally, through the various layers of social, political and economic institutions, which make up the fabric of society. This causes an on-going, but often invisible suffering among people who represent a threat to the order imposed by the dominant power, in this case, the crown and mainstream Pakeha society. Colonial interventions in New Zealand, such as the removal of Māori children 
from their parents in the $20^{\text {th }}$ century, 'pepper potting' policies following urbanisation, and corporal punishment for speaking Te Reo Māori at school, have had profoundly negative and violent repercussions ${ }^{13}$.

Drawing on Woolford (2013), Tauri (2014) argues that to understand the subjugation and control of indigenous peoples, we need to understand the inter-relation between the macro, meso and micro levels of governance. The macro level refers to the way social and economic issues are understood on a broad level and represented and articulated symbolically in the media and public opinion. The meso-level is the techno-bureaucratic layer of governance that "brings together various state and state-sponsored agencies that are essential to the operations of contemporary settler colonialism, namely, policing, the legal system, the military and health, education and welfare policy sectors" (Woolford 2013, 172). While the micro level is the frontline of the administration of social control and settler colonialism through the disciplinary practices of state institutions and their spaces, such as Work and Income (WINZ), the police, prisons, corrections, mental health wards, and Child, Youth and Family. Intervention and structural violence, for example, continue to intersect by targeting Māori through "militaristic-style policing strategies, the biased application of public disorder offences and discretionary powers, and the criminal justice-led large-scale removal of Indigenous children and youth to detention centres, and Indigenous adults to the prison system" (Woolford 2013, 25 - 26).

Moreover, in New Zealand, where ethnicity and class heavily intersect (Poata-Smith 2004), Māori find themselves in a double bind, where they are victims of both a colonial legacy, and the rise of neoliberalism (Bryers Brown 2015). A factor evident in many of my participants lives. Spirit, for example, grew up in a state house in Otara in the early 90's, a low-income neighbourhood in South Auckland, which experienced immense shockwaves following the neoliberal reforms of the early 80 's, such as a lack of stable employment, rising rent prices, and slashed welfare payments. Neoliberal restructuring of labour laws, which undermined unions, collective bargaining, job and wage security, "disproportionately affected Māori by

\footnotetext{
13 Pepper potting was a policy in the 1950s where Māori were dispersed among mainly Pakeha communities
} 
focusing on sectors of the labour market where Māori typically worked" (Bryers Brown 2015, 13). This led to a dramatic increase in unemployment for Māori who had to rely on welfare payments to survive. Coinciding with the removal of labour protections were severe cuts to benefit payments in the 1991 budget, as well as funding for a range of other social programs, which had a huge impact on those in the bottom $10 \%$ of income earners (Hodgetts et al. 2014).

Then, in 1992, the Housing Restructuring Act moved away from income tested rents in stateowned homes, where rents were up to $25 \%$ of household income, towards "a new system of provision of state houses based on market rents, with direct income supplements to lowincome households" (Waldegrave, Love \& Stuart 2000, 114). The new act, based on the neoliberal logic that public housing created dependency, reduced incentives for housing improvement, and was inefficient at distributing housing availability, was touted as a more equitable solution to housing woes for those on low-incomes in the private sector who received little assistance in comparison to those in public housing (Waldegrave et al. 2000, 114). Waldegrave et al. (2000) found in their study, however, that most state housing tenants ended up paying significantly more than $30 \%$ of their income on rent, around $30 \%$ of their participants paying over $50 \%$ of their household income on rent (Waldegrave et al. 2000). This disproportionately affected Māori, who made up the largest percentage of state housing tenants, due to discrimination in the private housing market, and their generally lower socioeconomic level, and consequent purchasing power (Gagné 2013). Scholars have documented the profound effect neoliberal reforms on the economy exert on low-income households, from being trapped in debt to deal with increasing living costs, to going without electricity, taking children out of school programs, and treating food as a luxury (Green 2012). Waldegrave et al. $(2000,121)$ also noted that the financial strain itself manifested in personal relationships, and occasionally, an increase in violence in the home, "it's very hard, and that's when they start lashing out at their kids and lashing out at one another. And money is the thing that breaks up marriages, or partners".

Indeed, much of Spirit's earlier associations with home were characterised by strains on interpersonal relationships: 
Back when I first went on the streets I cut my family off, just too much lies and talking shit behind my back, you know? Back stabbing, my sister aye and I just got sick of it bro and I left and closed the door on them sorta thing.

While social and economic inequality has proliferated over the last few decades due to both ongoing neo-colonial practices and neoliberal political-economic orthodoxy, so too have punitive measures on behalf of state institutions tasked with responding to these new levels of inequality (Wacquant 2009; Hodgetts et al. 2014). Issues of poverty are increasingly understood as individual deficits, and state institutions, drawing on the morality of neoliberalism, are meant to encourage self-reliance and responsibility, thereby excusing any woes of the prevailing economic order, as being located within the failings of the individual (Bauman 2005; Bourdieu 1998). In New Zealand, welfare payments now go hand in hand with increased scrutiny of people's lifestyles and 'choices', and recipients are required to undergo drug tests, provide evidence that they are looking for work full time, and under-take retraining or re-education, with the ever-looming threat, that their noncompliance will result in their benefit being revoked (Hodgetts et al. 2014, 2037). Hodgetts et al. $(2014,2038)$ state that "structural violence is often enacted through technocratic systems and procedures for 'managing' the poor, which have become normalised and taken-for-granted as simply 'how things are done around here'"'.

Scholars have documented the way in which poor people are punished for their own poverty under neoliberalism, where their ways of being, speaking and acting are undermined and seen as impediment to their advancement, whether it be perceived laziness, lack of education, poor speaking skills or violent tendencies (Wacquant 2009). When they fail to comply with the system or become economically productive citizens, they are perceived as representing a threat to internal social order. In these cases, the disciplinary powers of the state intervene to sequester people who represent a threat to mainstream society and public spaces, to be placed in boys' homes, borstals, and prisons (Wacquant 2009; Foucault 2000; Tauri 2014).

Five of the people I interviewed, and many more I spoke to, had served time in prison ranging from decades to months, grown up in borstals, been taken by Child, Youth and Family as a child, or had their children taken as an adult, and all of them were Māori. It can be argued, 
that our habitus of exclusion and division has resulted in the building of enclosures to sequester people threatening to our values and sensibilities, to contain and 'civilise' them, overwhelmingly targeting poor, Māori and Pasifika communities. A process of sequestering echoed by Tony:

Homeless people have been institutionalised under religious dogma most of their lives, that's where they would've been bought up under in those institutions... how do the poor behave after being bought up around symbols in religious institutions... I spose they were there to morally contain them or give them some sort of goals in life.

Yet these practices are not located solely within the past but are active in the present, enacted through the very physicality of the city, social service provision, media coverage and private property interests.

\section{Being 'Made' in the City}

To the extent by which personhood, within society, is frequently defined and distributed by our position and participation within a wider system of capitalist relations of power and production, whereby we pay rent or rates, consume, and invest in our social capital by building up references, networks, and social media profiles homeless people remain largely on the margins. They become social outcasts and pariahs, subsumed into broadly sweeping, homogenizing categories that seek to emphasise their shared status as outsiders, the threat they pose to wider society and their need for paternalistic assistance, focusing on their individual failures. This is reflected in the proliferation of articles discussing the threat of beggars to society (see, for example, Bob Jones 2017), politicians suggesting begging bans (Nicola Young 2016), and claims that beggars aren't even homeless. The latter invoked as an argument to invalidate the suffering of beggars and undermine the legitimacy of their claims, implying that the ill effects of poverty are solely located within the absence of a material dwelling, and exaggerating instead, the desires of 'opportunists' taking advantage of the goodwill of the innocent, housed public. This, however, misrepresents the constrained choices and survival strategies both the homeless and the poor must sometimes make to get by, a point made by my participants: 
It's no different than people in houses bro. There's a lot more struggling in houses than out here, with their kids and you know? And same as like some of the boys out here, who've got addictions, same as in houses - mental illnesses...You could put in there, Spirit says the same issues that arise on the streets happen with housed people too, you know! There's no difference. Everything's quite similar. Just some stay outside and some stay inside... I think it's actually worse for people indoors bro. They struggle hard. Like poverty is full on, you know? No shit, my heart goes out to the house people. [laughs]

Similarly, Justin, expressed the constrained notions of choice when it came to choosing between a house and a backpack:

The backpack becomes so fucking oppressive. You know, sometimes all you fucking want is a walk without anything. You just want to go for a walk without a backpack, without a reason, to just enjoy the walk. But the only way you can do that is if you have a house and then you have even more problems. You have to pay bills, rent, deal with the council, you have to buy clothes, bedding etc. All your money or benefit is gone and you struggle to maintain your house, so you end up having to beg. I don't want a house for that reason, it's worse than the backpack. Less freedom. Everyone I know whose been put in a council flat in the last 8 or so months has ended up having to go out on the streets and start begging.

Part of the societal anger towards begging arises because we see homeless people as having either failed to participate in, or as actively trying to undermine, the system, within which we participate to receive access to socially legitimate forms of being, and societal belonging. Why, it is suggested, should people begging receive or expect the capital we have earned because of our complicit agreement to partake in these capitalist relations of power and production (Hodgetts et al 2014). The inequalities inherent in these relations, or the influence of neo-colonial practices and neoliberal policies and rationales are obscured by "the prevailing logic of the meritocracy, that anyone can achieve their desires if they work hard enough" (Foster 2016). Aptly reflected in the views of prominent New Zealand business and property magnate Sir Bob Jones: 
I was in the city yesterday, in Wellington, and one bugger was standing there, he had a message, this Māori bloke, 'I'm not on welfare' - and this apparently was an achievement - 'so give me money' (NZ Herald 2017)

Moreover, in a recent mayoral campaign, candidate Nicola Young, a prominent Wellington City Councillor made it her platform to ban begging in the city, publicly posting on her Facebook page about her intentions (Figure 12).

\section{Ficola Young \\ 5 April $2016 \cdot 3$}

The number of beggars in central Wellington has rocketed in the past six years - something I notice as a Te Aro resident, walking around the CBD. Opportunistic begging has become rife around special events, cruise ship arrivals - and whenever Wellington is at its busiest. It's a terrible look for a city marketing itself as the events capital of the country, and it's something I will address as Mayor - after all, there's nothing compassionate about letting people rot on our streets.

Begging is often driven by addiction (drugs and alcoholism) and crime; sadly mental health issues complicate matters further. People assume beggars are homeless, but that's rarely the case and our Council staff do wonderful work for those who genuinely need shelter.

The problem is partly due to Wellington's relative wealth, but the Mayor's failure to develop realistic solutions has made the situation worse - the idiotic 'Alternative Giving' scheme squandered $\$ 40,000$ of rates to raise $\$ 3,500$ in eight months.

As Mayor I will introduce a bylaw banning begging in the CBD and near cash machines - the most lucrative spots in our city - as part of a larger strategy involving the Police, WINZ, the DHB and charities. We will guide vulnerable people to a more secure existence: this will require extra resources from the Council - but I'm confident these can be found when we dump some of the profligate municipal expenditure for which Wellington has become famous in recent years.

Figure 12: Nicola Young Public Facebook Post

Language like this divides homeless into the deserving and undeserving, based on perceived neediness and how much they are seen to contribute to their own situation. It approaches 
the suffering of the homeless with suspicion and derision, seeing their presence as detrimental to the interests of making Wellington a marketable city, as well as praying on our good will. By blaming mental illness, drugs and alcohol and using words like 'opportunistic' to describe the actions of people living on the street, these narratives of personal responsibility invoke a pathology of deficit. This perceives homelessness as the result of personal failings and character deficiencies on the part of the individual and as a result, treats homelessness as a confined and isolated problem, absolving councils, states and communities of any obligation to address systemic inequalities. By using the word 'rot', Young implies that Streeties are unproductive waste, in an otherwise, clean, vibrant city, to be removed through dispersal strategies (Walby \& Lippert 2012). Yet, such a view comes across as a reflection of the domiciled population being more concerned with the management of urban homelessness and poverty, which is currently infringing on our enjoyment of urban space (Hodgetts \& Stolte 2016). Rather than implying any meaningful action, it is usually more concerned with sequestering homeless bodies into low income housing, council flats, religious centres, and mental wards.

What Jones and Young discount in the process, however, is the normalised state of precarity, within which drug use, alcoholism, and antisocial behaviour become inseparable. They ignore the context within which inequality flourishes, materialising in Streeties' very bodies and the strategies they enact to survive and deal with living on the streets. They fail to address issues like widespread unemployment, which disproportionately affects Māori, and the on-flow effects of neo-colonial practices where Māori ways of being have been systemically undermined. There is the added impact of a privatised housing market that recently released prisoners struggle to enter and the complex bureaucratic landscape people living on the street must navigate: dancing between changing welfare rules, bail requirements, court house orders and social service providers.

Moreover statements issued by powerful public figures legitimise the everyday violence and processes of dehumanisation that Streeties undergo on their journeys through everyday life. The contours of 'our' streets, and 'our' city, as outlined by Sir Bob Jones in the above mentioned article, excludes Streeties from the right to the city. By suggesting that 'our' city is under threat, not only excludes Streeties, but positions them in a confrontational and 
adversarial relationship with domiciled people. All this, however, rests on notions of what constitutes legitimate forms of urban space use. As Mitchell (1995) has highlighted, public places and spaces are almost always defined by parameters of inclusion and exclusion, and homeless people, despite living most their life in the public eye, are rarely considered as members of the public.

McGovern (2013) explored the reclamation of Glover Park, Wellington by ex-Mayor Kerry Prendergast in the mid-2000's. The park had been a gathering site of Wellington City Streeties, leading to complaints, fear and discomfort on the behalf of domiciled Wellingtonians. She highlights that whenever there is contestation over public space use, "homeless people often ace exclusion as a result of other informal and form social control mechanisms" $(2013,121)$. In this case, Wellington City Council evoked similar language to Nicola Young, to legitimise their redevelopment project. Ironically, in her opening speech, Prendergast made the case that they had reclaimed the park from a small group of individuals who had tried to 'privatise' the park for themselves, instead turning it into a public sanctuary for all to use. Except, in this case, the homeless who had no other places to go (McGovern 2013, $122-123)$.

Governing space has become a hot topic, with some businesses in Auckland adopting sprinkler systems to deal with Streeties sleeping in doorways and on steps, and in Wellington where sensory technology is being implemented to detect socially deviant behaviour, such as begging. McGovern $(2013,142)$, in her discussion of who has the rights to space, argues that, although understandings of public space and their boundaries alter over time, urban space in Wellington has been adopting an increasingly $24 / 7$ way of life. She states that the logic of this transition finds expression in the implementation of "walkwise wardens, installation of CCTV cameras, and changes to the liquor ban in Wellington" $(2013,142)$. This has a drastic impact on Streeties whose lives are often necessarily lived 24/7 in public, urban spaces, eroding their privacy and subjecting them to increased surveillance and are often underpinned by the increasing corporatisation of public space (Brenner \& Theodore 2002).

Pita, for example, once on the streets, would find places to sleep around Wellington CBD at night, ideally sheltered and out of the way of people. Preferring to keep to himself, he often 
chose to forgo the Wellington Night Shelter, which also allowed him to save $\$ 70$ of the total $\$ 120$ he received from WINZ and he figured he may as well pocket the extra cash as he got a poor night sleep either way. Avoiding the night shelter was also an active step on his behalf, to avoid socialising with people who shared similar addiction issues as himself. Though, once sleeping outside Pita faced a number of potential hazards and threats to his livelihood. Due to the cold and a lack of food, Pita was plagued by chest infections, pneumonia and ended up with a case of hypothermia during the 2015 winter.

He was also regularly harassed by a range of authority figures. Outside civic square, for example, security guards would frequently wake him up and tell him to move on. On average he may get about $4-5$ hours of light sleep a night:

Pita: I mean, cause you don't get any sleeping during the night most of the time cause you're being followed around I guess and told to move on, you gotta go to the library or some place that lets ya just chill out and sleep for a couple of hours I spose so your main thing is getting something to eat in the mornings or at night and, trying to find a nice warm place during the day cause that's you know, it's pretty hard to find a place to sleep during the night, isn't it? Which is pretty cold, but during the day time it's nice and warm so try and find some place where it's like um, warm. That helps aye.

Get a good couple of hours sleep during the day cause you know everyone's up and about so I spose they leave you alone a lot more during the day don't they?

Jonathan: Do you think they feel less threatened in the day?

Pita: I think so, yeah, like if it's light and there's a lot more people around I spose it's more secure for people isn't it? Whereas it's the same place anyway it's just that there's probably less people and it's night time [laughs]. There's still the same threat isn't there?

Jonathan: Do you feel like that is kind of one of the main things that stops people who are homeless being able to get work and that?

Pita: Yup, that's a big part of it aye, like you know, no sleep does something to you aye. Like if you don't get a good 8 hours sleep or 7 hours sleep or something in a nice warm bed, then how do you feel after that?

Jonathan: Pretty shady 
Pita: Yeah, yeah. So if you're doing it every day and you're only sleeping like a couple of hours during the day on fucking concrete or something it doesn't do good things for you does it?

Sometimes security guards would take his stuff to discourage his presence, call him names like 'homeless piece of shit', and on one occasion, he woke up to a security guard kicking him. He has been accused of trying to break in to buildings, as well as committing theft while searching for a place to sleep, all in the name of private property interests. When drawing attention to such issues of injustice, Pita has resigned himself to the fact that people are generally going to listen to the security guard over himself. Moreover, he has to avoid other drunk members of the public and people living on the street who will and have potentially stolen his belongings before. He has had phones, clothes and sleeping bags stolen so frequently that he has developed little attachment to them. Other people I spoke to had experienced violence at the hands of members of the domiciled public, been spat on, had water squirted at them by shop owners, and experienced harassment and other forms of abuse.

To deal with this, Pita's alcohol consumption steadily increased as it helped him sleep in spite of the cold and hostility, as well as providing a welcome respite from his unchanging circumstance. Unfortunately, this further strained his relations with the public, authorities, and shops and he became an easy target for potential thieves and harassment. He has been targeted for drinking in public despite having no private abode, while police seemingly fail to address younger party goers in town openly drinking bottles of wine and scrumpy.

As his consumption increased, his income was no longer enough to cover the costs of his alcohol dependency so he began shoplifting to compensate. A crime for which he has since been caught and prosecuted on multiple occasions, leaving him with a criminal record. One of the first times I met Pita, at the Soup Kitchen in the morning, he was red faced, almost drooling and slurring his words. He had been out all night drinking and using drugs, and had lost his sleeping bag and his phone. Not two hours later, an ambulance had arrived and carried him out in a wheelchair. He had also been refused service at liquor shops after being identified as homeless as well as being asked to leave bars with no explanation. 
While it is unhelpful to discount the negative impact of drugs, alcohol, crime and violence in Pita's life, without understanding how these experiences are shaped by political-economic conditions and sociocultural circumstances, these factors on their own can misrepresent his situation. His entanglement with the city and its spaces, as well as how he experiences time, is mediated by these forces. Night time for most of those who are housed is a time and space for rest and regeneration, or play and relaxation; for Pita the night ushers in the potentiality of hostility and threat. It is a time and space where he may experience physical violence, theft, discrimination and targeting by authorities as well as dangers to his health. Alcohol, theft and assertive behaviour become short term safety nets for shutting out the city, acquiring new resources and protecting old ones.

Most recently, Pita was learning to wash windows when, within five minutes, two police cars stopped. The officers said they had been tipped off about shady behaviour and asked him what he was doing. Pita had been washing parked car windows in order to learn the graft of this informal economic practice, but they didn't believe him. They accused him of scoping out cars to steal possessions. He protested but they arrested him and charged him with unlawful obstruction of a motor vehicle.

Ironically, Pita had been washing windows to supplement his meagre income on the benefit as he was unable to find work, due in part to his criminal record, which has accumulated a series of offences since originally ending up on the street. Recently hopeful that he was going to get a job at a timber yard, his aspirations were cut short by his criminal record, which contains a series of offences for drinking in public and theft.

Many of these experiences are characterised by Pita seeming 'out of place'. At night he embodies the role of a 'dangerous other, a homeless Māori male', the kind of person who in the rhetoric espoused by mayoral candidate Nicola Young, and prominent member of the public Bob Jones, is likely to rip you off, physically accost you and/or engage in a range of other criminal behaviour.

The criminal justice system was pertinent to the lives of many of my participants and people I spoke to who found themselves cycling in and out of prison for breaching unmanageable 
bail conditions. At its peak, Pita found himself being arrested and detained three times in one week. Twice for the same breach of bail because of a mistake, where someone had failed to note that he had already been processed. Despite this, he was still locked up in the cells, until the error was noticed. This mirrors findings from Philippe Bourgois and Jeff Schonberg's (2009) ethnographic research into the lives of homeless drug addicts living under the San Francisco freeway. He found that the punitive version of neoliberalism, which was achieving hegemony during his research, trapped addicts in an 'abusive carceral cycle', where criminal records and low job skill levels from years of forced idleness resulted in chronic unemployment once released from prison. Incarceration becoming the only form of stable shelter in their lives.

\section{Moral and Social Economies}

Pita's bail conditions stipulated that he was not to be found drunk in a public place, despite the fact he suffers from alcoholism and had no accommodation for five years. Nor did the restrictions take into consideration the fact that he is embedded in social and moral economies with people who still live on the streets. Sometimes the obligations he experiences towards other people living on the streets run in friction with what authorities and social services expect of him. Bourgois and Schonberg $(2009,20)$ use the concept of moral economy to describe the non-market set of relations, which the drug addicted Edgewater Homeless are enmeshed in, "begging, working, scavenging, and stealing, the Edgewater homeless balance on a tightrope of mutual solidarity and betrayal as they scramble for their next shot of heroin, their next meal, their next place to sleep, and their sense of dignity" (Bourgois \& Schonberg 2009, 20). Many of my participants were enmeshed in relations with friends, lovers, and rivals, sometimes characterised by betrayal, tension, shared drug use, and theft. As when Pita housed his homeless friends on the agreement they would help use their benefit money for his rent, only for them to disappear on pay day, before turning up with the expectation of being housed a few nights later. Arguments and falling outs were had, but friendships could be patched up, and grievances forgiven, as long as both parties felt they were getting a fair deal. Often there was as much emphasis put on the performative dimension of asserting one's self-respect and sense of control over a situation. Sometimes these relationships would put them at odds with their bail and housing requirements, but they were also the networks that socially sustained them. 
Despite this, Pita, along with all my participants, were often subjected to the disciplinary measures by state institutions such as Work and Income, and by some social service provisions, whose help can sometimes come across as paternalistic. This was expressed by Pita regarding a disagreement he had with a social worker over his new council flat:

I mean she's only been on board the last couple of months, a few months and then, you know, she doesn't realise that it's taken probably two or three other people before her to sort of get this place you know, like I've been working with other people as well and, you know, I did most of the stuff anyway and carried on with the application, which has taken me 4 years, the way I look at it anyway. You know, like, there's a lot of other people that've been helping and it's like I've been the one going down there and it's, you've just come on board as soon as I've just got the place you know, and now she's tryna tell me like what to do and, 'you can't do this, you can't do that'... you don't really need that do ya?

Pita felt like there was often a pressure to comply with people, even when he felt like being left alone, in case it hurt his chances of being able to access resources and help. Tony, likewise, was suspicious of the supervision of homeless people. He questioned why he always had to sign in to use services. Tony felt these policies were more concerned with managing and keeping tabs on people, bringing homeless people into the watchful eye of the state, rather than addressing poverty or understanding people's concerns and experiences. Though he didn't blame the social workers, per se, seeing them as mostly genuine, but felt the logic of taking peoples details fed into a wider pattern of social control. He believed it unnerved those with power in society and made them feel uncomfortable that there were homeless people living off the grid, not partaking in consumerism or economic productivity. We discussed the new Salvation Army centre being built in Newtown and Tony believed it was part of a wider trend of city planning in the Western world of containing marginal and potentially social disruptive populations, segmenting them from the rest of society. 


\section{Conclusion}

Thus when I saw the man walking down the street screaming, it was hard not to see how his appearance embodied a threat to the normative social order and socially sanctioned behaviour of the urban environment. Although Desjarlais (1997) is correct in pointing out the way writers emphasise social difference for dramatic effect, inadvertently contributing to stigmatizing discourses of homeless people being almost less than human, something about the man I witnessed yelling was viscerally and psychologically confronting, in both appearance and attitude. The scream was a kind of social violence, a threat that denotes real danger and represents an uncontained wildness. I considered Pita's reflections that if you do not behave in a manner concurrent with societal expectations, you become an outsider, disruptive to the refined and cultured surroundings of the city, and his use of the adjective 'wild' to denote his interpretation of being, or inhabiting, this lifeworld outside the confines of the domesticated city.

In hindsight, this process did not occur naturally, but was the result of neo-colonial social control practices, and neoliberal morality and rationales. Rationales that found themselves embedded in proper notions of public space use, in the discourses of service provision and state institutions, and in the discursive and symbolic understandings of homelessness and street life, as articulated by the media and prominent public figures. Identity was not just constructed discursively; it was lived, felt, produced, and negotiated through people's everyday engagement with their inhabited lifeworld. Regardless of their pathways into homelessness, Streeties underwent processes in the city, which decimated their bodies, and subjected them to disciplinary and paternalistic practices in order to receive the resources they needed. Streeties and the homeless, then, are not just homeless in a material sense but are actively made into 'homeless' subjects through these processes, which deny their access to legitimate forms of personhood. To undercut one dimensional stereotypes, we need to understand both the historical forces that come to situate people as homeless, as well as contemporary contingencies. We need to deconstruct our own understandings and assumptions, critically reflecting on our own perceptions. Moreover, we need to understand the ways in which Streeties, who have been denied access to socially legitimate forms of being, manage and develop their own personhood. Despite the sometimes overwhelming 
forces shaping their trajectories, Streeties lives were never fully eclipsed by the relations of power shaping their experience of the city.

While my participants lacked the resources to mount any meaningful kind of resistance against the state, they managed to "subvert authority by breaking rules in their everyday lives" (Scott 2009, 4). Sometimes this came in the form of embodying discourses of personal responsibility to attain the necessary resources to get by and support loved ones. Streeties sometimes rejected assumptions as to what they required to get by, living life on their own terms and embracing life on the margins, as articulated by Pita:

Sometimes you do get used to it, but the main goal was to get a place, but you know, seeing as I wasn't getting a place I just had to make do with what I had and that was living on the streets with my bag and my sleeping bag so you know, after a while, after four years its sorta grown on me [laughs] 


\title{
I'm Houseless Not Homeless!
}

\begin{abstract}
"I connect up there hard bro [points to the sky], especially on the streets. That's our roof right there, we all under the same roof, you know? It's not about having a house or anything, you know? If you look at life that way, it's way different. Doesn't mean we're any different cause we're not in a house" - (Spirit)
\end{abstract}

\begin{abstract}
"My experiences in Central Australia had led me to explore the notions of home, not as something given but as something made, not as a bounded entity but as a mode of activity" - (Jackson 1995, 149)
\end{abstract}

In this chapter I explore the way Streeties come to engage with the concept of home, elucidating some of the tensions and contradictions, which emerge from the process of housing people materially. I argue that the apprehension Streeties express towards 'going inside' ${ }^{14}$ emerges not just from a fear of, or unwillingness to, change, but from the potential for the erosion of the sense of self and personhood they have developed while living on the streets, in relation to both their physical surroundings and other people. As Westerners inhabiting built environments, we tend to presuppose that people share what Jackson calls our 'material habitus', which "sees boundaries as a precondition of meaning" $(1995,85)$. We are unnerved and feel uncomfortable by the presentation of unbounded sites, indeterminate horizons and fragmented realities.

For people who have been forced to carve out a life on the streets, inhabiting spaces that are both physically and socially marginalised, understandings of what constitutes a home may differ radically (Jackson 1995). Likewise, so may their experience of what it means to feel comfortable, secure and 'at home' in the world. I argue that by conceptualising home as a mode of activity continually 'going on' in the present, where meaning is borne out of experience, rather than as a place where meaning is codified and predetermined, located in

14 'Going Inside' was a term frequently invoked by Streeties to refer to being housed 
a material dwelling, we can begin to understand the ways Streeties create non-traditional living spaces, broadening our understandings of what constitutes a home, and what it means to feel 'at home' in the world.

To do this, I introduce Spirit, the circumstances within which I met him, and his experience of recently coming back to the streets after moving inside. I will also introduce the Church organisation who housed him. Following this, I suggest that the meanings we attach to home, and their conflation with a material dwelling are not underpinned by an innate and universal logic but are rooted in a specific Anglo-European history, taking their shape from a bourgeois sensibility that emerged with the new middle classes of $19^{\text {th }}$ Century England. I then proceed to problematize the assumption that the house, in and of itself, is the solution to the problems of Streeties. Arguing that rather than seeing a material dwelling as a necessary precondition to meaning, being and belonging, we need to understand the diverse ways in which Streeties relate to the world around them, carving out a home, not as an abstract space, but as a living place, constantly issuing forth in the here and now, where modes of meaning, being and belonging emerge from day-to-day experiences of living on the streets. The sense of home that emerges when understood as a mode of activity, is a place in which the inhabitant is an active participant in the world they are making; connoting both a sense of individual autonomy and control, but also of belonging and connectedness, for the sense of person and place that emerges in the currents of life activity is always contingent on the subtle and ongoing negotiations we make in relation to our surroundings, which include other people, material objects, and cosmological orientations.

Where this chapter explores home and house, my film focuses on the exploration of place as something made through our movement through everyday life.

\section{A Journey to Spirit's Home}

It was a Friday night. I had been texting Spirit over the last couple of days to meet up for a second interview: 


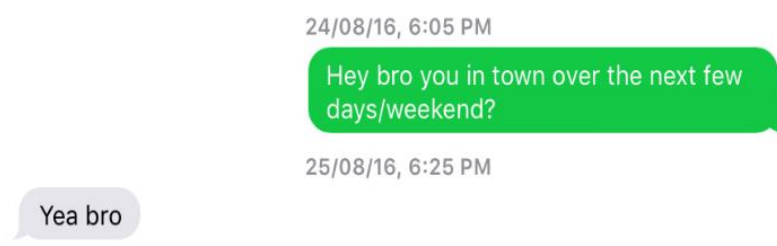

26/08/16, 9:39 AM

Sweet keen to link up and finish the

interview this weekend?

26/08/16, 11:13 AM

Yes plz bro

Sweet, you in tonight?

Yea bro

I be bk Courtney

Cool I'll come in, what times good to

meet you?

15

26/08/16, 2:12 PM

After 6

26/08/16, 3:29 PM

Sweet I'Il text you around then

26/08/16, 4:35 PM

Sweet I'm bk now whenever your ready

my bro

$26 / 08 / 16,5: 48$ PM

Just show up when u want my bro my phones going flat

Sweet I'm gonna bus in, in like 10 mins

so will prob be on Courtney in 30ish,

where on Courtney should I meet you?

I'm outside bk

I got off the bus at the bottom of Courtenay Place and proceeded to wander up the street lugging around my camera equipment, unsure of whether I would be filming. There was an All Blacks game at Westpac Stadium on Saturday night so town was busy.

On the corner of Courtenay Place and Tory Street, I saw Spirit lying on the ground. He was nestled between the entrance to Burger King on his left, and an ATM on his

${ }^{15}$ Texting Key: Green - Jonathan; Grey - Spirit 
right. Another metre or so along from the ATM was the doorman for an upmarket cocktail bar where I used to work.

'Spirit!' I yelled to get his attention. He was napping in a green sleeping bag surrounded by bags, a blanket and a pillow. His posture was relaxed and he looked comfortable. In front of him a cardboard sign read 'Smile and Be Happy!'

His eyes opened and he gave me a nod of recognition. I ask if I could sit down and he moved his stuff out of the way.

Spirit: Do you want some blanket bro?

Jonathan: Oh yeah, go on.

He folded his blanket into a comfortable chair and cleared some space for me. We shook hands and he stretched out. Now there was just a sleeping bag between him and the ground. I sat down on the newly cleared space and asked if he is okay to do the same thing we did the last time we spoke when I set him up with a microphone lavalier.

Spirit: Yeah bro. I'm staying back out on the streets now.

The last time I interviewed Spirit, about two weeks earlier, he had been staying intermittently at a church based out in Wainuiomata. Some members of the church had taken an interest in homelessness during the last six months after seeing an increase in the number of people sleeping rough, and the widespread media coverage it was receiving. One of the church members, a Māori man in his late 30's, had stopped to speak to a few people begging in the train station after seeing them with smart phones and wondering how they could afford them:

I kept seeing all these guys sleeping everywhere and begging. I saw these guys at the train station begging but they had these flash smart phones, and I was like 'are they really poor?' so I went up and talked to them. I asked how they afforded those smartphones. But it turned out that was all they had. There was nothing else, just devices. I listened to their stories and they were just heart breaking aye. 
After hearing their stories, he felt compelled to act, so he recruited fellow interested church members and they established an organisation to deal with homelessness. They ran a weekly barbeque on Saturday nights, where they set up a cooking station on the back of a ute, played music and offered food to people living on the street. Church members would alternate the weeks they went out, but the two main organisers could usually be seen every weekend. They provided hot meals, soups, cakes, buns, as well as tea, coffee and milo. The team relied on the relationships they had built with some of the Streeties they met for word to get around, and sure enough a steady flow of people would turn up, stay and chat for a bit, before heading off into the night. Along with food, they also provided sleeping bags and clothes that had been donated by church members to people who needed them. In exchange, they took Streeties' old clothes and sleeping bags out to the church to be washed and then returned them the following week.

We've been coming out here once a week but it's not enough, they need this all the time.

We come here on Saturday nights and do this, and then come pick them up on Sunday morning for Church, those that are keen. After church, they can shower and shave and then we drive them back into town. We are kitting out our church at the moment to sleep more people.

As they developed stronger relationships with some of the Streeties they started housing people out at their church in Wainuiomata. The first time I went, the key organiser informed me that he was committed to their namesake of making a difference and was adamant the situation could be fixed or improved, and they were more than willing to shake up the current landscape of social service provision.

Although he cited government negligence and lack of compassion in his reasoning for why the situation had gotten so out of hand, he still saw a failure of personal responsibility on the behalf of Streeties as the primary cause. This was despite reiterating to me how saddened he was by the hardships some of them had faced when he originally decided to establish the organisation. Consequently, the people whom he saw himself being able to help, were those 
who were ready to move on from their mistakes, and change their lives for the 'better'. The logical solution to the problem being housing:

We've managed to get 5 people into a house already. J***e's moving into a place next week and we're gonna kit it out with furniture and everything. Bed, tv, tables, kitchenware.

Man if I won that $\$ 40$ million lotto, I'd be able to solve all this. The government doesn't know what it's doing. Give me $\$ 100,000$ and I'll have this thing sorted out, houses built and that, but I don't have the money.

Jonathan: Yeah, but what about the causes and drivers of homelessness? Like how do you deal with those? How these people got here in the first place?

Most of them got here through bad choices. You know, they make mistakes, but when they're ready to get out we're here to offer them a way out. Until then we try ease the situation.

Incidentally, it was through them and some of the other homeless community who they have been involved with that I met Spirit a couple of weeks later, when I accompanied them on a night sleeping rough. Our second interview took place a few weeks afterwards:

A lady walked by while I was setting the microphone up and asked Spirit if he wanted some coins. She stretched out her hand and gave him a handful, apologising saying it was all she had.

'Thank you! God bless!' Spirit says in return, leaning against the wall.

Jonathan: So, why've you been staying back in town?

Spirit: Just better bro

Jonathan: Better? What's better about it?

Spirit: Cause I like staying outside [pause]... I'm not ready to go inside yet. 
Jonathan: Why do you feel that is?

Spirit: Dunno. I know I will eventually this year.

The ambivalence or sense of unease Spirit expressed when the conversation of housing arose was not an uncommon feeling among Streeties that I spoke to during my fieldwork, nor was the indeterminate response. 'Not being ready to go inside yet' was something I heard with relative frequency. Mark, another man who had been staying out in Wainuiomata and coming back in periodically, also expressed a tension around moving inside:

Well I'll tell you something. People are out here by choice. Most don't need to be but some do. It's the alcohol and drugs. Me, I probably don't need to be out here but I'm not ready.

I became interested in why Streeties experiencing the more extreme end of homelessness sometimes expressed an ambivalence towards being housed, which to many, appears to be the obvious solution to homelessness. An assumption echoed, despite his good intentions and pragmatic grassroots work, by the founder of the church organisation tasked with fighting homelessness, as well as a recent Cross-party inquiry (2016) into the extent of homelessness in New Zealand. Moreover, I wanted to explore the notion of 'choice', a word that was frequently invoked by both Streeties and domiciled people to explain homelessness. Narratives of personal responsibility and individual choice, which suggest homeless people either choose to be homeless or that they have ended up on the streets through their own failures and inability to constructively manage their autonomy, failed to fully explain or comprehend Streeties apprehensions toward 'going inside' and decisions to stay on the street.

The source of Spirit's unease, as I could see it, did not stem from an internalised well of discontent isolated from the bodies of water within which he lived his life, or the currents in which his life activities were carried out. It emerged from a disjuncture between his personal experiences of home and house, as both material and mental spaces, sometimes hostile to his ability to live well, and the ways society presupposes the meaning, importance and functionality we assign to material dwellings by conflating them with a sense of place and belonging. Jackson (1995) attributes this to our living in built-up environments where our 
movement through everyday life is constricted by walls, houses, rooms, buildings, corridors, fences, walkways, and motorways. A consequence of this, he says, is that we have developed a "habitus of walls and enclosures, of well-marked exits and entrances, paths and roads" (Jackson 1995, 85) whereby existential security, meaning, and status are derived from the substantiality or permanence of the places we build and the ideas we develop.

\section{House and Home}

This fetishism of the house as a necessary material precondition to meaning, and even being, has a long history in European thought (Jackson 1995; Ingold 2000; 2011). With the onset of the capitalist political economy in the $17^{\text {th }}$ century, ownership of land transferred from the commons to private property. The process of 'primitive accumulation', by which people were pushed off their land to 'free' them to sell their labour, also freed up land to become privately owned (Marx 1990). A consequence of this was a rise in individualised land ownership, seen as a necessity to securing a livelihood and reaping economic rewards in the form of rent, and in the consequent ability to increase one's social status. For land to become commoditised, though, and thereafter subject to market exchange, it needed to be attributed a standardised use value based on quantifiable characteristics, it needed to be able to be measured and matched in relation to the value of other land (Polanyi 2001). Those with power and economic capital could then metaphorically and physically cut it up to sell and purchase in incremental blocks, each plot of land held under individual title. To maximise profit, it was in the interests of landowners to subdivide their land and construct as many properties and buildings as they could to extract rent. In this context, the permanence of the structures and dwellings they built translated to permanent, steady and stable income. Thus, it was in the interests of those in power, for society to embrace private property, secure dwellings and the meanings associated with them.

The kinds of meanings and being that emerged with the house though, were not just solely imposed from above, rather they became expressions of the newly formed class and social relations. Within the home, for example, a gendered division of labour emerged, which, according to Engels (1940), was not innate, but an outcome of "specific modes of production and social organisation" (Buchli 2013, 110). The male, who was the head of the household, stepped out into the world as the breadwinner, while the wife was confined to the home, 
and the nuclear family composed of mother, father and children became the primary kinship unit and source of emotional affection. Houses, now embedded in the logic of a capitalist society, emerged as spaces to both access and flaunt social capital, and to reaffirm normative kinship and gender relations. They became an indication of how civilised one was, and served as a sanctuary from the competitive capitalist rat race and the often hostile and morally tenuous external world (Fishman 1987; Jackson 1995). Thus, the gendered division of labour coincided with the rise of the 'home' as a domestic sphere, and with the associated meanings and divisions between purity and pollution, and private and public.

These meanings, however, did not emerge from society as a whole, composed of different social classes, but arose in relation to a bourgeoning bourgeois sensibility of aestheticism, morality and social values. In his book 'Bourgeois Utopias', Fishman explores the rise of Anglo-American suburbs, here referred to as the residential communities that develop on the periphery of urban areas, and argues that as the ultimate expression of "class wealth and privilege... suburbia embodies a new ideal of family life, an ideal so emotionally charged that it made the home more sacred to the bourgeoisie than any place of worship" $(1987,4)$. Homes and suburbs emerged, then, as key sites for the formation and reification of bourgeois subjectivities and, he argues, the victory and hegemony of middle class values. Much like the home, whose meaning transpired from its recognition as a private and domestic space, a retreat from the unbridled and unbounded outside world, suburbia emerged as a solution to the ills of city living. An idea propagated by the influential evangelical movement in $19^{\text {th }}$ century England, "the city was not just crowded, dirty and unhealthy, it was immoral. Salvation itself depended on separating the women's sacred world of family and children from the profane metropolis... Suburbia was to be the ultimate solution" (Fishman 1987, 38).

In a society where our spiritual and social aspirations, and our individualised identities find themselves so intimately embedded, and expressed, in our material possessions, particularly the spaces we call home, being without a house, is almost to live without spiritual meaning, a fulfilling social existence, or a sense of selfhood. Although much has changed in the time since then, the conflation of house and home, and the pervasive undertone that both are a necessary precondition to a certain kind of meaning, being and belonging has persisted into the present. Rapaport, exploring the meaning of home and house to Americans quotes John 
Steinbeck saying "home - the very word can reduce my compatriots to tears" $(1969,132)$. The social, moral and spiritual value that house and home took on, was so immense that entire national identities were formed centring on home ownership as a fundamental tenet of societal belonging, reflected in both the American dream of a large family home, with a white picket fence, surrounded by grass and trees, and the New Zealand dream of a quarter acre property. Despite the reality that, in the States, most people rarely lived in such homes, and in New Zealand, that home ownership is becoming increasingly unattainable due to soaring house prices, these dreams, according to Rapaport (1969), serve as symbols of motivation for the aspirational to work towards.

Moreover, house and home are not neutral concepts but are politically and morally charged spaces of contestation. The dominance of houses and homes as centres of meaning in Western society has led to the values we associate with homes appearing universal, obscuring their origins to the point we find it difficult to fathom that others may not share our affinity with privately owned abodes, or see substantive dwellings as a necessary preclusion to meaning. This has led to the marginalisation of nomadic peoples the world over, leading them to be treated with either suspicion or outright hostility. This is evident, for example, in the treatment of Irish Travellers by the British government (Okely 2014), Romani gypsies in Europe (Okely 2014), and Aboriginal Australians by white Australia (Jackson 1995). The transience of these groups is often blamed for their inability to function and integrate in society, and is often seen as the primary barrier to socioeconomic achievement. Aborigines are derided for going walk about, having no sense of private ownership, and for ruining infrastructure provided to them in community settlements, even when there has been little consultation about their needs (Jackson 1995, 116). Jackson argues that this stems from a profound ignorance of the ways Aborigines develop relationships to the landscape. Moreover, in New Zealand, the decision to build thousands of state homes in the 1930's, failed to comprehend Māori kinship relations, their ways of living, typical forms of sociality and their relationships with land. By assuming the universality of Anglo-European values and sensibilities regarding normative home life, morality and kinship relations, these state homes created dislocation and disconnection, rupturing communities and Whānau from each other and the land (Barcham \& Walker 2010). 


\section{Meanings of home and the marginalisation of people}

Many of the ideas connoting divisions between purity and pollution, safety and danger, and private and public also survive in today's world. Gentrifying projects, like the creation of public space or parks, are often underpinned by a logic of 'purifying' tainted spaces. For example, Dooling (2009) found that a public design charrette in Seattle aimed at designating future green spaces to make it an ecologically sustainable city, conceived of low income housing blocks and night shelters for the homeless as polluting to the ecological functionality of the city, and were removed to be replaced by parks reserved for natural amenities. Moreover, they conceived of the homeless people living in camps in the parks "only in terms of threats to the safety of housed residents who entered public spaces" (Dooling 2009, 30).

These discourses have a long history in the Western world, centred on narratives of renewal and regeneration, often targeting dilapidated, poor areas (Newman 2011; Harvey 1996; Checker 2011). Intimately tied with capitalist urbanisation, these regeneration projects inevitably lead to the destruction of housing blocks, parks, and other amenities under the pretence of cleansing, displacing the people who live there. In France, for example, Newman (2011) tracks the building of a park in a poor suburb in North east Paris, composed of mainly immigrant families from the Maghreb and West Africa. He situates this within a wider framework of urbanisation and regeneration, where renovating urban space usually occurs along class and ethnic lines, 'reclaiming' Paris from its ghettoization and making it a city safe for everybody (Newman 2011). These projects, he argues, inevitably entail large scale evictions of poor immigrants, the construction of new high rises and soaring prices, and an increased presence of policemen, designed to protect the interests of the newly regenerated space.

Thus, while Jackson (1995) suggests we have a habitus of walls and enclosures, I would argue that by symbiosis we also have a habitus of exclusion and division. The very pretence of home as a bounded concept, built of physical walls, separating outside from in, has always been exclusionary and its meaning emergent from the ways we make sense of our experience of the kinds of relations that develop through these divisions. This is an idea that has been explored by Sissons (2011), in relation to the adoption of European styled architecture by 
Hawaiian Royalty. He argued that the destruction of previous ritual sites and construction of new European dwelling spaces was the material manifestation and emergence of a highlycentralised power and hierarchical order. New relations and subjectivities emerged based on divisions between "pure/impure, male/female and superior male/inferior male" (Sissons 2011, 203). He focused on the specific ways in which walls, as material things, actively plunged into the field of social relations, creating new subjectivities through processes of concealment/revelation, and inclusion/exclusion.

Here in Wellington, the same logic has manifested in the treatment of public space, as previously outlined in the preceding chapter, when the Wellington City Council under exMayor Kerry Prendergast tried to create a bylaw that would ban "sleeping, camping and "residential activities" in public spaces and means the homeless could be moved if people felt intimidated by them" (NZ Herald 2003). This punitive approach to people performing private acts in public, situates homeless people with no private abode in a difficult position (Dooling 2009; Mitchell 1995).

This is not to suggest that humans have not always inhabited dwellings of some kind, seeking shelter and respite from the external world, just that the emergence of the privately-owned house was not innate but was enmeshed in an all-encompassing field of relations, that included the arrival of a new political economic system, the consequent rise of private property, middle classes, gender divisions, neighbourhood segregation and the nuclear family as the primary family unit. Likewise, the values we attach to public and private space emerge from a sensibility that decides what is and is not appropriate behaviour for specific areas, while often failing to address the reasons in which people live on the street. Housing them, in this context, can be as much about 'managing' homelessness for the sake of the domiciled city residents as it can be about homeless peoples' wellbeing (Hodgetts et al 2014).

\section{'Choosing' the Streets/Making the Streets Home}

In the case of my participants, their reasons for ending up 'choosing' the streets were not always so clear cut. Spirit ran away from his family after experiencing a personal betrayal of trust, he no longer felt safe in his home, so he moved to the streets as a young man: 
They just broke my heart bro, that just put the icing on the cake sorta thing. I was like 'fuck youz' and just left, didn't go back [pause] for ages. But just that first experience on the streets made it home brother... I just had a couple of bros. There was quite a few of us that used to hang out.

His brother in law distilled homemade alcohol, and Spirit's step-mother who suffered from alcoholism, found and drank a bottle which had yet to be filtered, passing away the same day. In amongst a series of other issues, Spirit found himself being blamed for her passing and left his home and family, his trust broken. After a small stint in Jail, Spirit wanted to get off the street but did not want to stay in the halfway house because it was filled with criminals and he didn't want to be around people living in that world.

Red, still suffering from her heroin addiction, as well as the trauma of prison and her children being taken off her by CYF's, set up camp along the greenbelt. Here, she did her best to recover and gain control of her habit to get her life back and see her children again.

Pita had lost his job, broken up with his partner, and began drinking again after a five year period of abstinence as he descended into homelessness. He tried staying at the night shelter but it only made him worse being surrounded by so many people suffering from issues with drugs and alcohol, a sentiment shared by many of my participants. He had been on a Housing New Zealand waitlist the entire duration of his five years living on the streets, but no houses in Wellington had come up.

Mick, another man with whom I spoke to, had been living in a Housing New Zealand flat, which had a leak. He had been complaining about the leak for weeks, yet nothing was done. After two months, significant levels of mould had formed in his house and had become a health hazard. Someone was finally sent in to look at it, but he had decided it was too late; angered by their lack of attention he moved into his jeep. Not so concerned with a roof, he chose to live with his dignity and a sense of control over his situation, instead of being at the whim of an organisation that had showed little in the way of respect for his concerns. 
It was not that they saw living on the street or in green space as a permanent solution, or that they rejected the notion of housing entirely, but more often the conditions that went with it, and the fact it failed to deal with their reasons for ending up homeless in the first place. Similarly, Dooling found that the homeless park users she interviewed had chosen to live there for lack of a better option due to poor social housing alternatives $(2009,627)$. Night shelters were viewed by her homeless participants as spaces of crime and violence, where meals were accompanied by a religious agenda that they found alienating or insulting, while the single-room occupancy hotel had a pervasive drug culture and with their frequent inspections carry a sense of constant surveillance (Dooling 2009).

Many of my participants resisted the desire to be controlled or to be bound physically, institutionally or socially, and refused to be subject to the whim of others. Spirit resented the label of homeless and felt it dehumanising, pointing out he does not call those people living in houses 'house people'. He didn't like the assumption that just because he was living on the street he was incapable of managing life or that his life did not have meaning. Wayne also steered away from social services because he liked his privacy and was rightfully, given his history of institutions, suspicious of people knowing his whereabouts. Pita wanted a house, but also had to make life on the streets work for him until that came about. Sometimes this included committing crimes like stealing food and alcohol, drinking to drown out the sounds of the city and the cold of the night, ending up in fights with security guards who he felt were harassing him, and breaking into private carparks to find sheltered places to sleep.

Their reasons, though, were not always positioned against a desire to be housed, but in favour of a life without walls and enclosures. In Spirit's lifeworld, the bounded entities we associate with house and home made him uncomfortable, he often referred to feeling 'stuck' or being 'surrounded' when indoors and struggled to keep busy. Tony found it stressful and debilitating hanging around homeless spaces or low income housing. Even though he liked to cheer up some of the more vulnerable, mentally unstable service users, he felt you had to be careful that their negativity didn't seep into you. He felt spiritually unwell being in the spaces where these people lived and socialised, and preferred to live in the bush around trees, being surrounded by the wild. 
Physically, Spirit described the house as making him stressed and claustrophobic. The four surrounding walls became sources of oppression, leaving him trapped with his thoughts. Moreover, he felt like a burden to those who were helping them. For a time, Spirit was offered accommodation in a house with the church organisation mentioned previously. He expressed his sincere gratitude and appreciation to them for opening their homes, but felt uncomfortable with the dwelling offered to him:

Jonathan: Was there things you missed about Courtenay place or just the street generally when you were back in Wainui?

Spirit: Yeah ummm yeah it gets a bit, aww it's been good out there, just on the church side of things. But I sort of let my guard down and, cause I wasn't staying in the church, I was staying with some of the sisters and just sorta got a bit used to it and attached, where it's not very good you know? Can't expect to stay somewhere forever, aww you know what I mean.

Jonathan: Yeah

Spirit: Let them live their lives and me live mine, sorta buzz. I sorta let my guard down and I stayed there for like a whole week there last week, but yeah, it's better just to carry on where I was going you know?

Jonathan: Did they say something or did you kinda just feel that?

Spirit: Aww, umm, she just had a lot of things going on herself, so, and then I sorta realised that you know, I let my guard down. It was all good though. I was paying my way and that. It was nothing like that.

Unlike Spirit, Wayne struggled with excess time and felt unable to comply with their no drugs and alcohol kaupapa:

It's a lot of idleness. That's the problem out in Wainui. You just sit round. It's not their fault though, they're doing great things, opening their house up to us and that. That's 
why I left, I feel bad taking up their space. I can survive out here, I don't wanna waste their time and space. But it would be good to do some work out there. I'm at a point where I'd like to be able to do something and I think I could. Hopefully that opportunity comes up soon. Some of the younger guys there, and not just the younger, they don't respect their Kaupapa, and it fucks me off. You know, they ask for no drugs or alcohol to be consumed, but like this morning I get up and see 3 or 4 of them loading up their bongs and I'm like 'don't you fucken smoke that shit here! It's disrespectful, they're putting you up!'... That's why I don't like staying there cause I'm still doing those things and I don't like to disrespect their Kaupapa.

Being inside, especially in another person's dwelling, requires subtle compromises of the self to avoid confrontation and/or stepping on peoples' toes. It also involves sacrificing a level of control over your situation, and an admittance that the fate of your situation rests in the hands of others. Spirit's ambivalence rose in part due to tensions between himself and another, managing both physical and emotional zones of engagement, trying to retain a sense of ownership of his circumstance, while being at the whim of someone else. Wayne, on the other hand, was attempting to work through his drug and alcohol issues, and felt disrespectful using their space when he is unable to stop using.

This reminded me of a passage from Jackson's 'At Home in the World', in which he recounts a conversation with Ringer, an Aboriginal man who belonged to the community where Jackson was spending time:

When I asked him what it was like in the hospital he said he did not like being closed in. He did not like walls. They made it hard for him to see or hear or smell what was going on around him. He missed a fire in the open, a windbreak, the bush. I was reminded of something Pincher Jampijinpa once told me in Lajamanu: 'A house is just like a big jail.' In the West we have a habit of thinking of home as a house. Walls make us feel secure. Individual rooms give us a sense of privacy. We tend to believe that living in a house is synonymous with being civilised. We have an ingrained prejudice against nomads and drifters. With proprietal pride we will defend the privacy of our homes but fail to grasp that nomadic people feel just as strongly about the places they hold dear, the landscapes they call home. Perhaps this bias has its origins in the Neolithic when human beings first learned to domesticate animals and cultivate grain. 
Those who remained beyond the pale of human settlement were seen as threatening and barbaric $(1995,85)$

Jackson contends that his aboriginal friends did not simply feel an aversion to 'Whitefella'16 spaces in preference of their own, but that their reservations were intimately linked with the degrading and damaging experiences of the world of 'Whitefellas'. It is not just overt racism or explicit intolerance one encounters, but "the myriad ways in which one feels inept, uncomfortable, and diminished in a habitus that is not one's own and in which one has no recognised place" $(2013,238)$. The space of the other, be it social, material or discursive, becomes reminiscent of the gaze of someone who holds more power than oneself, carrying with it a sense of shame. In the case of Jackson's Aboriginal friends, this found its expression in their complaints of feeling unwelcome, or that it was not their place, or that they didn't belong.

Similarly, in her book 'Being Māori in the City', Gagné (2013) explores how Māori families who live in Auckland understand and experience the city. She found they felt a sense of powerless and lack of control over their lives. The inability to find work due to discrimination, and the restrictive circumstances surrounding their choice of residence led to many of her participants feeling as though the city was "not theirs"; a place in which they had little or no place" (Gagne 2013, 63). The city was experienced as a 'colonised' space, where Pakeha ways of knowing and being dominate the landscape. Where the demands and interests of tangata whenua or urban Māori boards are seen as stumbling blocks on the road to Auckland's progress. Gagne picked up on a tension between 'comfort' and, accordingly, 'discomfort' express by her participants when conversations about how they relate, or feel at home, in the city came up.

Discomfort was associated with walking in unfamiliar worlds, in the context of Gagne's participants lives, this was the city, especially upon arrival. In contrast, comfort was a term evoked to describe the sense of home Māori experienced by participating in a variety of

\footnotetext{
${ }^{16}$ Whitefella is a colloquial term used by Indigenous Australians to refer to White Australians
} 
activities, settings or situations, which allowed them to feel at home in their environment. Both are related to their experience or sense of belonging in different groups.

Radice, who she draws on, talks about the interplay between internal and external states of being, and the role comfort plays mediating the subjective in-between:

It allies several different realms of experience, including 'internal' factors like one's emotional state, sense of security, and knowledge; 'external' factors such as the weather, available information, physical ease and fellow city-dwellers' attitudes; and 'in-between' ones like having room for manoeuvre (both literal and metaphorical), interacting with other people, being satisfied or not with one's material fortunes, and so on. 'Feeling comfortable' is therefore the bridging concept par excellence between 'inside' and 'outside' $(2000,131)$

Feeling at home for Māori, was often expressed in their sense of comfort in a place, which included their relationship to both their material and social surroundings. The feeling of comfort, though, was not a permanent state of being, and its existence entails the possibility of feeling uncomfortable (Gagné 2013,73). Thus, negotiating one's comfort in the world was a constant process and depended on multiple factors, making it not so much something one felt despite their involvement, but was made and remade in the context of their everyday lives, whether through building positive relationships with others, finding or making a space for respite from the city or engaging in cultural practices where they could express their identity without fear of not fitting in. Moreover, comfort and its logical opposite were also related to ones "sense of security and insecurity, which can be physical, emotional, or social" (Gagne 2013, 74). One of her participants, Kahu, stated 'Auckland drains me,' (Gagne 2013, 74). She could not articulate why this specifically was, just that it felt like a draining and austere place to live. A sense of loneliness pervaded the narratives of her participants living in Auckland, separated from their safety net and support network. In contrast, when one is incorporated into a whānau, they felt more at ease in the city. A source of discomfort is the unknown, while experience and knowledge are a source of comfort.

Although her participants are predominately middle class to upper middle class Māori families in Auckland, her analysis of the fluid role played by comfort and discomfort, has heuristic value when exploring Spirit's relationship with home and housing. Feeling 'at home' 
for the Māori in Gagne's research, as for those in Borell's (2005), arose from the sense of safety and control that emerged from the familiarity and comfort people experience though their everyday involvement with a particular environment.

My participants did not always feel like they belonged in house society, and felt more at peace, more comfortable on the streets. Their experience of living inside was often one of subjugation and compromise, leaving them feeling diminished. Spirit rejected the assumption that living in a house was inherently better:

Actually sit there and feel sorry for people that are going to work, you know, cause you see them, how they look and we ain't got, you know, people think we got it bad, bro, fuck a lot of people out there have got worse than us, you know. Just cause we ain't got a, just cause we don't wanna stay in a house.

Wayne wanted to leave the streets, but was hesitant because there were aspects of living on the streets that worked for him:

Aww yeah I'm institutionalised as fuck bro. All my life. I haven't been a good boy, you know. But now I'm fuckin' 60 and I don't wanna do that stuff anymore. I can't. It's a young man's game, even being out here. As you can see I'm getting fuckin' sick.

I also like the streets in some ways. I like my privacy. I don't like people knowing where I am or what I'm doing. I don't even have a phone. I think that's why I partly don't use services.

This came into conflict with aspects of living inside:

The idleness is bad. It just gives you time to dwell on shit and you get bored or don't feel good and you go back to drinking or drugs, or in my case wanting to go back to prison. They know that at places like the DCM. That's why they do stuff there. They have the jam sessions, the looking for work programs, the Te Reo courses and that. I think big ups to that crew. They do good work up there. You need that stuff otherwise you just go crazy. 


\section{Ideological constructions of home}

Despite this, there is an explicit tension between the dominant ideological notions of what is considered a proper home, and what kind of patterns of human habitation are allowed in different spaces. The official New Zealand definition of homelessness is an entirely material and place bound conception:

Homelessness is defined as living situations where people with no other options to acquire safe and secure housing: are without shelter, in temporary accommodation, sharing accommodation with a household or living in uninhabitable housing (Statistics New Zealand 2009)

My participants fall predominately within the 'without shelter' section, which is further defined as:

The intersection of housing with the social, legal, and physical domains means for those in living situations in the 'without shelter' category, they do not have personal living space, cannot maintain privacy and do not have safe accommodation within the social domain. They are without exclusive possession of accommodation and security of occupation in the legal domain, and do not have habitable housing in the physical domain (Statistics New Zealand 2009)

While these frameworks form an important purpose in providing a structure within which to identify and tackle homelessness, their narrow scope leaves no room for the ways Streeties define living space, privacy and safe accommodation. Many of the Streeties having actively chosen, and created, spaces in which they feel their ontological security, safety, and wellbeing, are nurtured in ways that have been denied by traditional conceptualisations of home and house. Ingold (2000) would argue these contested notions of home arise from the differences between a 'dwellers' and a 'builders' perspective. The former taking the immersion of the dweller in their environment as fundamental to their condition of existence, where "the world continually comes into being around the inhabitant, and its manifold constituents take on significance through their incorporation into a regular pattern of life activity" (Ingold 2000, 153). In contrary, the essence of the builder's perspective, whose logic is rooted in Cartesian dualism, sees acts of dwelling as "preceded by acts of world making" 
(Ingold 2000, 179). It sees the meaning that is derived from dwelling as necessarily precluded by building, by the imposition of buildings for future occupation, whose meanings are already codified into their walls.

This is not to suggest we should abandon trying to house people altogether, or that houses are not a part of the solution, but the way in which we approach the extreme end of homelessness should adopt a more critically reflexive and open-ended interpretation of how people make a home in the world. We need to pry home away from fixed and bound form to see the myriad ways home emerges in the context of peoples' everyday active engagement in the world.

\section{Spirit's Home}

In the same way that home embodied a sanctuary from the unbounded and immoral spaces of the urban industrial world, for example, Spirit found this in the open space of the city:

Spirit: It just brings me peace bro. It's like my sanctuary you know?

Jonathan: What about it makes it your sanctuary?

Spirit: Just even in Auckland I stay on the streets and be clean and... even though down here, no matter where I am I stay clean, but yeah. Just like home bro. I like sleeping outside. It's like fresh air, you know? It doesn't matter if it's cold. [pause] I dunno how to explain it. It'd probably be like if you have a place that's sorta, you know, the same to you. But mines outside [laughs]. Or you might like going up on a mountain, or you know... Just sorta people, you know? There's just like heaps of energy. As long as you make the energy good it's alright.

Jonathan: How do you make the energy good?

Spirit: Just be yourself. Be happy, smile, you know? House people, just same things bro.

The street allows Spirit to live life on his own terms and in line with his values. He feels at home in the unbounded spaces of the city, where he can live his life in relation to his spiritual 
beliefs, which draw no distinction between housed and unhoused; a place where he submits himself to the wider nexus of relations within which he is enmeshed.

In this way, Spirit's relationship to place and environment is mediated by an interplay of agency and patiency. Between what he knows, can control and manage, and the factors beyond his control and comprehension, lying largely outside his reach (Jackson 2016, 308). Jackson characterises these modes of thinking as "an active, disciplined, focused application of thought to being, [while] the second characterise[s] a more passive, attentive, openminded approach in which the thinker simply registers or channels thoughts that appear to come from elsewhere" $(2016,308)$. In the case of living on the streets, which can be at times, emotionally, physically, and existentially discomforting and arduous, where one's movements and experiences are often shaped and dictated by processes of exclusion and containment over which Streeties have little power, being 'active' all the time would be exhausting. Patiency, or rather submitting oneself to a situation largely beyond one's control, allows Spirit to find peace of mind in the processes of the city. He resigns himself, in this way, to the texture of the lived-in city. Though, this is always mediated by activity, an engaged way of thinking about and acting within one's lifeworld.

His responsibility to others was vital to the sense of self he had developed living on the streets over the years, and was intimately connected to his spiritual orientation and perception of home, which was not geographic place bound, but was rather a mode of activity, of life carried out in a given landscape:

Jonathan: What do you think it will take for you to feel ready?

Spirit: Probably a wife! [laughs] Job... aww I just wanna get me a car bro, then just stay in the car and go for a bit of a holiday, have a break from this sort of shit. This good shit [laughs]

Jonathan: Why do you wanna car? To travel?

Spirit: Yeah just to stay in and get around New Zealand for a little bit. Then get a job and back to normal life you know? 
Jonathan: What kind of job would you like?

Spirit: Anything so I can save up bro! Even just volunteer or I dunno, I'm not sure. I don't really know where I'm going yet, or what I'm doing. I just know god hasn't finished with me out here yet.

Jonathan: What do you mean by that?

Spirit: Aw cause I've been taking some back to go indoors. Even one of the bro's just come in on his own and then like I went by him for a night cause he's having a bit of trouble out there and he's detoxing, so yeah, it's all good though.

Jonathan: Is that another streetie?

Spirit: Yeah. There's a few others I've been trying to take back but they're not ready. It's just being out here so they, you know, if I can get one a week or one a month it's still all good, you know?

He looked after other Streeties by mentoring younger people, keeping an eye out for those who were struggling, and linking up newcomers with the necessities they need to survive on the streets. This was evident during the night I slept rough, when Spirit arrived with the man who he found walking around the city. Having initially met Spirit at the beginning of the night, he had spent the rest of the night out hustling, while we set up a cardboard camp in a sheltered carpark. Around 3am though, I was awoken by the sound of his voice. He had arrived at the camp with another person called T. After they had a conversation in town, it turned out $\mathrm{T}$ had nowhere to go and was sleeping rough for the first time in his life after being laid off from work. Spirit brought him to our camp site to set him up with a place to sleep, gave him his blankets and a pillow, made him a makeshift bed, got some food for him and introduced him to the others, informing them to show him where the soup kitchen was and any other services he might need. 'Don't worry, we'll look after you brother!' He said, assuring The was in good hands.

The next time I saw Spirit, I asked how they had crossed paths: 
Aw he just happened to walk past me the first time I hit him up for a smoke, a cigarette, to buy a smoke off him and he didn't have one but he said he'll come back with one, then I seen him go past again but sorta like, aww I dunno if I should say it but, you know how you sort of have little gifts and you can see peoples' needs and, you know what I mean? I could just feel it from him, and I hit him up and he was staying on the streets bro! And yeah, it was actually his first night out here so that's why I bought him over there, cause the food was there and gave him my blanket just so he could have a sleep and rest... he was exhausted as, cold, hungry, yeah...

Spirit found it hard to keep busy once he transitioned to living indoors. Living on the street, he was often out earning money, finding food, talking to members of the public, looking after other Streeties, breaking up fights outside the Courtenay Place nightclubs or watching out for places to sleep. Once inside, he was no longer engaged in these activities, but there was also nothing to replace the sociality of the streets and he had an increased amount of time with his thoughts, leaving him feeling isolated. Moreover, much of his life on the street entailed a sense of responsibility to others. He had a responsibility to the environment he was inhabiting; environment in this context being the surroundings that Spirit makes home, including Burger King, their staff, the public, the streets, other Streeties and shops. Living in a house, far away from the street removed him from the role he played on the street, or at least, limited his capacity to fulfil it. Thus, his sense of increased time and lack of sociality was also accompanied by an erosion of the place he had developed in this world. Living inside undermined his ability to manage relationships with others.

\section{Conclusion}

House and home are not neutral concepts, but are politically charged and contested categories with specific cultural and historical trajectories. Their meanings are not innate, nor emergent from a universal logic, but denote a particular way of relating to the world. The very essence of house as a bounded concept, and home as innate, obscures the exclusionary practices which underpin private ownership and access to bourgeois values. Moreover, they ignore the ways people, who have been forced to carve out new kinds of homes, make their lives on the street and in makeshift encampments along the green belt. 
The meanings my participants attributed to home arose from their experiences of both the bounded, fixed structures we call home, and the places where they grew up, and were often associated with violence, betrayal and traumatic experiences. Once on the streets, their experiences of being housed often involved being extracted from the worlds they had created, derived meaning from and bore a responsibility towards, while failing to acknowledge their reasons for living on the streets. In contrast to indoor spaces, where Spirit sometimes felt unwelcome, uncomfortable or diminished, on the street, he was comfortable, his knowledge was useful and he was familiar with the world, both in its protocol and etiquette and in the sensory experience it provided.

Home, being and belonging did not necessarily exist in the substantive, be it a physical dwelling, a piece of land or a family, though it could be expressed through these outlets. Rather, it was about feeling 'at-home-in-the-world', "when what we say or do seems to matter, and there is a balanced reciprocity between the world beyond us and the world within which we move" (Jackson 1995, 154). Home, to Spirit, was not geographically confined, nor temporally permanent, but was a "node in a matrix of movement" (Ingold 2000, 219). It involved a flux between active participation, playing a part in various social and moral economies, and submission to his circumstances, treating the open spaces of the city as a sanctuary where he could relax, heal and find peace with himself. If we can loosen up our hold on the house as a necessary preclusion to a sense of meaning, being and belonging, we can begin to create more just and successful living spaces.

Spirit's understanding or experience of home was not defined by a material dwelling or bound by place, but by the sense of comfort he gained from living his life on the street, the connections he made with other Streeties and the public as a result. It was the sense of control and autonomy he had over his journey through life, and this did not always find expression in either substantive thoughts or dwellings:

Jonathan: How do you think you know when you're ready?

Spirit: Dunno. You'll be sick of being out here I spose. Or just wanna change. Just like how you know what you wanna do in your life probably.

Jonathan: Sometimes, sometimes I don't [laughs] 
He was quick to point to the similarities underpinning our motivations and interpretations of experiences despite our significantly different circumstances. When I asked him how he will know when he is ready to leave the street, he threw the question back on me, forcing me to reflect on both the question I had asked and how I would answer. 'Readiness' whether homeless or housed is often a state defined by ambiguity and indeterminacy. Our immersion in the world and our relationship with the future is necessarily mediated by our inescapable home in the here and now, which makes it hard to objectively define what we need out of life.

In fact, he touched a raw nerve because much of my life at that stage, was characterised by uncertainty and unknowing. People would ask what I was doing next, whether I had plans or knew the direction I was heading, and although I had a series of well scripted answers to fend off these enquiries, underneath the surface I was not sure what was coming next. I had ideas and desires, but these were not always concurrent with people's expectations of where or what I should be doing. Consequently, I felt I was often navigating the dissonance between outward expectation and my personal sense of self. Thus, while our circumstances, and the respective trajectories shaping our movement, may be radically different, I could on some level relate to Spirit's feelings of indeterminacy and the subtle everyday negotiations he was making. In this situation, the perceived solution to Spirit's state of homelessness created friction with the way Spirit chose to live his life, disrupted the role he had carved out for himself, and the meaning he derived from this role. The streets, while not a long-term solution, provide him a place within which to negotiate the future on his terms:

Spirit: I just wanna stay out here and just think, have a bit of time to think and, cause it's coming to crunch time soon, I know it. I can feel it.

Jonathan: What's crunch time?

Spirit: Just sorta you know, my times coming to fucken get off here. So I just sorta love it while I can, instead of like, you know, so I don't miss it too much. 


\section{A Hope for Life}

As with goodness and reasonableness, our difficulty of achieving wellness does not diminish its hold over our imaginations, for it signifies a hope without which existence would be untenable - that life, for ourselves and those we care about, holds more in store for us than less (emphasis added; Jackson 2011, i)

Spirit and I sat outside the entrance to Burger King on Courtenay Place, and discussed his hopes for the future. A few people stopped to give him some change, while others walked by, stealing side-glances. Spirit joked that people probably thought I was a Streetie because of my shaved head, beanie and baggy jacket.

Jonathan: Do you think you'll always live on the street?

Spirit: Na, cause I don't want to anymore, you know? Hopefully this is my last year. Aw well that's what I'm going to try and do anyway. I just wanna get a car bro and then it will be all different from there.

Jonathan: Would you rather move into a car than a house?

Spirit: Yeah, if I'm still single, yup. Or even if I found a missus that wanted to travel around and just live it rough in a car. Just get a gas cooker you know, and some pots and shit. Soon find places to have a wash, every day. Just enjoy life bro, you know? Fuck going to work for fuck all. Aw at the moment anyway. I'll settle down eventually. Hopefully in another month I'll sort of have a more clear idea of what I want to do.

Thinking about hope conceptually, as a certain kind of intangible yearning for change, began to take on more significance for me as I reflected on my fieldwork experiences and the lifeworlds of my participants. It appeared to be intimately linked with the way they structured their lives, both in relation to other people and places, as well as with their sense of existential satisfaction. In this chapter, I want to explore the interplay between hope, 
space and temporality; the ways in which present hopes are informed by past circumstances and experiences, and the way imagined or potential futures influenced my participants' actions in the present, and their intersection with movement through space. I am interested in the role hope played in their lives and why their expressions of hope are often imbued with an indeterminacy. I wanted to know if hope functioned as a catalyst for change and action, or if it was a sign of powerlessness, a way of coping with the present they had little chance of altering. Moreover, I was curious about what their hopes revealed about their desires, values and needs to get by, make meaning and live well - how did the relationship between hope and well-being influence the conditions in which my participants negotiated everyday life and their relationships with others?

I begin by exploring the way hope has been conceptualised in the literature, drawing on both anthropology and philosophy. I proceed to problematize the distinction between hope as being either active or passive, suggesting that in the lifeworlds of my participants, it was neither clearly one nor the other. I argue, rather, that its expression was conditional on a range of intersecting factors, such as their current state of mind, their relationship to peers, partners, authorities, and other inhabitants of their lifeworld, their ability to access resources, and the ways they rationalised and made sense of their situations. I then look at the ways in which my participants' movements through space, both geographically and socially, have been shaped by their desires and hopes for change, continuing to tease out the dichotomy made between active and passive modes of hope. I argue that my participants' hopes were shaped by a desire to get by and live well, both in concert with themselves and with others. This involved a struggle of both exercising their will to bring about change in their life when required, and submitting themselves to the currents of lived activity, when they did not have the resources or power to resist. I suggest that both being in control, and forfeiting control were necessary in the management of their well-being, and ability to navigate life in the margins. Well-being, however, was never stable, and was contingent on a multitude of factors, fluctuating as Streeties negotiated their relationships with others and their own sense of self. Similarly, the connection between their hopes and well-being was equally tenuous. Thus, in the final section I explore what happens when Streeties were no longer able to balance agency and patiency, and their hopes are eroded. 


\section{What is 'Hope'?}

Understanding hope as a conceptual category requires navigating its use as a term, which is often vague, elusive and imbued with a plurality of meanings. Hage highlights that the language of hope, as well as being associated with significantly divergent aspirations (ranging from ice cream, for example, to world peace), can also be divided between affect and affective practice $(2003,10)$. Affect relates to something one has, while affective practice is something one does. Hage suggests there is a difference between "hope as a momentary feeling and hopefulness as an enduring state of being" $(2003,10)$. Psychologists, meanwhile, have attempted to categorize these pluralities of meanings and clarify their distinctions. Farran, Herth and Popovich (1995), for example, were interested in hope and hopelessness as theoretical constructs that impact the health and bodies of hospital patients (Walker 1996, 44). They highlight that the elusiveness of hope is tied to its various expressions, "as a way of feeling (affectively), as a way of thinking (cognitively), and a way of behaving or relating (behaviorally) (Farran et al. 1995, 5).

Philosophers, less concerned with breaking hope down into analytic categories, have also mused on the relationship between hope and our very being in the world. Although there are a multitude of meanings associated with the word hope and many conceptions of the idea of hope, most agree that it is oriented toward a vision of the future. Some view it through a positive lens of the possible, while others see hope as a negative, a force that deludes us from addressing our present ills. Nietzsche belongs to the latter camp, equating it with "the worst of all evils, for it protracts the torment of man" $(1986,45)$. Arendt (1998, 178), on the other hand, associates hope with the unexpected, the potential for new beginnings, which underpins the formation of all existence, stating:

The new always happens against the overwhelming odds of statistical laws and their probability, which for all practical, everyday purposes amounts to certainty... The fact that man is capable of action means that the unexpected can be expected from him, that he is able to perform what is infinitely improbable. 
Ernst Bloch $(1988 ; 1995)$ also saw hope as a yearning for something new, something missing from our lives, which we may have once possessed; a future, which orients us in such a way that it can be said to be unfolding in the present. Speaking with Adorno, Bloch (1988) defended the role of hope in utopian projects, focusing on Thomas More's vision of an island utopia in the South Seas. It is not something that yet exists, but neither is it entirely a fiction, "rather it is not yet in the sense of a possibility; that it could be there if we could only do something for it. Not only if we travel there, but in that we travel there the island utopia arises out of the sea of the possible - utopia, but with new contents" (Bloch 1988, 3). Bloch characterizes this unfolding in the present as a 'pregnancy of the present', and Hage argues that the difference between 'realistic' and 'unrealistic' hope can be captured by 'the extent to which hope is grounded in 'the pregnancy of the present' as opposed to being totally detached from reality" $(2003,11)$.

Anthropological scholarship on hope has looked at its relationship to individual and collective agency (Gibson 2011; Zigon 2009; Miyazaki 2006; Crapanzano 2003; Hage 2003), though, considerably less has been written on the intersection of hope and well-being, Jackson (2011) being the notable exception. Because agency is often discussed in terms of intentional action, and an individual or groups' ability to act (Ortner 2001, 77), questions concerning hope have often centred on whether or not it is active or passive, realistic or unrealistic, inspiring direct, tangible action (having agency) (Miyazaki 2006) or whether hope in its very definition is passive because it necessarily relies on the intervention of an 'other' (lacking agency) (Crapanzano 2003). These discussions have often centred on the distribution of power and an individual's ability to act within a set of circumstances, usually focusing on how successfully an actor is able to resist the dominant structures of society, which may be impinging on their livelihood. To understand the way in which agency and hope are unevenly distributed in society, Gibson (2011) focused on their relationship to 'being'. Her argument builds on Bourdieu's concept of being, which "refers to a meaningful human life, one's sense of identity significance and purpose, and is something that we all struggle to accumulate throughout our lifetimes", and his proposition that hope is an emergent capacity of our being (Gibson 2011, 14). 


\section{Active or Passive?}

Hope, in the lifeworlds of my participants, far from being solely active or passive, appeared to be in motion, though its expression was murky, ill-defined and not necessarily future oriented. Rather, hope was embedded in a kind of epistemological and ontological stance; a way of thinking about the inhabited world, of acting within it, and of submitting to its rhythms. This hope-in-motion was continually issuing forth in the present but elements of both the past and future intermingled to give it its distinctive shape and character. This was expressed, for example, in Spirit's characterization of his life as a journey towards an unknown and often changing destination, geographically and spiritually, or the way Wayne oriented his actions in the present, out of the reflections of past misdeeds.

Likewise, hope was not simply contained within an individual and expressed outwardly, but was generated within the currents of life activity, contingent on relationships with other people, objects, ideas and changes in circumstances. Pita's hopes, for example, ebbed and flowed as he moved through states of homelessness to being housed. In his desire to overcome his alcoholism and gain more rights to spend time with his daughter, or in his need to drink and drown out the sensory overload of the city for sleep, and the consequently turbulent relationship with authority figures he had to manage. His hopes were oriented by his desire to retain his autonomy, while simultaneously requiring the assistance of others. His ability to balance relationships with his social connections from the streets without losing his housing rights, and in his capacity to find and sustain work to support himself and treat his daughter, despite a criminal record and social stigma, were all important factors contributing to his ability to hope.

Zigon has attempted to overcome this passive/active dichotomy in his work alongside his Muscovite interlocutors by suggesting that rather than either/or, hope should be understood in "its shifting aspects of both/and" $(2009,258)$. He observes two aspects of hope in the lives of his interlocutors. On the one hand, it can be considered as a stance of existential being-inthe world, whereby hope operates in the background sustaining an individual to live and persevere through life, somewhat resembling the passive mode of hope. While, on the other, in times of moral and social breakdown, when life is called into question via conscious 
reflection, hope can behave as a catalyst for taking intentional and ethical action towards improving one's existence. By focusing on the temporal dimensions of hope, Zigon (2009, 258) argues that we can better understand how hope serves to motivate us to persevere through the life we are thrown into. Thus, hope is not necessarily oriented towards a better future, but the perseverance in the present of a sane life.

Such an approach still largely characterizes people's ability to make it through life as a struggle against some greater power, defined by their capacity to work towards positive change, or to begrudgingly weather the conditions of a life that remains largely outside of their control, albeit acknowledging a level of fluidity between the two. In the lifeworlds of my participants, however, it was not always a struggle against a formidable force where people appeared to derive existential meaning. Sometimes it took the form of stoically persevering through the present, but it also expressed itself in their ability to glean a sense of satisfaction from everyday life. It was a hope to live well, then, both in themselves and in concert with others that motivated their movements and actions in the world. This was aptly reflected by Spirit's cardboard sign:

Smile and be happy

Or when he made fun of my guarded presence:

Spirit: You don't show much emotion do you?

Jonathan: Me? Yeah, I guess I keep a pretty straight face...

Spirit: Guarded, haha your poker face! Ohh there's a smile! I've just been through enough in life bro it's like fuck, might as well just be happy.

Peoples' sustenance emerged from their capacities to form and sustain positive relationships with other people and things of value to them, to retain a sense of ownership and autonomy over their trajectories and circumstances, and to create or maintain a feeling of self-worth and fulfilment despite the conditions overshadowing their lifeworlds and positions as social and economic outsiders, without the resources or power to mount a challenge against the system. 
It was their ability to manage these factors, to make and derive meaning, in and from their circumstances that appeared to be acutely linked with their sense of hope. My participants' ability to work towards the maintenance of these ideals was always historically constituted, as well as embedded in sets of cultural, social, political, economic and material relations that sometimes sought to thwart these endeavours, or at the very least, limit their capabilities, but their livelihoods just as frequently escaped the total grasp of the conditions of their possibilities (Jackson 2013, 8).

\title{
Hope, Movement and Time: Journey Through the Present
}

\begin{abstract}
I'm on a spiritual journey. I actually followed the Holy Ghost, the Holy Spirit and was meant to come down here. Took me a wee while to get here but yeah, cause even the energy in Auckland changed. I could feel it I didn't wanna be there anymore and then I got directed to here. I've only just recently gone indoors and now I only stay indoors about half the week, come back on the streets to help others get off the street - (Spirit)
\end{abstract}

Spirit's yearning for change drove him to leave Auckland in search of different possibilities. In contrast to the distinction drawn between active and passive hope in much of the literature, whereby passive hope is associated with a reliance on an unrealistic faith in external powers to shape their life conditions, Spirit readily submitted his trajectory, movement, desires and hope for change to a higher power. This departs drastically from the view that religion and religious hope - corresponding to passive hope more generally - blinds people to their social realities, making them less inclined to act to change their circumstance (Hage 2003, 11). This is an idea embodied, according to Fromm, by the man in Franz Kafka's 'The Trial' who patiently awaits permission to enter heaven, never taking the gumption to enter on his own accord. Hage suggests hope, in this example, "is seen not only as working against reality but also against knowledge of reality which can lead to its (hope) demise" $(2003,12)$.

In contrast, Spirit often spoke of being driven places by Spirits or God, or of fortuitous encounters that either involved his submission to a greater power, or the intervention of spirits, loved ones or benevolent strangers. Moreover, these calls to an unseen higher power 
did not work against knowledge of reality but were embedded in, and embodied by, reality. The way one thinks about their world is always mediated by their experience of it, thus they cannot be separated. Spirit mentioned to me awhile later:

I was on a journey of getting sorted anyway cause I actually left Auckland as well to give up drugs and shit like that.

Evidently, the Holy Spirit was not taking him on a journey to Wellington for the sake of it, but was connected to his desire to get away from drugs and find something new; somewhere he could live a better life in line with his values. During our second interview, Spirit expressed reservations about a trip he was taking to Auckland the following day. He was going to meet up with a female friend, and potential love interest, who had an abusive ex-partner. When I asked him if this made him uncomfortable he stated 'I don't even wanna be up there bro. It's like going back, back to the past going up there. I just can't be bothered.'

Similarly, Katelyn, resisted calls to travel back to her parents' home in Gisborne, despite living on the street:

My family said to me I'd have to come back to where they were staying and stuff. But that wasn't an option, that's the reason why I had left Gisborne and everything, so I could be someone. Not bum around and be on the benefit and live off my parents and everything... I explored and left, and my parents had always said to me 'aww well you can come back home but we won't give you money and stuff' and I was like, well it's kind of pointless, so I didn't. It was a good option but it wasn't an option for me, because if I had have gone back I would've been back drinking, I probably would have been smoking weed, probably $\mathrm{P}$ and everything because that's what that lifestyle is, that's what that circle is, and cause I had made progress in the bridge program ${ }^{17}$, I just thought I would've wasted everyone's time that had helped me to be clean and sober, to go back, just because I'm homeless, so I didn't make it an option.

All my participants had been in limited supply of socially legitimate forms of being, and the consequent choices, forms of intentional agency they could exercise, and ways in which they could hope were all shaped by these circumstances. Thus, they manoeuvred as life allowed

17 Preparing for work bridging program 
them to avoid the situations which ran counter to their hopes and desires, be it remaining clean, or making an independent life for oneself. Wayne, for example, hoped for a future in which he was around for his grandkids in a way that he was not able to be for his children. He wanted them to be proud and to show them he was a productive and creative individual. Though this was not without its own struggles:

I've been on hard drugs and alcohol too long. I've been in and out of prison for the last 20 years. Have been out 5 years now, but it's hard. You know, sometimes I wanna commit a crime just to go back in. You know, it's like in there I'm a fuckin' somebody. I have what I need, I'm respected. I'm known and I know people. Out here I'm on the fuckin' streets, nothing.

For Wayne, living on the streets represents a complex choice, and illustrates the arbitrariness of drawing too clear a distinction between agency and patiency, and active and passive hope. His hope is future oriented, in that he is thinking about where he might be in $5-10$ years' time for his grand kids, as well as being mediated by his relationship to the past, that is the decisions he has made which have impacted the kind of life he is able to lead. Thus, although it is grounded and unfolding in the present, his hopes are not necessarily realistic, nor inspiring direct action. What they do serve, however, is a potential future for him to imagine, and to work towards, to make life liveable in the present. Moreover, while he has actively avoided violent crime and theft, both an act of choice and constrained agency, living on the streets, for Wayne, involves a submission of himself. He lost the being he had accumulated in the world of crime and prisons, and instead made his living through begging.

Despite these constrained choices, my participants were not always motivated by doing their best to survive, but also by a desire to live well, have fun and experience positive relations with others.

\section{Hope and Well-Being}

I walk round and smile, say good morning and all that, have my shit days just like everyone else, have good days all the time too! You know what I mean? We're just all the, you know, we're still human. Have laughs and be, you know, you already know, you've met a couple of the bros! [Laughs] - (Spirit) 
Well-being is not easily defined or located, nor is it a permanent or stable state of being (Jackson 2011). As a concept, it has largely been ignored by sociocultural anthropology, left instead to the realm psychologists (Thin 2009). This is perhaps due to anthropologists' aversion to western measurements of well-being, which tend to draw their structure from a biomedical worldview of mental health, lending themselves to ethnocentric interpretations, whereby happiness is viewed through the prism of the individual, as having a stable or abiding character', becoming something we either 'have' or 'lack'. In reality, however, understandings of wellbeing, and what constitutes wellness, remain much more aloof, escaping the grasp of both those with and without power. Existential dissatisfaction experienced just as frequently by the wealthy and privileged, as the poor and marginalized. As a field of struggle and contingency, well-being is "elusive, transitory and unevenly distributed" (Jackson 2011, i), though Matthews and Izquierdo $(2009,5)$ have attempted to define it, "Well-being is experienced by individuals - its essential locus lies within individual subjectivity - but it may be considered and compared interpersonally and interculturally, since all individuals live within particular worlds of others". I would add to this that it should be understood intersubjectively.

Hodgetts and Stolte (2016) argue that leisure is critical to the well-being of homeless people, yet it remains a critically under researched area. Although the lifeworlds of my participants were often characterised by pain, loss and suffering, they were also filled with moments of joy, laughter and sociality. Moreover, for many of them, living well and sustaining positive relations with either partners, family members of friends motivated them through their lives in the present.

Spirit's well-being was often dependent on his relations with others, fluctuating as friendships and relationships developed and dissipated.

\section{Breakdown of Hope}

Just as hope is synonymous with the possible, it is equally tempered by the impossible. The conditions that give rise to our ability to hope also give rise to insecurities and anxieties, and to feelings of fear that our hopes may never be fulfilled, or that when they are fulfilled we will be disappointed. In this way, Jackson (2011), argues that hope should never be conflated 
with confidence. Moreover, the presence of hope necessarily implies the possibility of hopelessness. Thus, we are all involved in a struggle to manage our hope and balance it against reality.

Miyazaki (2006) analysed the loss of hope among left thinking social theorists in the latter half of the $20^{\text {th }}$ century following the fall of socialist regimes across the world and the rise of neoliberalism. He noted that the inability of the left to imagine an alternative future had resulted in a loss of hope and frustrations among its ranks (Miyazaki 2006, 162). Philosophers and theorists, such as Mary Zournasi (2003) and David Harvey (2000), argue that the left had fallen behind the rise of mass media, and failed to match the speculative spirit of capitalists, as well as balance their critiques of capitalism by postulating alternatives to the current neoliberal global order (Miyazaki 2006, 162 - 163). In their view, it was necessary for leftist thinkers to recapitulate hope in their analyses, to be active subjects, and to work towards emancipatory projects.

This analysis produces a few interesting points and tensions. When one's realistic hopes, in this case leftist thinkers who had recently witnessed, or been a part of, crumbling socialist regimes and movements across the world, are unable to be realised, one's creativity and ability to imagine other possibilities becomes stunted and feelings of frustration, disappointment and anger emerge. In contrast, large and mostly unrealistic hopes are cast as a positive form of future oriented thinking. The spirit of speculation, the courage of the mind, and the ability to be an active agent become key tenets of a positive framework for hope, despite the indeterminacy of outcome.

In this sense, our feelings of hopelessness do not necessarily emerge from a failure to live up to big dreams, but from an inability to manage or grasp what we expect to be within our power. In contrast, indeterminate hopes and open ended desires for change, are never seen as being immediately achievable or realistic, and instead serve as a motivation for living life, for thinking about life, for venturing suggestions as to what one needs out of life to live well and be content, and for making life liveable in the present. 
Indeed, this was often how hope and hopelessness were expressed and experienced by my participants, and where tensions arose. Katelyn's disappointment stemmed from her inability to change her immediate situation. She felt like a failure, despite having to support both herself and her partner, who was sick and was required to carry a colonoscopy bag with him always. Although she faced significant barriers to getting off the street, she still internalised feelings of shame, guilt and embarrassment, mostly stemming from her inability to alter the immediate hardships she and her partner were facing. Her resilience wore away and, at times she found herself drinking more, and hanging out with people who had similar issues, while trying to maintain a façade of normality:

\footnotetext{
The way that I maintained myself, the way I held myself, I wasn't sad about it, I never showed anyone really my true feelings, because I was already stressed, the world was on my shoulders and I had to carry my partner. And he just didn't get what to do being homeless, it was just terrible... broke my soul, cried heaps of times at night, I think I cried a few times in the day time in front of the homeless, just the situation.
}

To make life liveable, Katelyn had to come to terms with the reality of what she could alter in her situation. Living well became entwined with being able to stoically endure the hardships of the present. This was emphasised by the obligations she felt to her partner:

My partner had already crumbled, so if I crumbled, I would be no use, we both would be of no use to each other and we would've still been in that situation now you know, not being housed. So me, I decided that if he can't maintain our lifestyle and everything, mentally and physically, then I was the next person.

While she accepted her immediate situation, Katelyn held on to a hope that their circumstances would be alleviated in time. Indeed, at a court hearing for breaching bail earlier last year, the judge found out she was sleeping on the street and immediately ensured contact was made with Housing New Zealand. Within a month, she was living in a council flat, despite her years of being told she was not priority. Zigon $(2009,262)$ argues that where we expect to find hopelessness, is often where we stumble across hope. This is because those with comfortable and convenient lives, do not experience the state of hope as a necessary precondition to survival. Hope, in this way, Zigon (2009) argues, is born out of socio-historical 
circumstances and personal experiences of struggle. His Muscovite interlocutors suggest that hope is necessary to persevere and live through difficult times. Hope, to some extent, is a substitute for those without power; a way enduring hardships they would be able to alleviate, provided they had access to forms of power.

This mirrors elements of Jackson's $(2013,19)$ argument that agency, or exercising ones will on the world, must often be balanced by submission, by stoically accepting what cannot be changed, in the lives of those who face significant external burdens or hardships. This does not mean that one is passive, but that "subjection must be place on a par with agency as a human coping strategy" (Jackson 2013 19). Ironically this runs into friction with neoliberal narratives of personal responsibility, which often encouraged individualised forms of 'agency', through both government institutions and social service provision. As Desjarlais (1997, 204) observed in the homeless shelter where he researched, the "staff's understanding of agency meshed with themes central to the cultural values inspired by capitalism and the industrial revolution (autonomy, self-sufficiency, productivity, progress, reliability)". The danger of this approach is that it can encourage or force people to focus too intensely on altering themselves, or being acting subjects, without understanding the pressures or external barriers they face to overcoming their situations. People who have had to endure tremendous difficulties, live in precarious situations, or experience trauma, can experience overwhelming feelings of failure and suffering when they are required to confront their realities in this way.

Pita, for example, partook in a preparing for work bridging course during my research, which was intended to help him address his personal barriers to work. He attended literacy workshops, examined his criminal record, went to counselling and addiction services and CV writing workshops. Out of the twelve people who started the eight-week program, Pita was one of only four to complete it. At first, he was feeling hopeful and optimistic that he was going to get a job and his situation was going to change. Slowly as the weeks passed on, he received more and more rejection letters, and I saw him become increasingly frustrated. Still struggling financially on welfare and living in a council flat, Pita had done his best to be an active agent, taking steps to address his personal issues, with the implication that he would be uplifted, but he remained stuck. This can cause tensions in his relationship with himself, 
with other people and with institutions. In this case, he resented having to dig up his criminal history to 'face' his past, as he now felt this was what was holding him back.

While Spirit, on the other hand, readily submitted the trajectory of his life to his hope and belief in a benevolent higher power, he occasionally found himself face to face with reality. This was sometimes brought on through interactions with his partner, and at other times with social and counselling services, and the general stresses of daily life. His well-being, and sense of hope was never stable, and was often compromised, sometimes by the lack of stability afforded by his living situation, but was also brought on by a reality, which when unmediated by the will of a higher power, was rife with personal pain:

I was supposed to start counselling but I sorta done one session... cause I actually committed suicide last year. This was my second time but this time I died. One of my good friends saved my life. She's like sorta helped me wean off the streets a bit, but, at the end of the day when like I've left her, I've always come straight back bro. But yeah, I hung myself then she just got pushed out of the room by a feeling, a spirit, whatever you wanna call it and I was in the other room hanging bro. I was purple, gone. And she cut the thing down and then she couldn't undo it, and then she prayed like you know, prayed to Jesus like, you know 'don't take him, he's a good man blah blah' and then the thing around my neck just came loose on its own and it took yeah, it took them like an hour til they sorta brought me back properly and took me in the ambulance to the hospital.

Earlier that week I had a counselling session, so I think counselling's not that good for me. It sorta just touched all the raw nerves sorta thing and then a little thing just sparked it off and then it all overwhelmed me and it's like you're falling bro. And you can't even claw your way out bro or grab on to the light or anything. It's quite, yeah, then everything that overwhelms you, you just sorta turn it on yourself and then boom, no good bro.

It wasn't the fact of being on the streets, it was like missing my kids and a lot of things bro. Yeah just having dramas in your life, having a shit day at the same time. Like fuckin no money, fuck all food. Yeah just a lot of little things that just sorta built up. Then, cause I sorta isolate myself a lot, even with the bros; wasn't even talking to them, they didn't even pick up on it. Then I took off, I just wanted to leave this side of town I just, fuck, I had enough, I just didn't even wanna see public, you know? 
Without reality being mediated by his spiritual relationship, the day-to-day stresses of Spirit's life became overwhelming; the lack of relationship he has with his children, his struggle to wean off the streets as he puts it, and the inability to manage his everyday livelihood. During these times, Spirit is often negotiating his relationships with others, be it friends, helpers or strangers, and with space, moving in search of respite and change. He would often remove himself from situations, mediating his relationship with others by spending time on his own. This can also create friction with the texture of homeless spaces, where family values are encouraged, or where there are large congregations of other Streeties:

I'm sort of a loner anyway. Couple of the boys I can sort of be with but just not all of them aye. Sort of yeah, different pages, different strokes for different folks, I dunno what you'd call it. We're all bro's but yeah. Even out here I was always by myself, you know? Stay by myself and stuff. That's why you didn't see me sleep where everyone slept that night, you know?

This reflects the tension implicit in our humanity being both shared and singular; in the desire to retain our individuality and experience union with others. It is a paradox of plurality, Jackson $(2013,6)$ states, where we define ourselves in relation to others, identifying with them, while simultaneously seeking to differentiate ourselves. A situation that especially difficult to manage and mediate when living on the streets.

This is not to suggest that agency does not have a place, nor that family values or sociality should be cast to the side. What I am arguing rather, is that we need to understand the volatility of well-being and the way people enact coping strategies that draw on both agency and patiency to get by and live well; as well as the tension between maintaining one's individual needs in an environment where their choice of sociality and dwelling is limited, and people's need to be a part of something more than themselves, such as a community. I argue that understanding the way people hope reveals their needs, desires and values, as well as aspects of the barriers, which they face, and the ways in which they make life liveable in the present. Sometimes this includes stoically enduring the present, while at other times it involves laughing, having fun, and imaging a future where the allure of the new exists, an 
open-ended lifeworld, where Streeties and their loved ones can live well, a place to work towards. 


\section{Conclusion}

Underpinning this thesis, and tying all these chapters and film together, is a struggle to be and belong, and to carve out a space in the margins, where Streeties can make a life worth living. As individuals, the Streeties I met all had unique histories, dispositions and personalities, though there were also commonalities in their experiences. They all expressed a desire to maintain a sense of themselves as rational, thoughtful and intelligent human beings, who had relationships with others, found a sense of place and home in nontraditional living places, and had ambitions and hopes, which shaped their relationship to the present and the future. Equally, they found ways to exercise their will, to act in a way that was not concurrent with societal expectations and to challenge threats to their autonomy, in ways that sometimes undermined their access to resources and services. This did not mean they were always active agents, however, as being able to submit control of their trajectory to a higher power or external circumstances often became an important way of orienting oneself in the present, and persevering through what would otherwise be untenable hardship.

I have argued that the choices Streeties must make in their lifeworlds are always historically, socially and politically constituted. Experience and being, in this way, are mediated by their upbringings in low income, predominantly Māori communities, surrounded by unemployment, violence, and substance abuse. These intimate experiences of hardship and trauma growing up were bound up in histories of colonialism that found themselves continually manifesting in the present through neo-colonial practices, and neoliberal policies and rationales that promoted freedom, autonomy, and choice, obscuring the structural barriers, which had systemically undermined both poor and Māori communities. These rationales were embedded in the present, weaving their way through ideal notions of proper public space use, in the practices of state institutions and social service providers and in the discursive and symbolic understandings of homelessness and street life, as articulated by the media and prominent figures.

Moreover, the structural violence inherent to neoliberalism and neo-colonialism decimates bodies and wears away at Streeties' resilience. Their everyday experiences of life in the city 
are shaped by these practices, causing them to 'become' homeless in both a physical and existential sense. The choices they then make are often tied to getting by, and living well, in relation to the moral and social economies they are embedded in. However, Streeties lives are never totally encapsulated by the forces that have shaped their trajectories. They are always unfolding in the present, and the possibility to resist being subsumed by the structures of the city underpins every interaction. In this way, Streeties, such as Pita, find ways to subvert the normative social order by embracing their identity and life in the margins, making it work and finding ways to be happy and fulfilled despite the adversities they face.

Being and belonging did not necessarily exist in the substantive, but was rather defined by one's ability to feel comfortable in a space where their skills and knowledge were valued. It was never fixed, but borne out of activity and presence. Feeling 'at home', denoted a sense of being and belonging to a place where one matters, and to which one bore a responsibility towards in a world that felt familiar. Sometimes government initiatives, which focused on housing people, alienated Streeties, isolating them and removing them from the social and moral economies where they derived their sense of self and meaning. This can have serious repercussions on their ability to live well. In the case of both Wayne and Spirit, moving inside made them feel uneasy and uncomfortable. They felt like they were imposing on others, and like they lacked control over their situation, while they were simultaneously no longer able to partake in the activities that gave them a sense of fulfilment, seriously eroding their being. Hodgetts et al (2014) and others have questioned the practices of governments in these instances, suggesting that their solutions appear more focused on managing and sequestering the poor.

I demonstrated that the house as a material dwelling, and the meanings we associate with home, are not innate but have a specific cultural history, arising from the enclosure movement of $17^{\text {th }}$ century in England, and culminating in the emergence of suburbia in the $19^{\text {th }}$ century. These meanings have persisted into the present and form a habitus of walls and enclosures, where we seek security in substantive things, both places and ideas. As Jackson (1995) says, we feel less at home with indeterminate horizons. Streeties, though, who have experience home as violent, traumatic or oppressive spaces, seek out the respite of nature, of the city and of makeshift dwellings. Red could heal while living along the green belt in her 
tent, while the open spaces of the city, for Spirit, served as a sanctuary and respite where he could relax, heal and find peace with himself. Spirit's understanding or experience of home was not defined by a material dwelling or bound by place, but by the sense of comfort he gained from living his life on the street, the connections he made with other Streeties and the public as a result. It was the sense of control and autonomy he had over his journey through life, and this did not always find expression in either substantive thoughts or dwellings. If we can loosen up our hold on the house as a necessary preclusion to a sense of meaning, being and belonging, we can begin to create more just and successful living spaces.

What motivated Streeties through life, I have argued, was a hope to live well, both in concert with themselves and others. Rather than being active or passive, their hopes for the future, though often open-ended and indeterminate, helped them live well and sustain life in the present. I argued that my participants' hopes were shaped by a desire to get by and live well, both in concert with themselves and with others. This involved a struggle of both exercising their will to bring about change in their life when required, and submitting themselves to the currents of lived activity, when they did not have the resources or power to resist. I suggest that both being in control, and forfeiting control were necessary in the management of their well-being, and ability to navigate life in the margins.

This thesis has looked at what it means to be and belong, to be an autonomous individual, and a member of wider network of relations, what it means to feel 'at home' in the world, what it means existentially and discursively to 'be homeless', and what it means to live 'well'. It has done this by exploring the way Streeties in Wellington carve out new spaces for living, how they construct their sense of self, and the ways in which they hope for a better life and relate to their environment through both film and text. 


\section{Bibliography}

Anderson, Ian, Sue Crengle, Martina Leialoha Kamaka, Tai-Ho Chen, Neal Palafox, and Lisa Jackson-Pulver. 2006. "Indigenous Health in Australia, New Zealand, and the Pacific." Lancet 367: 1775-85.

Arendt, Hannah, and Margaret Canovan. 1998. The Human Condition. Chicago: University of Chicago Press.

Bauman, Zygmunt. 1995. Life in Fragments: Essays in Postmodern Morality. Oxford: Blackwell.

Bauman, Zygmunt. 2005. Work, Consumerism and the New Poor. London: McGraw-Hill.

Baxter, Ellen, and Kim Hopper. 1981. Private Lives/Public Spaces. New York: Community Service Society.

Bloch, Ernst. 1995. The Principle of Hope. Cambridge: MIT Press.

Bloch, Ernst, Jack Zipes, and Frank Mecklenburg. 1988. The Utopian Function of Art and Literature: Selected Essays. Cambridge: MIT Press.

Borchard, Kurt. 2005. The Word On The Street: Homeless Men in Las Vegas. Reno, Nevada: University of Nevada Press.

Borell, Belinda. 2005. “Living in the City Ain't so Bad: Cultural Diversity of South Auckland Rangatahi" Master of Philosophy in Psychology Thesis, Massey University.

Bourdieu, Pierre. 1998. Acts of Resistance: Against the Tyranny of the Market. New York: New Press.

Bourgois, Philippe, and Jeff Schonberg. 2009. Righteous Dopefiend. Berkeley: University of California Press.

Bourgois, Philippe. 2011. "Lumpen Abuse: The Human Cost of Righteous Neoliberalism." City \& Society 23, no. 1 (Wiley): $2-12$.

Braun, Kwame. 1998. Passing Girl, Riverside: An Essay on Camerawork. 24min.

Brenner, Neil and Nik Theodore. 2002. "Cities and the geographies of 'actually existing neoliberalism.' In Spaces of Neoliberalism: Urban Restructuring in North America and Western Europe. Edited by Neil Brenner and Nik Theodore, 2 - 32. Oxford: WileyBlackwell.

Bryers Brown, Tarapuhi. 2015. "'He Reached across the River and Healed the Generations of Hara': Structural Violence, Historical Trauma, and Healing among Contemporary Whanganui Māori." MA Thesis, Victoria University of Wellington.

Buchli, Victor. 2013. An Anthropology of Architecture. London: Bloomsbury Academic, an imprint of Bloomsbury Publishing. 
Burrows, Alicia. 2017. "Sir Bob Jones Labels Beggars a 'Disgrace to Society.'” New Zealand Herald, January

http://www.nzherald.co.nz/nz/news/article.cfm?c id=1\&objectid=11783845

Castaing-Taylor, Lucien. 1996. "Iconophobia." Transition, 69: 64-88.

Castaing-Taylor, Lucien, and Illisa Barbash. 2009. Sweetgrass. Film. New York: The Cinema Guild.

Castaing-Taylor, Lucien. 2016. "Sweetgrass: 'Baaaaaaah. Bleeeeeeet.'” In Beyond Text? Critical Practices and Sensory Anthropology. Edited by Rupert Cox, Andrew Irving and Christopher Wright, 148 - 155. Manchester: Manchester University Press.

Checker, Melissa. 2011. "Wiped Out by the 'Greenwave': Environmental Gentrification and the Paradoxical Politics of Urban Sustainability." City \& Society 23, no. 2 (Blackwell): 210-29.

Cloke, Paul, Jon May, and Sarah Johnsen. 2008. "Performativity and Affect in the Homeless City." Environment and Planning: Society and Space 26, no. 2 (Sage): 241-63.

Collier, John, and Malcolm Collier. 1986. Visual Anthropology: Photography as a Research Method. Albuquerque: University of New Mexico Press.

Collins, Damian. 2010. "Homelessness in Canada and New Zealand: A Comparative Perspective on Numbers and Policy Responses." Urban Geography 31, no. 7 (Taylor \& Francis): 932-52.

Corrections NZ. 2016. "Prison Facts and Statistics." http://www.corrections.govt.nz/resources/research and statistics/quarterly prison statistics/prison stats december 2016.html

Cox, Rupert A., Andrew Irving, and Christopher Wright, eds. 2017. Beyond Text? Critical Practices and Sensory Anthropology. Manchester: Manchester University Press.

Crapanzano, Vincent. 2003. "Reflections on Hope as a Category of Social and Psychological Analysis." Cultural Anthropology 18, no. 1 (Blackwell): 3-32.

Cross Party Inquiry. 2016. "Ending Homelessness in New Zealand." https://www.greens.org.nz/sites/default/files/Homelessness Cross Party Inquiry Report.pdf.

Desjarlais, Robert. 1997. Shelter Blues: Sanity and Selfhood among the Homeless. Philadelphia: University of Pennsylvania Press.

DeVerteuil, Geoffrey, Jon May, and Jürgen von Mahs. 2009. "Complexity Not Collapse: Recasting the Geographies of Homelessness in a 'punitive' Age." Progress in Human Geography 33, no. 5 (Sage): 646-66.

DCM Annual Report. 2015. https://www.dcm.org.nz/ 
Dolson, Mark S. 2015. "By Sleight Of Neoliberal Logics: Street Youth, Workfare, And The Everyday Tactics Of Survival In London, Ontario, Canada". City \& Society 27, no. 2: 116135.

Dooling, Sarah. 2009. "Ecological Gentrification: A Research Agenda Exploring Justice in the City." International Journal of Urban and Regional Research 33, no. 3 (Blackwell): 62139.

Duneier, Mitchell, and Ovie Carter. 1999. Sidewalk. New York: Farrar, Straus and Giroux.

Durie, Mason. 2006. Measuring Maori wellbeing. Wellington, New Zealand: New Zealand Treasury. New Zealand Treasury Guest Lecture Series.

Engels, Fredrich. 1940. The Origin of the Family, Private Property and the State. London: Camelot Press.

Farran, Carol J., Kaye A. Herth, and Judith M. Popovich. 1995. Hope and Hopelessness: Critical Clinical Constructs. Thousand Oaks, CA: Sage.

Fishman, Robert. 1987. Bourgeois Utopias: The Rise and Fall of Suburbia. New York: Basic Books, Inc.

Fong, Megan; Braun, Kathryn L.; and Tsark, J. 2003. "Improving Native Hawaiian Health through Community-Based Participatory Research." Californian Journal of Health Promotion 1, no. 1: 136-48.

Foster, Jonathan. 2016. "Homelessness Is More Complicated than You Think." The Wireless, 22 November 2016.

http://thewireless.co.nz/articles/homelessness-is-more-complicated-than-you-think

Foucault, Michel. 1978. The History of Sexuality Volume I: An Introduction. Translated by Robert Hurley. New York: Pantheon Books.

Foucault, Michel. 1997. "The Birth of Biopolitics." In Ethics: Subjectivity and Truth, edited by Paul Rabinow, 67-71. New York: The New Press.

Foucault, Michel, and Paul Rabinow. 2000. The Essential Works of Michel Foucault, 19541984. Vol. 1, Ethics: Subjectivity and Truth. UK: Penguin Books.

Gagné, Natacha. 2013. Being Māori in the City: Indigenous Everyday Life in Auckland. Toronto: University of Toronto Press.

Gell, Alfred. 1998. Art and Agency: An Anthropological Theory. Oxford: Clarendon Press.

Gibson, Lorena. 2011. "Hope, Agency, and the 'Side Effects' of Development in India and Papua New Guinea." PhD diss., Massey University, Manawatu Campus, New Zealand.

Glasser, Irene, and Rae Bridgman. 1999. Braving The Street: The Anthropology of Homelessness. New York: Berghahn Books. 
Gowan, Teresa. 2010. Hobos, Hustlers, and Backsliders: Homeless in San Francisco. Minneapolis: University of Minnesota Press.

Gravitas Research and Strategy Ltd. 2005. "A Plan For Homeless \& Marginalised Populations in Auckland's Inner City."

Green, K. 2012. Life on a low income. Resolution Foundation, London.

Grey, Sandra, and Charles Sedgwick. 2013. "The Contract State and Constrained Democracy." Igps.victoria.ac.nz.

Grimshaw, Anna. 2001. The Ethnographer's Eye: Ways of Seeing in Anthropology. Cambridge: Cambridge University Press.

Groot, Shiloh Ann Maree. 2010. "Contextualizing Street Homelessness in New Zealand: A Case Study Approach." Hamilton, New Zealand: University of Waikato.

Groot, Shiloh Ann Maree, Darrin Hodgetts, Kerry Chamberlain, Alan Radley, Linda Waimarie Nikora, Ottilie Emma Elisabeth Stolte, and Eci Nabalarua. 2008. "Homeless Lives in New Zealand: The Case of Central Auckland." Maori and Psychology Research Unit, University of Waikato, 68-73.

Groot, Shiloh, Darrin Hodgetts, Linda Waimarie Nikora, and Chez Leggat-Cook. 2011. "A Māori Homeless Woman." Ethnography 12, no .3 (Sage): 375-97.

Hage, Ghassan. 2003. Against Paranoid Nationalism: Searching for Hope in a Shrinking Society. Sydney: Pluto Press Australia.

Harvey, David. 1996. Justice, Nature, and the Geography of Difference. Oxford: Blackwell Publishers.

Harvey, David. 2000. Spaces of Hope. Berkeley, CA: University of California Press.

Heather, Ben. 2014. “\$40,000 'Giving' Campaign Scrapped." Stuff.co.nz, 22 July, 2014. http://www.stuff.co.nz/national/10292724/40-000-giving-campaign-scrapped.

Henley, Paul. 2000. "Ethnographic Film: Technology, Practice and Anthropological Theory." Visual Anthropology 13, no. 2 (Taylor \& Francis): 207-26.

Henley, Paul. 2007. "Seeing, Hearing, Feeling: Sound and the Despotism of the Eye in 'Visual' Anthropology." Visual Anthropology Review 23, no. 1 (Blackwell): 54-63.

Heyl, Babara Sherman. 2017. "Ethnographic Interviewing." In Handbook of Ethnography, 369-83. London, UK: SAGE Publications Ltd.

Hodgetts, Darrin, Ottilie Stolte, Kerry Chamberlain, Alan Radley, Linda Nikora, Eci Nabalarua, and Shiloh Groot. 2008. "A Trip to the Library: Homelessness and Social Inclusion." Social \& Cultural Geography 9, no. 8 (Taylor \& Francis): 933-53. 
Hodgetts, Darrin J., Ottilie Stolte, Kerry Chamberlain, Alan Radley, Shiloh Groot, and Linda Waimarie Nikora. 2010. "The Mobile Hermit And The City: Considering Links Between Places, Objects, And Identities In Social Psychological Research On Homelessness". British Journal Of Social Psychology 49, no. 2: 285-303.

Hodgetts, Darrin, Kerry Chamberlain, Shiloh Groot, and Yardena Tankel. 2014. "Urban Poverty, Structural Violence and Welfare Provision for 100 Families in Auckland." Urban Studies 51, no. 10 (Sage): 2036-51.

Hodgetts, Darrin, and Ottilie Stolte. 2016. "Homeless People's Leisure Practices within and beyond Urban Socio-Scapes." Urban Studies 53, no. 5 (Sage): 899-914.

Ingold. 2005. Epilogue: Politics of Dwelling. Conservation and Society 3, no. 2: $501-508$.

Ingold, Tim. 2008. "Anthropology Is Not Ethnography." In Proceedings of the British Academy, Volume 154, 2007 Lectures, 68-92. British Academy.

Ingold, Tim. 2011. Being Alive: Essays on Movement, Knowledge and Description. London: Routledge

Ingold, Tim. 2013. Making: Anthropology, Archaeology, Art and Architecture. London: Routledge

Ingold, Tim. 2014. "Undergoing Anthropology, Suffering Life." Journal of the Royal Anthropological Institute 20, no. 4: 771-73.

Ingold, Tim. 2014. "That's Enough about Ethnography!" HAU: Journal of Ethnographic Theory 4, no. 1: $383-395$.

Jackson, Emma. 2015. Young Homeless People and Urban Space: Fixed in Mobility. London: Routledge.

Jackson, Michael. 1989. Paths toward a Clearing: Radical Empiricism and Ethnographic Inquiry. Bloomington: Indiana University Press.

Jackson, Michael. 1995. At Home in the World. Durham and London: Duke University Press.

Jackson, Michael. 2011. Life Within Limits: Well-Being in a World of Want. Durham and London: Duke University Press.

Jackson, Michael. 2013. Lifeworlds: Essays in Existential Anthropology. Chicago: The University of Chicago Press.

Jackson, Michael. 2016. As Wide as the World Is Wise: New Directions in Philosophical Anthropology. New York: Columbia University Press.

Jackson, Moana. 2007. "Globalisation and the Colonising State of Mind." In Resistance: An Indigenous Response to Neoliberalism, edited by Maria Bargh, 213. Aotearoa: Huia. 
Jackson, Moana., and New Zealand. Department of Justice. Policy and Research Division. 1988. The Maori and the Criminal Justice System: A New Perspective = He Whaipaanga Hou. Part 2. Wellington, N.Z.: Policy and Research Division, Dept. of Justice.

Jones, Nick. 2017. "Strategy to 'End Homelessness' in Auckland Officially Launched." New Zealand Herald, May 232017. http://www.nzherald.co.nz/nz/news/article.cfm?c id=1\&objectid=11823445.

Just Speak. 2017. "Bailing out the Justice System: Reopening the Window of Opportunity."

Just Speak. 2017. "Media Release: Justspeak Calls on the Government to Adopt Waitangi Tribunal Recommendations and Address Structural Racism in the Justice System JustSpeak."

2017. http://www.justspeak.org.nz/justspeak calls on the government to adopt waitang i tribunal recommendations.

King, Pita, Darrin Hodgetts, Mohi Rua, and Tiniwai Te Whetu. 2015. "Older Men Gardening on the Marae: Everyday Practices for Being Māori." AlterNative: An International Journal of Indigenous Peoples 11, no. 1 (Sage): 14-28.

Latour, Bruno. 1999. “On Recalling Ant.” The Sociological Review 47, no. 1 sup (Sage): 15-25.

Lancione, Michele. 2016. Rethinking Life at the Margins. Farnham, UK: Ashgate Pub Ltd.

Leggatt-Cook, Chez, and Kerry Chamberlain. 2015. "Houses with Elastic Walls: Negotiating Home and Homelessness within the Policy Domain." Kōtuitui: New Zealand Journal of Social Sciences Online 10, no. 1 (Routledge): 10-22.

Leimbacher, Irina. 2014. "The World Made Flesh - Film Comment." Film Comment.

Levinson, David. 1974. 'The Etiology of Skid Rows in the United States.' International Journal of Social Psychiatry 20:25-33.

Liebow, Elliot. 1993. Tell Them Who I Am: The Lives of Homeless Women. New York: Penguin Books.

Lyon-Callo, Vincent. 2017. "Medicalizing Homelessness: The Production of Self-Blame and Self-Governing within Homeless Shelters." Medical Anthropology Quarterly 14, no. 3: $328-345$.

Lynch, Jenna. 2016. "New Govt Homeless Scheme Goes beyond Beds." Newshub, July 29 2016. $\quad$ http://www.newshub.co.nz/home/politics/2016/07/new-govt-homelessscheme-goes-beyond-beds.html.

Lynch, Jenna. 2016. “John Key: Homeless Don't Want Help." Newshub, June 32016. http://www.newshub.co.nz/home/politics/2016/06/government-homeless-dontwant-help.html 
MacDougall, David. 1991. "Whose Story Is It?" Visual Anthropology Review 7, no. 2 (Blackwell): 2-10.

MacDougall, David. 1999. "Social Aesthetics and The Doon School." Visual Anthropology Review 15, no. 1 (Blackwell): 3-20.

Marsh, Kate. 2006. "People Out Of Place: Representations And Experiences Of Female Homelessness In Christchurch, New Zealand". MA, University of Canterbury.

Mathews, Gordon, and Carolina Izquierdo. 2009. Pursuits of Happiness: Well-Being in Anthropological Perspective. Oxford: Berghahn Books.

Mathieu, Arline. 1993. "The Medicalization of Homelessness and the Theater of Repression." Medical Anthropology Quarterly 7, no. 2 (Blackwell): 170-84.

Marx, Karl. 1990. Capital: A Critique of Political Economy. Vol. 1. London: Penguin Classics.

McGovern, Bronwyn Jewell. 2013. "A Life Lived on the Corner." PhD diss., Victoria University of Wellington.

Mitchell, Don. 2017. "The End of Public Space? People's Park, Definitions of the Public, and Democracy." Annals of the Association of American Geographers 85, no. 1 (Taylor \& Francis): $108-133$.

Miyazaki, Hirokazu. 2006. "Economy of Dreams: Hope in Global Capitalism and Its Critiques." Cultural Anthropology 21, no. 2 (Blackwell): 147-72.

Neale, Joanne. 1997. "Homelessness and Theory Reconsidered." Housing Studies 12, no. 1 (Taylor \& Francis): 47-61.

Newman, Andrew. 2011. "Contested Ecologies: Environmental Activism and Urban Space in Immigrant Paris." City \& Society 23, no. 2 (Blackwell): 192-209.

NZ Census. 2013. "Census Ethnic Group Profiles: Māori."

NZ Herald. 2003. "Capital moves to keep vagrants off its streets," July 62003. https://www.nzherald.co.nz/nz/news/article.cfm?c id=1\&objectid=3511198

Okely, Judith. 2014. "Recycled (Mis)representations: Gypsies, Travellers or Roma Treated as Objects, Rarely Subjects." People, Place and Policy Online 8, no. 1: 65-85.

Orsman, Bernard. 2017. "Using Sprinkler Systems to Deter Rough Sleepers 'Inhumane and Draconian', Says Councillor." New Zealand Herald, May 5.

Ortner, Sherry B. 2001. "Specifying Agency. The Comaroffs and Their Critics." Interventions 3 (March): 76-84.

Ortner, Sherry B. 2006. Anthropology and Social Theory: Culture, Power, and the Acting Subject. Durham, NC: Duke University Press. 
Otago, University of. 2016. "Homelessness Accelerates between Censuses," June 32016. http://www.otago.ac.nz/medical-school/news/otago613529.html.

Passaro, Joanne. 1996. The Unequal Homeless. New York: Routledge.

Passaro, Joanne. 1997. "'You Can't Take The Subway To The Field!": 'Village' Epistemologies In The Global Village". In Anthropological Locations, edited by Akhil Gupta and James Ferguson, 147 - 162. Berkley: University of California Press.

Pink, Sarah. 2004. “Guest Editor's Introduction: Applied Visual Anthropology Social Intervention, Visual Methodologies and Anthropology Theory." Visual Anthropology Review 20, no. 1 (Blackwell): 3-16.

Pink, Sarah. 2007. Doing Visual Ethnography: Images, Media, and Representation in Research. London, UK: Sage.

Pink, Sarah. 2008. "Mobilising Visual Ethnography: Making Routes, Making Place and Making Images." Forum Qualitative Sozialforschung/Forum: Qualitative Social Research 9, no. 3 (Art): 36.

Pink, Sarah. 2010. "The Future of Sensory Anthropology/the Anthropology of the Senses." Social Anthropology 18, no. 3 (Blackwell): 331-33.

Poata-Smith, Evan Te Ahu. 2013. "Inequality and Māori." In Inequality: A New Zealand Crisis, edited by Max Rashbrooke, 153-62. Wellington: Bridget Williams Books.

Polanyi, Karl. 2001. The Great Transformation: The Political and Economic Origins of Our Time. Boston: Beacon Press.

Radice, Martha. 2000. Feeling Comfortable?: The Urban Experience of Anglo-Montrealers. Montreal: Presses de l'Université Laval.

Rapoport, Amos. 1969. House Form and Culture. New Jersey: Prentice-Hall.

Robinson, Catherine. 2011. Beside One's Self: Homelessness Felt and Lived. New York: Syracuse University Press.

Rose, Nikolas S. 1990. Governing the Soul: The Shaping of the Private Self. London: Routledge.

Rose, Nikolas, Pat O’Malley, and Mariana Valverde. 2006. "Governmentality." Annual Review of Law and Social Science 2, no. 1: 83-104.

Ruddick, Susan M. 1996. Young and Homeless in Hollywood: Mapping Social Identities. London: Routledge.

Sachdeva, Sam. 2016. "Social Agencies Helping Kiwi Homeless 'at Crossroads', Cross-Party Inquiry to Hear." Stuff.co.nz, 22. http://www.stuff.co.nz/national/politics/83400718/Social-agencies-helping-Kiwihomeless-at-crossroads-cross-party-inquiry-to-hear 
Scott, Susie. 2009. Making Sense of Everyday Life. Cambridge: Polity.

Sissons, Jeffrey. 2011. "The Tectonics of Power: The Hawaiian Iconoclasm and Its Aftermath." Oceania 81, no. 2 (Blackwell): 205-16.

Spink, Emily. 2016. “City's Homeless Population Not Always Visible." The Press, May 232016. http://www.stuff.co.nz/the-press/80131872/citys-homeless-population-not-alwaysvisible

Spradley, James P. 1970. You Owe Yourself A Drunk. Boston: Little, Brown.

Stanley, Elizabeth. 2017. The Road to Hell: State Violence against Children in Postwar New Zealand. Auckland, NZ: Auckland University Press.

Statistics New Zealand. 2009. New Zealand Definition of Homelessness. Wellington. http://www.stats.govt.nz/browse for stats/people and communities/housing/home lessness-definition.aspx

Stoller, Paul. 1997. Sensuous Scholarship. Philadelphia: University of Pennsylvania Press.

Tauri, J. M.; Ngati Porou. 2014. “Criminal Justice as a Colonial Project in Contemporary Settler Colonialism - ProQuest." African Journal of Criminology and Justice Studies 8, no. 1: 2037.

Thin, Neil. 2009. "Why Anthropology Can III-Afford to Ignore Well-being". In Pursuit of Happiness: Well-Being in Anthropological Perspective, edited by Gordon Mathews and Carolina Izquierdo, 1 - 12. Oxford: Berghahn Books.

Wacquant, Loïc J. D. 2009. Punishing the Poor: The Neoliberal Government of Social Insecurity. Durham, NC: Duke University Press.

Walby, Kevin, and Randy Lippert. 2012. "Spatial Regulation, Dispersal, and the Aesthetics of the City: Conservation Officer Policing of Homeless People in Ottawa, Canada." Antipode 44, no. 3 (Blackwell): $1015-1033$.

Waldegrave, Charles, Catherine Love and Shane Stuart S. 2000. "Urban Māori Responses to Changes in State Housing Provision". Social Policy Journal of New Zealand 14.

Walker, Ryan, and Manuhuia Barcham. 2010. "Indigenous-Inclusive Citizenship: The City and Social Housing in Canada, New Zealand, and Australia." Environment and Planning 42, no. 2 (Sage): 314-31.

Waterson, Roxana. 1990. The Living House: An Anthropology of Architecture in South-East Asia. Oxford: Oxford University Press.

Watson, Sophie, and Helen Austerberry. 1986. Housing And Homelessness. London: Routledge \& Kegan Paul. 
Wolch, Jennifer and Stacy Rowe. 1992. 'On The Streets: Mobility Paths of the Urban Homeless.' City and Society 6, no. 2: 115-140.

Woolford, A. 2013. "The next Generation: Criminology, Genocide Studies and Settler Colonialism." Revista Critica Penal Y Poder 5: 163-85.

Wellington City Council. 2013. "Alternative Giving Campaign off to Steady Start," July 192013. http://www.scoop.co.nz/stories/P01307/S00248/alternative-giving-campaign-off-tosteady-start.htm.

Young, Nicola. 2016. "Begging Ban."

Zigon, Jarrett. 2009. "Hope Dies Last: Two Aspects of Hope in Contemporary Moscow." Anthropological Theory 9 (3): 253-71.

Zournazi, Mary. 2003. Hope: New Philosophies for Change. London: Routledge. 